University of Tennessee Health Science Center UTHSC Digital Commons

$11-2021$

Responding to the Pandemic: A Multicountry Study on SocialPolitical Factors and Health Outcomes of COVID-19

Lan Yao

Follow this and additional works at: https://dc.uthsc.edu/dissertations

Part of the Epidemiology Commons, Health and Medical Administration Commons, Health Services Administration Commons, Health Services Research Commons, Investigative Techniques Commons, Other Public Health Commons, Public Health Education and Promotion Commons, and the Virus Diseases Commons 


\title{
Responding to the Pandemic: A Multicountry Study on Social-Political Factors and Health Outcomes of COVID-19
}

\author{
Abstract \\ Introduction. Coronavirus Disease 2019 (COVID-19) poses a major global threat to human beings, which \\ has caused devastating consequences of population health, political, and economic crises in many \\ countries. This dissertation was composed of three research activities to study the following aims: (1) \\ review the existing literature focusing on political factors and health outcomes of COVID-19; (2) assess \\ the relationship between democracy and case fatality rate of COVID-19 by controlling for the effect of age, \\ comorbidity, health expenditure, healthcare workforce, and population density; and (3) identify the \\ trajectory pattern cases peak days, deaths peak days, and peak periods.
}

Methods. We accessed data from the World Health Organization (WHO), World Bank, Johns Hopkins University, and the Democracy Index 2019 database. First, we conducted a systematic review that searched three databases and synthesized the articles about democracy and health outcomes of COVID-19. Second, we analyzed data from 148 countries with at least 2,000 confirmed cases of COVID-19 by October 25, 2020. Multiple linear regression was used to examine the association between the Democracy Index and case fatality rate of COVID-19 while controlling for other variables, most notably the age distribution of the population. Lastly, we used the patterns of data at the early onset of COVID-19 from seven countries to estimate the time lag between peak days of cases and deaths.

Results. Our first research found that of 170 publications in the databases search, 12 publications were screened for systematic review. Among them, one study reported no association between democracy and health outcomes of COVID-19. Eleven articles claimed there was a relationship between democracy level and outcomes of COVID-19. Two papers reported negative associations between democracy and adverse outcomes of the population, while the other nine articles claimed there were positive associations between democracy and the poor health status of populations. When examining the relationship between democracy and health outcomes of COVID-19, the second research demonstrated that the number of hospital beds, the proportion of population above age 65 , and current health expenditure as a percentage of the gross domestic product (GDP) are significantly related to the case fatality rates of COVID-19 across 148 countries $(p<0.05)$. The Democracy Index was not statistically related to the case fatality rates of COVID-19 when considering all 148 countries analyzed but was negatively associated with case fatality rates among 47 high-income countries. In addition, the healthcare workforce, population density, and comorbidity were not statistically significant among the 148 countries. Finally, the findings in the last research suggested that comparative analyses of data from different regions and countries reveal the differences between peaks of cases and deaths caused by COVID-19 and the incomplete and underestimated cases in Wuhan. Different countries may show different patterns of cases peak days, deaths peak days, and peak periods. Error in the early COVID-19 statistics in Brazil was identified.

Conclusions. This research is the first to our knowledge to study the relationship between democracy and health outcomes of COVID-19 across countries with large sample sizes. According to the multicountry data, the cross-sectional study suggests that enhancing healthcare system facilities is vital to improving clinical outcomes. Protecting the population older than 65 and adjusting the health expenditure budget may need to be considered. The findings suggest that in high-income countries the higher democracy index is associated with more deaths from COVID-19, perhaps due to the decreased ability of the government to control the movement and behavior of its citizens. Besides, the simulated graphical trajectory method identifies statistical biases in surveillance data. This approach incorporates all sources of available data and provides a robust method to characterize the time course of an infectious disease. Regions and countries beginning with high mortality rates from the COVID-19 epidemic will suffer a long, painful period of the disease epidemic. Where the mortality rate is relatively high, healthcare 
professionals should prepare for a longer period of fighting this pandemic. Data quality is key to case fatality rate estimation which is needed by policymakers to make correct and timely critical decisions.

\section{Document Type}

Dissertation

Degree Name

Doctor of Philosophy (PhD)

\section{Program}

Health Outcomes and Policy Research

\section{Research Advisor}

J. Carolyn Graff, PhD

\section{Keywords}

Case fatality rate, COVID-19, Democracy, Healthcare system, Population

\section{Subject Categories}

Analytical, Diagnostic and Therapeutic Techniques and Equipment | Diseases | Epidemiology | Health and Medical Administration | Health Services Administration | Health Services Research | Investigative Techniques | Medicine and Health Sciences | Other Public Health | Public Health | Public Health Education and Promotion | Virus Diseases 
UNIVERSITY OF TENNESSEE HEALTH SCIENCE CENTER

DOCTORAL DISSERTATION

\section{Responding to the Pandemic: A Multicountry Study on Social-Political Factors and Health Outcomes of COVID-19}

Author:

Lan Yao
Advisor:

J. Carolyn Graff, Ph.D.

A Dissertation Presented for The Graduate Studies Council of The University of Tennessee Health Science Center

in Partial Fulfillment of the Requirements for the Doctor of Philosophy degree from The University of Tennessee

in

Health Outcomes and Policy Research: Health Policy Track

College of Graduate Health Sciences

November 2021 
Chapter 3 @ 2021 by Springer Nature Switzerland AG. All other material $\odot 2021$ by Lan Yao. All rights reserved. 


\section{DEDICATION}

This dissertation is dedicated to

My wonderful parents who have raised me to be the person I am today, My husband who believes in the richness of learning,

My daughter who makes me keen on progressing,

Myself who never expected to arrive at this milestone in my life. 


\section{ACKNOWLEDGEMENTS}

I would like to thank my mentor, Professor Joyce Carolyn Graff. Your mentorship was invaluable in formulating the research questions and methodology. Your insightful supervision and encouragement helped me to sharpen my thoughts and brought my work to an advanced level. I also learned a lot from you and admire your personality, intelligence and beautiful mind.

I would also thank my committee members, Dr. James E. Bailey, Dr. Scott C. Howard, Dr. Minghui Li and Dr. Jim Y. Wan, for their constructive guidance throughout my research. They provided me with the tools that I needed to choose the right direction and successfully complete my dissertation research.

I would particularly like to single out Dr. Donald Thomason and Dr. Weikuan Gu and acknowledge you for your support and contribution to the joint Ph.D. program.

To my family, I am forever grateful for your love, patience and understanding. Without you believing in me, I never would have made it. It is time to celebrate, you earned this degree right along with me. I have time now to reconnect with each of you.

I appreciate the scholarship and funding provided by University of Tennessee Health Science Center to support me through the training.

Last, thank you to the countless healthcare professionals worldwide who are selflessly saving, curing, and protecting humankind during the COVID-19 pandemic. 


\begin{abstract}
Introduction. Coronavirus Disease 2019 (COVID-19) poses a major global threat to human beings, which has caused devastating consequences of population health, political, and economic crises in many countries. This dissertation was composed of three research activities to study the following aims: (1) review the existing literature focusing on political factors and health outcomes of COVID-19; (2) assess the relationship between democracy and case fatality rate of COVID-19 by controlling for the effect of age, comorbidity, health expenditure, healthcare workforce, and population density; and (3) identify the trajectory pattern cases peak days, deaths peak days, and peak periods.
\end{abstract}

Methods. We accessed data from the World Health Organization (WHO), World Bank, Johns Hopkins University, and the Democracy Index 2019 database. First, we conducted a systematic review that searched three databases and synthesized the articles about democracy and health outcomes of COVID-19. Second, we analyzed data from 148 countries with at least 2,000 confirmed cases of COVID-19 by October 25, 2020. Multiple linear regression was used to examine the association between the Democracy Index and case fatality rate of COVID-19 while controlling for other variables, most notably the age distribution of the population. Lastly, we used the patterns of data at the early onset of COVID-19 from seven countries to estimate the time lag between peak days of cases and deaths.

Results. Our first research found that of 170 publications in the databases search, 12 publications were screened for systematic review. Among them, one study reported no association between democracy and health outcomes of COVID-19. Eleven articles claimed there was a relationship between democracy level and outcomes of COVID-19. Two papers reported negative associations between democracy and adverse outcomes of the population, while the other nine articles claimed there were positive associations between democracy and the poor health status of populations. When examining the relationship between democracy and health outcomes of COVID-19, the second research demonstrated that the number of hospital beds, the proportion of population above age 65 , and current health expenditure as a percentage of the gross domestic product (GDP) are significantly related to the case fatality rates of COVID-19 across 148 countries ( $\mathrm{p}<$ $0.05)$. The Democracy Index was not statistically related to the case fatality rates of COVID-19 when considering all 148 countries analyzed but was negatively associated with case fatality rates among 47 high-income countries. In addition, the healthcare workforce, population density, and comorbidity were not statistically significant among the 148 countries. Finally, the findings in the last research suggested that comparative analyses of data from different regions and countries reveal the differences between peaks of cases and deaths caused by COVID-19 and the incomplete and underestimated cases in Wuhan. Different countries may show different patterns of cases peak days, deaths peak days, and peak periods. Error in the early COVID-19 statistics in Brazil was identified. 
Conclusions. This research is the first to our knowledge to study the relationship between democracy and health outcomes of COVID-19 across countries with large sample sizes. According to the multicountry data, the cross-sectional study suggests that enhancing healthcare system facilities is vital to improving clinical outcomes. Protecting the population older than 65 and adjusting the health expenditure budget may need to be considered. The findings suggest that in high-income countries the higher democracy index is associated with more deaths from COVID-19, perhaps due to the decreased ability of the government to control the movement and behavior of its citizens. Besides, the simulated graphical trajectory method identifies statistical biases in surveillance data. This approach incorporates all sources of available data and provides a robust method to characterize the time course of an infectious disease. Regions and countries beginning with high mortality rates from the COVID-19 epidemic will suffer a long, painful period of the disease epidemic. Where the mortality rate is relatively high, healthcare professionals should prepare for a longer period of fighting this pandemic. Data quality is key to case fatality rate estimation which is needed by policymakers to make correct and timely critical decisions. 


\section{TABLE OF CONTENTS}

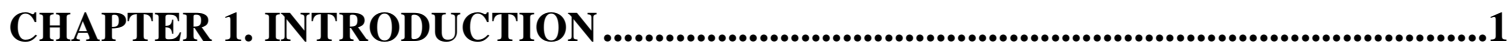

Social-Political Factors and Health Outcomes .......................................................... 1

Statement of the Problem..................................................................................... 3

Philosophical and Theoretical Frameworks ............................................................. 3

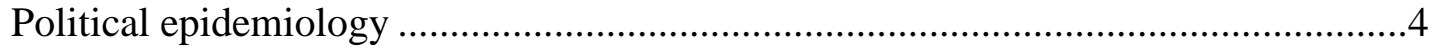

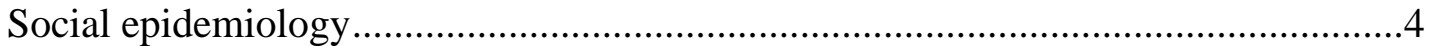

Social-ecological model ................................................................................

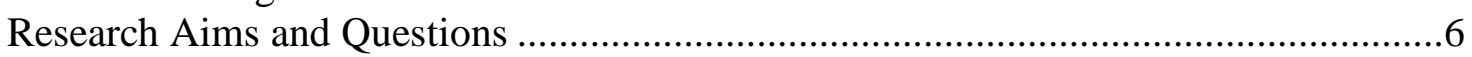

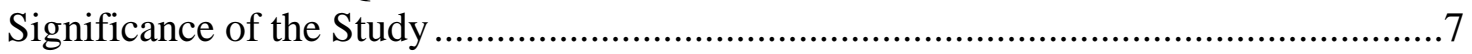

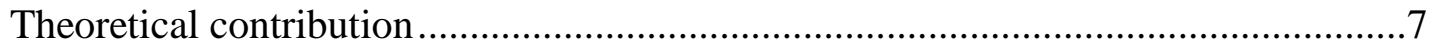

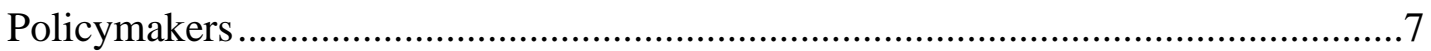

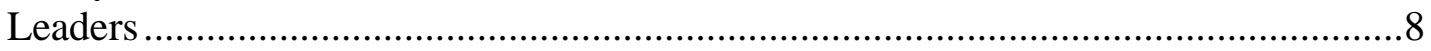

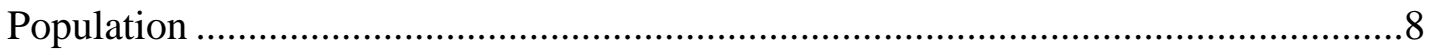

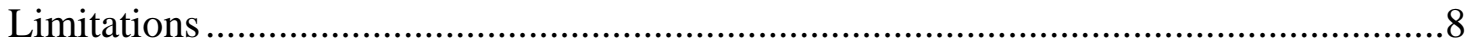

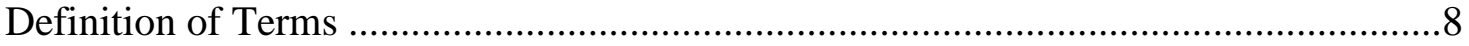

\section{CHAPTER 2. THE EFFECT OF DEMOCRACY ON HEALTH OUTCOMES}

IN COVID-19: A SYSTEMATIC REVIEW ...........................................................10

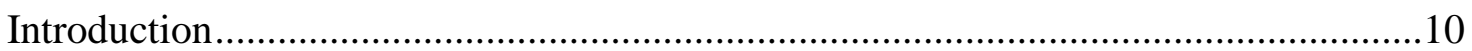

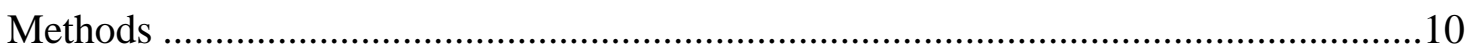

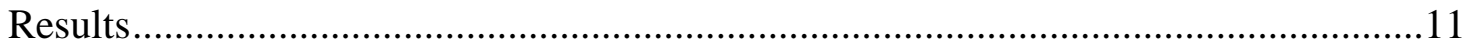

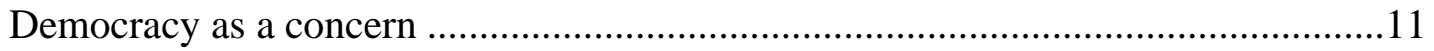

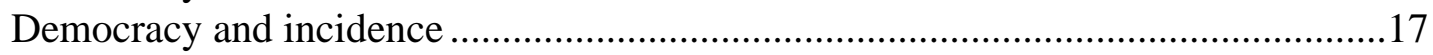

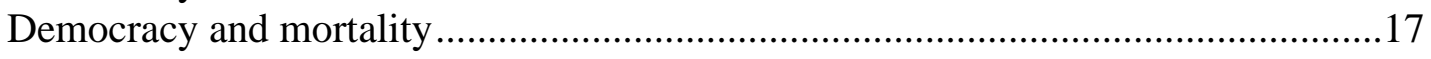

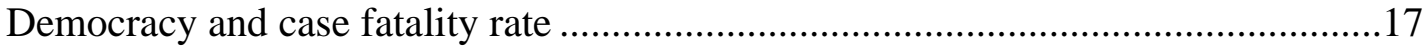

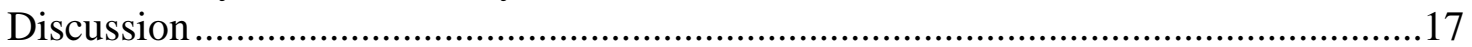

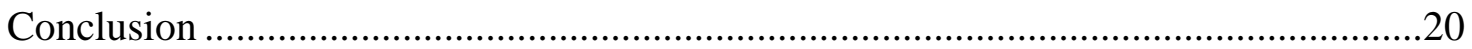

\section{CHAPTER 3. DEMOCRACY AND CASE FATALITY RATE OF COVID-19} AT EARLY STAGE OF PANDEMIC: A MULTICOUNTRY STUDY ...................21

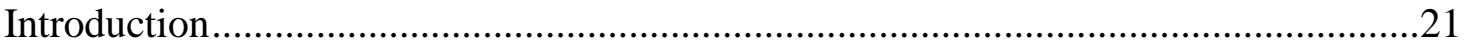

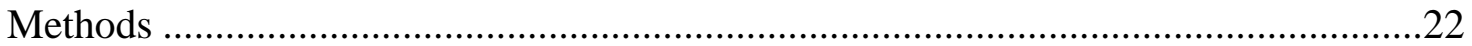

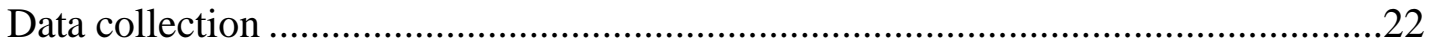

COVID-19-confirmed cases, deaths, and tests performed.............................. 22

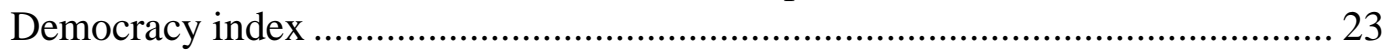

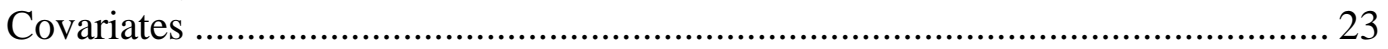

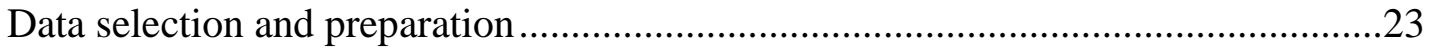

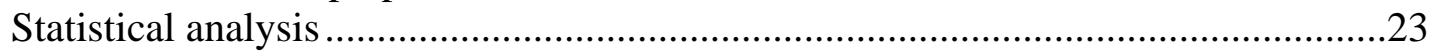

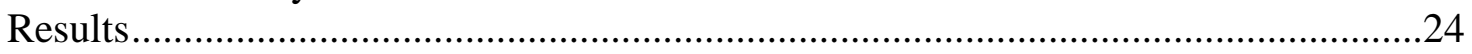

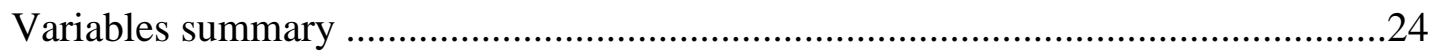

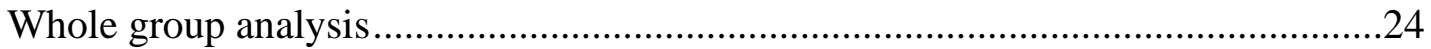

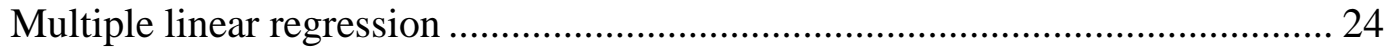

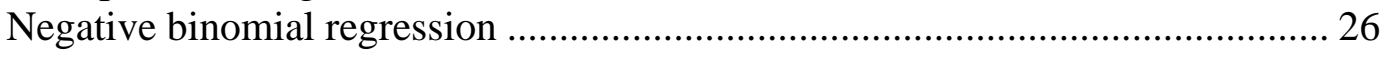




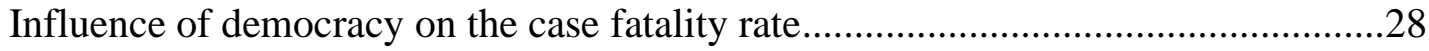

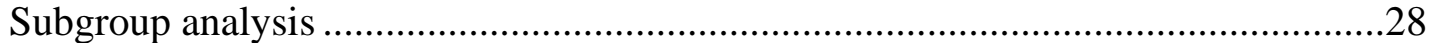

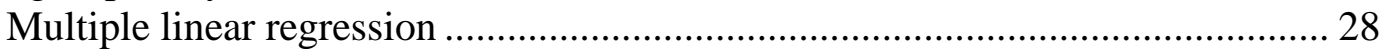

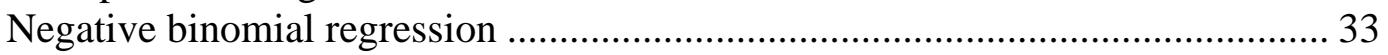

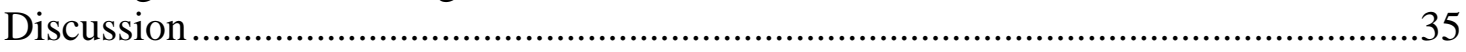

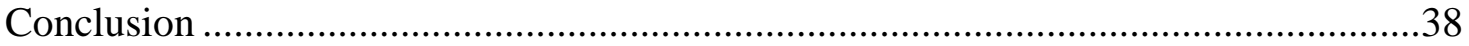

\section{CHAPTER 4. GRAPHICAL TRAJECTORY COMPARISON TO IDENTIFY ERRORS IN DATA OF COVID-19: A CROSS-COUNTRY ANALYSIS................40}

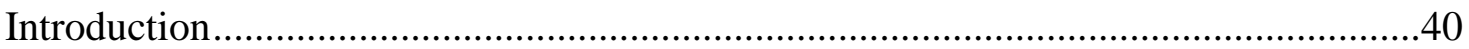

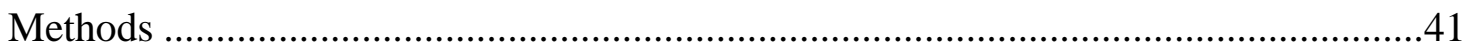

Data collection in the early stage of the pandemic .............................................

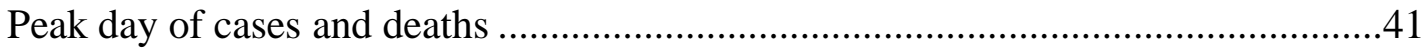

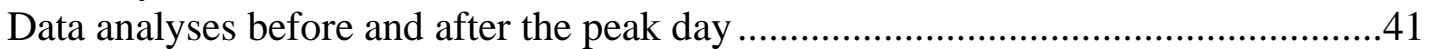

The time lag between peaks of cases and deaths ................................................42

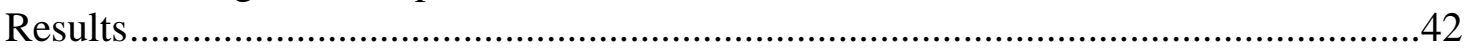

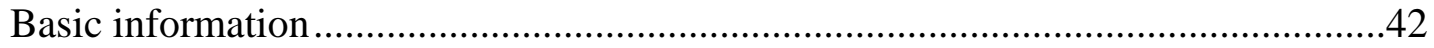

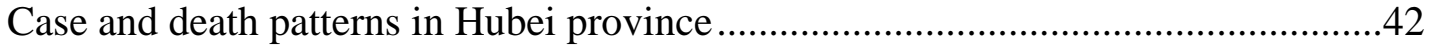

Case and death patterns in three countries with less disease severity .......................45

Case and death patterns in three countries with large pandemics..............................45

Patterns of death rate around the peak of disease onset ........................................45

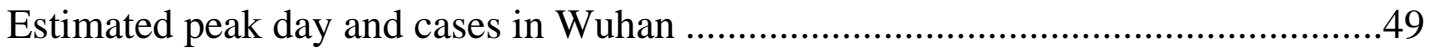

Potential data collection errors in Brazil .................................................................49

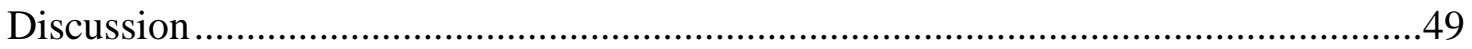

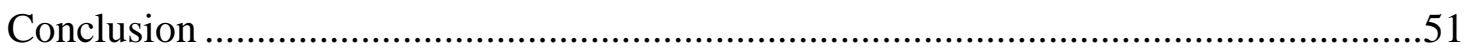

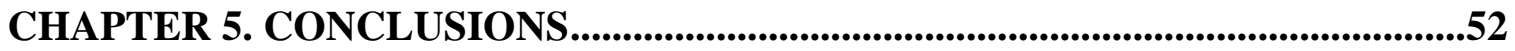

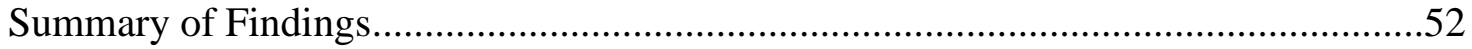

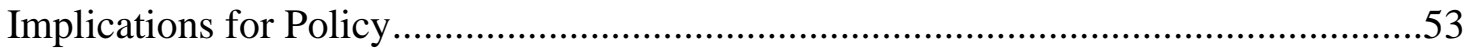

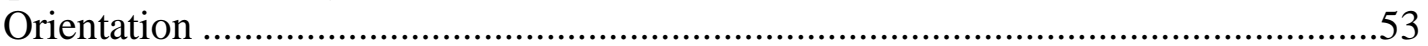

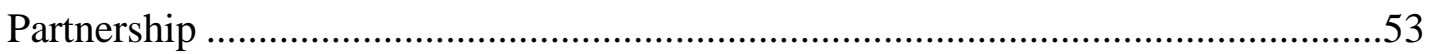

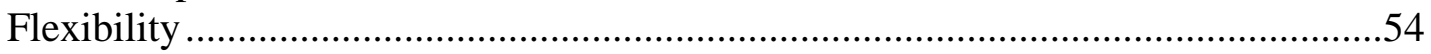

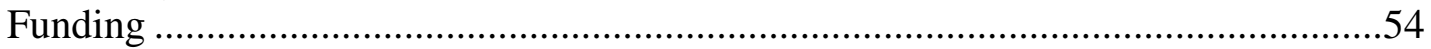

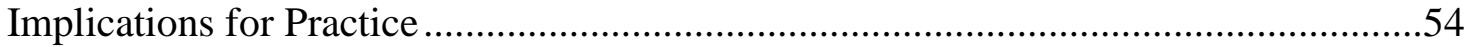

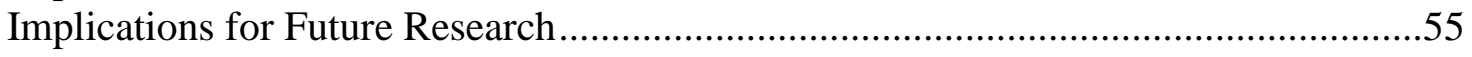

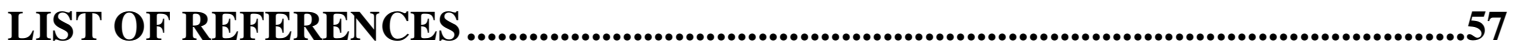

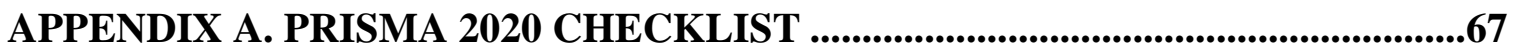

APPENDIX B. JBI CRITICAL APPRAISAL CHECKLIST FOR STUDIES

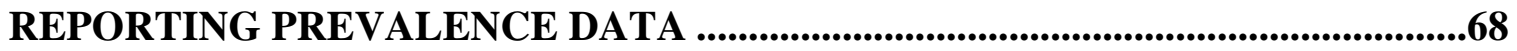

APPENDIX C. UTHSC IRB APPROVAL LETTER..........................................69

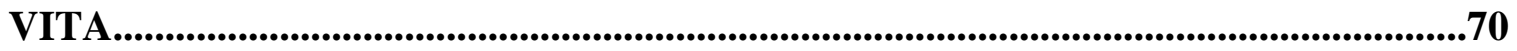




\section{LIST OF TABLES}

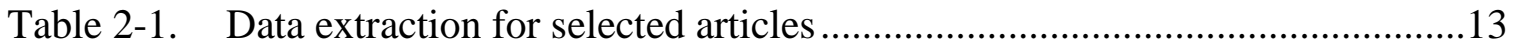

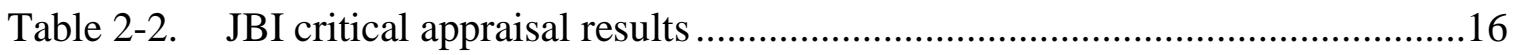

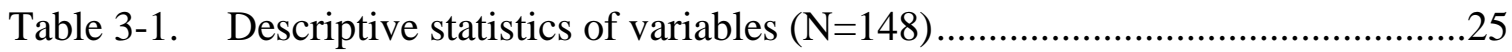

Table 3-2. Multiple linear regression results of the association between predictors

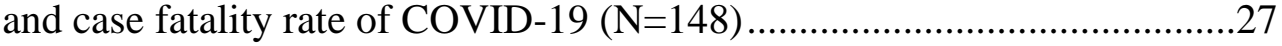

Table 3-3. Negative binomial regression estimated association between predictors

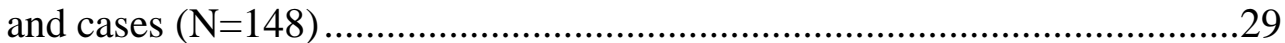

Table 3-4. Negative binomial regression estimated association between predictors

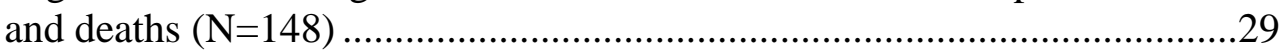

Table 3-5. Multiple linear regression results of the association between predictors and case fatality rate of COVID-19 in high-income countries $(\mathrm{N}=47) \ldots \ldots . .34$

Table 3-6. Negative binomial regression estimated association between predictors and cases in high-income countries $(\mathrm{N}=47)$...........................................36

Table 3-7. Negative binomial regression estimated association between predictors

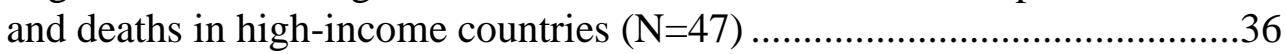

Table 4-1. Summary of indicators of cases and deaths of sampled regions and countries using data of an average of 7-day 


\section{LIST OF FIGURES}

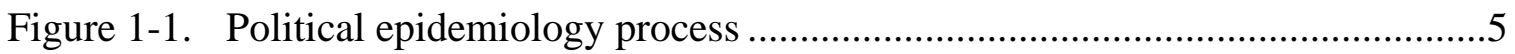

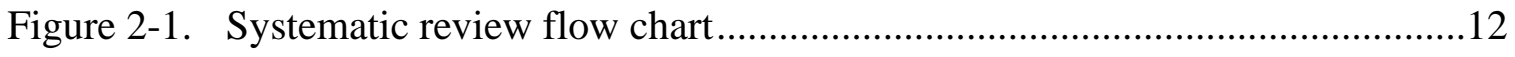

Figure 3-1. The cumulative confirmed cases and deaths of COVID-19, tests per $1,000,000$ population, and case fatality rate distribution by regime type ....30

Figure 3-2. Health expenditure of GDP and percentage of population ages 65 and above distribution by regime type

Figure 3-3. Healthcare workforce per 10,000 population and hospital beds per 1,000 population distribution by regime type

Figure 4-1. Patterns of cases and deaths from COVID-19 in three cities in China's Hubei province from January 19 to March 19, 2020

Figure 4-2. Patterns of cases and deaths from COVID-19 in three countries .46

Figure 4-3. Patterns of death in three different countries with persistently high numbers of COVID-19 cases

Figure 4-4. The graphic trajectory comparing COVID-19 death rates between Wuhan and five countries. 


\section{LIST OF ABBREVIATIONS}

$\begin{array}{ll}\text { AIDS } & \text { Acquired Immunodeficiency Syndrome } \\ \text { COVID-19 } & \text { Coronavirus Disease 2019 } \\ \text { CSSE } & \text { Center for Systems Science and Engineering } \\ \text { DUI } & \text { Driving Under the Influence } \\ \text { EIU } & \text { Economist Intelligence Unit } \\ \text { EMR } & \text { Electronic Medical Record } \\ \text { EHR } & \text { Electronic Health Records } \\ \text { HHT } & \text { Human-to-Human Transmission } \\ \text { HIV } & \text { Human Immunodeficiency Virus } \\ \text { JBI } & \text { Joanna Briggs Institute } \\ \text { NCD } & \text { Non-communicable Disease } \\ \text { PPE } & \text { Personal Protective Equipment } \\ \text { SARS } & \text { Severe Acute Respiratory Syndrome } \\ \text { WHO } & \text { Sorld Health Organization }\end{array}$




\section{CHAPTER 1. INTRODUCTION}

\section{Social-Political Factors and Health Outcomes}

Research on the determinants of health has crossed the conventional scope of the health care system and the public health domain. Income level, housing, food security and nutrition, education, and community security also play an important role in health promotion. ${ }^{1}$ What's more, in recent years, there has been a large number of published studies that look at health issues through the lens of social-political factors and describe the associations between social-political factors and health outcomes. Beckfield and Krieger argue that one section of epidemiological research calls for greater exposure to the social structures, networks, and fundamental social features, e.g., socioeconomic status, race, and gender, used to assess health outcomes. On the other hand, another section concentrating on the political economy of health focuses on how various types of policy institutionalizations, political processes, and organizations influence the wellbeing of the community. The authors also bring up the agenda that new exploration which consolidates the qualities of political science and social science studies of disease transmission is attainable, hypothetically important, and strategically applicable. ${ }^{2}$ Empirical studies have been conducted using longitudinal data that include political factors as major predictors. For example, Navarro et al. investigated the relationship between political ideology and health outcomes based on data from high-income countries. The authors conclude that political ideologies are related to some aspects of health outcomes. ${ }^{3,4}$

What we know about the association between political factors and health outcomes is mainly based on observational studies. However, the research that concentrates on political features and health outcomes repeatedly selects life expectancy, maternal mortality, and infant mortality as the outcomes to examine the potential correlation. Additionally, empirical investigations have focused on the correlation between political factors and life expectancy across countries with large sample sizes. For instance, Franco et al. examined the impact of democracy in $75 \%$ of the countries and territories around the world on life expectancy, maternal mortality, and infant mortality, taking into account the country's wealth, social justice, and the share of public sector investment. The authors suggest that health metrics demonstrate a statistically important association with the degree of democracy: the highest rates of healthcare capacity are in democratic countries, followed by partially democratic countries. The lowest levels of health care capacity are in authoritarian countries. After adjusting for income level, social inequality, and the total government expenditure (size of the public sector), a positive association between health and democracy remained. Therefore, political factors are variables that appear to be related to the health outcomes of a given population. ${ }^{5}$ Besley and Kudamatsu used longitudinal datasets collected from different countries to investigate the connection between democracy and health status. Their research reveals that life expectancy has been strongly associated with democracy. ${ }^{6}$ Similarly, Bollyky et al. implemented significant analysis and discussion on democracy and cause-specific mortality. These authors employed a dataset of 170 countries for 46 years to examine the 
relationship between democracy and population health. Life expectancy, cause-specific mortality, and democratization are correlated. The longer life expectancy is positively related to a higher level of democracy. ${ }^{7}$ In another empirical study, Lake and Baum report that, across the world, democracy has an optimistic and substantive effect on citizens' daily life and well-being. ${ }^{8}$ However, we should notice that health outcome is also associated with national wealth and total health care expenditures. ${ }^{9}$ Thus, the connection between political factors and health outcomes is confounded by a country's income level so that some existing research suffers from these confounding factors that modify the effect of an independent variable. Besides, data are more likely to be missing in lowincome countries which may lead to data being subject to bias and not representative.

The generalizability of the research discussed above is also problematic because the health outcomes studied only involve life expectancy, maternal mortality, and infant mortality; therefore, the correlation between political factors and health outcomes needs to be interpreted with caution. To date, few inquirers have been able to perform datadriven research to examine the effect of political factors on infectious disease outcomes. In an analysis of the HIV/AIDS disease, Gizelis has methodologically broken down how political features and public health strategies may help curb the spreading of AIDS and demonstrates that countries with more stringent regulations are more likely to mitigate the transmission of HIV/AIDS. Furthermore, the author contends that governments of solid dictatorships can execute effective measures with fewer requirements and are more proficient in controlling the infection of HIV/AIDS. ${ }^{10}$ Taking a theoretical perspective to examine the mitigation of SARS, Fidler has insisted that SARS was a novel pathogen for which there were no effective pharmaceuticals for treatment, vaccination, and therapy. For many countries, containing SARS depends on social distancing, isolation and quarantine, raising questions regarding measures necessary to protect the health of the community or population while upholding human rights. ${ }^{11}$

Studies have also demonstrated the impact of social-political factors on COVID19 since the outbreak. In an investigation into the current COVID-19 pandemic, Badr et al. argue that social distancing played an essential role in reducing the new cases between March and April in many American counties. This is based on their statistical analysis which showed a correlation between the patterns of human mobility and the decreasing transmission rate of COVID-19 in the United States, with Pearson correlation rates above 0.7 for 20 of 25 counties. ${ }^{12}$ What's more, Burkle and Devereaux claim that public health policy and regulations have been affected significantly by political pressure. The results of urgent healthcare management decision-making are important in determining the likelihood of health care effectiveness, the control of the epidemic, and the conservation of scarce resources. ${ }^{13}$ Edelman et al. discussed what they have observed and learned from the HIV/AIDS epidemic worldwide to inform the response to the COVID-19 pandemic. They emphasize that, unlike HIV/AIDS, a political misunderstanding of COVID-19 contributes to a strategic reaction that will be insufficient and awkward. ${ }^{14}$ Frey et al. found that autocratic regimes impose stricter lockdowns and rely more on contact traceability, along with real-time data that includes daily data about citizens' travel and movement in 111 countries. Even though autocracies have introduced stricter lockdowns and more contact tracing, democracies have been more successful in achieving the policy 
goal of reducing domestic mobility in their countries. ${ }^{15}$ A follow-up study on this subject, Greer et al. claim that there will be no way to explain the various responses and results of COVID-19 without understanding politics and policy. They continue to argue that a research agenda to address the COVID-19 pandemic that focuses on political factors will improve the implementation of feasible and effective policies and broaden our understanding of public health policy dealing with emerging and re-emerging pandemics. ${ }^{16}$ Similarly, Kavanagh et al. discuss important issues posed in the context of the COVID-19 pandemic about how we think about the interactions among government, population, and public health policy. The authors believe that the gap between countries on these aspects specifically defines how public health accountability can and should be integrated as authoritarian regimes have won compliments for their response while major democracies have wrestled to respond. ${ }^{17,18}$ These studies highlight the importance of assessing the role of social-political factors on COVID-19 outcomes and discover the pathways of these factors in determining the health outcomes of the population during the pandemic.

\section{Statement of the Problem}

COVID-19 poses a major global threat to human beings, causing devastating consequences from population health, political, and economic crises in many countries. ${ }^{16}$ The World Health Organization (WHO) announced that the novel Coronavirus Disease 2019 (COVID-19) outbreak was a public health emergency of international concern on January 30, 2020. ${ }^{19}$ On March 11, 2020, the COVID-19 outbreak officially became a pandemic, ${ }^{20}$ subsequently causing $191,686,787$ confirmed cases and 4,112,533 deaths worldwide as of July 20, 2021. ${ }^{21}$ The number of infections (as of July 20, 2021) are 23,677 times more than the infections that occurred during the previous outbreak of severe acute respiratory syndrome (SARS) from 2002 to 2003. ${ }^{11}$ Furthermore, according to the COVID-19 Dashboard by the Center for Systems Science and Engineering (CSSE) at Johns Hopkins University, the data show that the total numbers of confirmed cases and deaths related to COVID-19 vary dramatically across countries, which cannot be adequately explained because the pandemic started earlier in some countries than in other countries. $^{22}$

Although empirical investigations are illustrating the associations between the public health policy, healthcare, social-economic characteristics, and health outcomes of COVID-19, it is critical to inquire if the social-political factors are related to morbidity and mortality rates of COVID-19 worldwide. ${ }^{23-25}$ Therefore, identifying contributing factors that are not fully understood in previous research but potentially impact health outcomes during a global pandemic is necessary.

\section{Philosophical and Theoretical Frameworks}

The paradigm of this quantitative research is based on postpositivism. Postpositivism is a metatheoretical stance that critiques and amends positivism and has impacted theories and practices across philosophy, social sciences, and various models of 
scientific research. While positivists emphasize independence between the researcher and the participant or sample, postpositivists argue that the researcher's theories, hypotheses, background knowledge, and values can influence what is observed. ${ }^{26}$ Postpositivists pursue objectivity by recognizing the possible effects of biases. ${ }^{27,28}$

Theories are framed to interpret, foresee, and understand a phenomenon and to test and accumulate existing knowledge within the ranges of assumptions. The theoretical framework is the structure that can hold or support a theory of a research study. The theoretical frameworks describe the mechanisms that explain the associations between social-political factors and health outcomes. Postpositivists believe that theory, hypothesis, knowledge, and worldview of the researcher can affect what is observed. Postpositivists pursue objectivity by recognizing the possible effects of biases. ${ }^{26}$ This dissertation research utilizes the following theoretical frameworks to inform the study, i.e., political epidemiology, social epidemiology, and the social-ecological model.

\section{Political epidemiology}

Political epidemiology theory developed by Arthur Brownlea demonstrates that politics play a role in solving health problems and health crisis mitigation as significant as medical treatment and epidemiological strategies. Figure 1-1 displays the dimensions of the political epidemiologic process. Humankind first recognizes a health problem; in the next step, they deal with the information, adopt the value positions and then make political decisions; eventually, their interpretation and judgment will lead to certain evaluation and further social choices and problem recognition (Figure 1-1). ${ }^{29}$

\section{Social epidemiology}

Social epidemiology firstly obtained its name in the 1950s. Social epidemiology is a division of epidemiology that concentrates primarily on the effects of social-structural predictors on the status of well-being. Social epidemiology proposes that social class influences the distribution of disease and health. The theory assumes to identify societal features that influence the natural history of disease and health outcomes in society and to capture its mechanisms. ${ }^{30}$ Social epidemiology intends to address the questions of what effects social predictors have on individual-level and population-level health. The solutions will clarify the relationship between health outcomes and social-political infrastructures. $^{31}$

\section{Social-ecological model}

The social-ecological model was created to have an in-depth understanding of the interactive associations among individual and social-ecological factors. The social- 


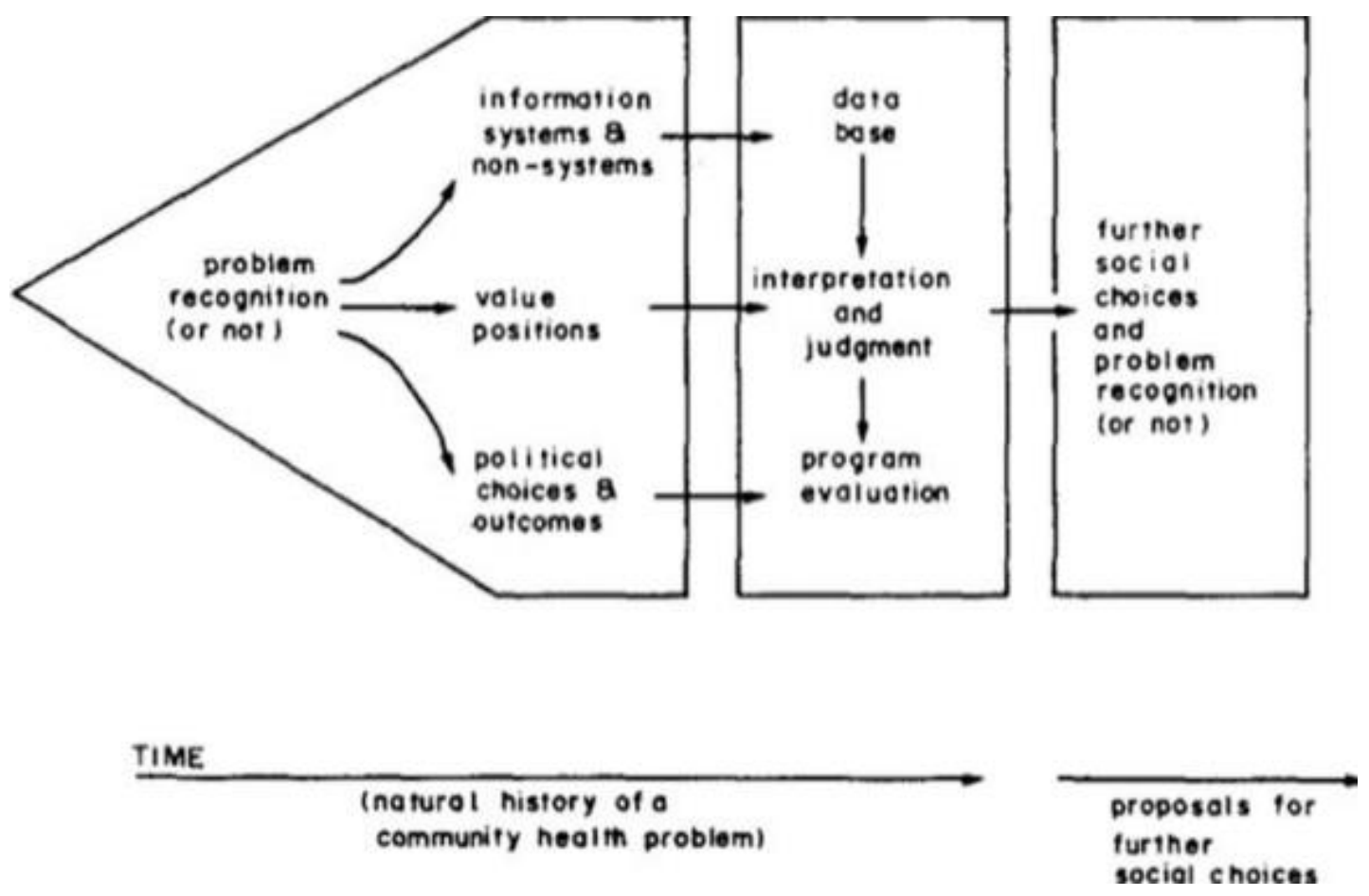

Figure 1-1. Political epidemiology process

Reprinted from Social Science \& Medicine, Part D: Medical Geography 15, no. 1, Brownlea, Arthur, From Public Health to Political Epidemiology, 57-67, (1981), with permission from Elsevier. ${ }^{29}$ 
ecological model was brought into use as a response to the scope of research directed by psychologists. ${ }^{32}$ The model points out that one factor exerts an effect on another. The essence of the social-ecological model is that an event influences another event, and each event presented is related to the dynamic circumstances while adjusting to the environment within which it exists. The five hierarchical levels are influenced by factors including not only gene expression but also the political systems. It is impossible to thoroughly perceive the meaning of the whole picture if researchers do not consider how these components impact and transform each other. When the elements communicate and interact, they realize the function and features of society. ${ }^{33,34}$

\section{Research Aims and Questions}

Our research addressed a set of questions with respect to the COVID-19 pandemic. The aims and questions were designed (1) to conduct a systematic review on the literature about political factors and health outcomes; (2) to examine the relationships between social-political factors and health outcomes of COVID-19; (3) to reveal the biases of cases and deaths of COVID-19 in terms of data collection problems:

Aim 1. First, we aimed to explore and evaluate the collective evidence in political factors and health outcomes and then investigate the relationship between political factors and health outcomes of COVID-19, with particular emphasis on identifying gaps in this field.

Question 1: Does democracy affect the health of a population?

Question 2: What is the relationship between democracy and health outcomes of COVID-19?

Aim 2. Second, we intended to examine the relationships between the Democracy Index and the case fatality rate of COVID-19 across countries. In addition, it also examined other factors, such as population density, comorbidity, and healthcare expenditures, which may be correlated with the case fatality rate of COVID-19.

Question 1: What is the relationship between the Democracy Index and the case fatality rate of COVID-19?

Question 2: What are the relationships between the Democracy Index and the case fatality rate of COVID-19 taking into account the covariates?

Aim 3. Last, we investigated the information biases of cases and deaths reporting of COVID-19 in terms of data collection problems. 
Question 1: What are the differences and similarities in the reporting of COVID-19 cases and deaths among sampled countries?

\section{Significance of the Study}

Identifying the predictors of COVID-19 related outcomes is very important for improving the health of the population worldwide when there is no approved pharmaceutical treatment and therapy during a pandemic. Currently, the role of socialpolitical factors on COVID-19 has not been thoroughly understood. This research helps identify the factors that impact the transmission rate and health outcomes of the COVID19 pandemic. This study is not only of great theoretical importance but is also beneficial to policymakers, leaders, and the population worldwide.

\section{Theoretical contribution}

The existing theories and literature lay a foundation for research that examines how social determinants and healthcare affect humankind's health. However, socialpolitical factors have always been treated as minor predictors of human well-being. This three-essay research study contributes to the growing body of knowledge that strengthens the theories and equips researchers and stakeholders to understand how social-political features affect the health outcomes of populations during an unprecedented health crisis. Additionally, this research suggests a graphical trajectory method to identify and examine biases resulting from the data collection at the initial phase of the epidemic. It also presents a new perspective for future work that would explore the attributes which are associated with quality of life, such as post-pandemic trauma and mental health consequences as well as morbidity and mortality of emerging/re-emerging communicable diseases worldwide.

\section{Policymakers}

Several groups of stakeholders may benefit from this study focusing on the association between social-political factors and health outcomes. Utilizing the findings from this study, policymakers can leverage the evidence-based results to establish specific public health policy about pandemic control under the circumstances both in terms of scarce resources and in terms of urgent decision-making. The findings could inform policymakers to propose health policies that will enhance a population's health status. Furthermore, policymakers can effectively disseminate the research findings in white papers to bridge the gaps between knowledge, a health policy proposal, and policy application. ${ }^{35}$ 


\section{Leaders}

By understanding that social-political factors influence the health of a population, the government leaders could more easily understand the need to make changes, improve, or reform their current policy. On the one hand, the results could assist leaders to recognize dynamic contexts, comprehensively integrate the interests of the individual and society, and enhance the accountability of leadership. On the other hand, an effective health policy would strengthen the political capital and governance capacity. This research represents an important step towards understanding the critical relationships among leaders, government, and health outcomes of a population. ${ }^{36}$

\section{Population}

This empirical study highlights the connection between social-political factors and health outcomes to effectively contain the COVID-19 pandemic. The population worldwide would benefit from the research findings, which optimize health policy and thus promote the health of a population. What's more, the unprecedented crises threatening people all over the world for two years would be addressed and possibly eliminated or allow a return to normal as the pandemic comes under control.

\section{Limitations}

The findings of this study must be seen in the light of four limitations. First, due to the self-reported data collected from different countries, the open-use datasets retrieved from international institutions and organizations may have heterogeneity of measurements across countries. Second, the confirmed cases of COVID-19 are likely to be underestimated because of the capacity of COVID-19 testing and scarcity of medical resources within some low-income or middle-income countries. For example, the PCR testing kits will likely limit the numerator of the morbidity rate calculation. ${ }^{37}$ Conversely, the deaths of COVID-19 are likely to be overestimated because of excess deaths and death certificate coding. ${ }^{38}$ Third, data collected for the original research purpose may not be able to respond to all research questions within this dissertation research. Finally, the causal relationships of social-political factors and health outcomes of COVID-19 cannot be assumed and tested due to the limited period of study. However, we encourage future work to leverage retrospective research designed to accomplish the goal of answering questions that cannot be addressed in this study.

\section{Definition of Terms}

This three-essay dissertation involves a series of well-established concepts used in the fields of public health, social science, economics, and ecology. The following terms clearly define the scope and meaning illustrated in this dissertation. 
Case fatality rate: "the proportion of people who die from a specified disease among all individuals diagnosed with the disease over a certain period of time". 39

COVID-19: "a respiratory disease caused by SARS-CoV-2, a new coronavirus discovered in 2019. The virus is thought to spread mainly from person to person through respiratory droplets produced when an infected person coughs, sneezes, or talks". 40

Democracy: "a system of governance in which rulers are held accountable for their actions in the public realm by citizens, acting indirectly through the competition and cooperation of their elected representatives". 41

Democracy Index: "an index compiled by the Economist Intelligence Unit (EIU), the research division of the Economist Group, a UK-based private company which publishes the weekly newspaper The Economist. The index is self-described as intending to measure the state of democracy in 167 countries, of which 166 are sovereign states and 164 are UN member states". ${ }^{42}$

Health: The current widely used definition of health is offered by World Health Organization (WHO). Health is a state of physical, mental, and social well-being and the absence of disease. ${ }^{43}$

Health expenditure: Health expenditure is the amount of money spent for health and healthcare service by citizens and the public sector out of total income. ${ }^{44}$

Health outcomes: The result of a medical status that directly influences the life expectancy or quality of life. ${ }^{45}$

Health policy: Health policy is defined as policies, strategies, and implementations made to achieve particular health care outcomes in society. There is a range of items that can be accomplished by a clear health policy. It establishes an orientation for future work and provides evidence for the current program. It points out the priorities and expected behavior of society. ${ }^{46}$

Morbidity: The percentage of people who have complications from a medical condition or after a procedure or treatment. ${ }^{39}$

Mortality: Alternatively used as death rate, is a measure of the number of deaths (in general, or due to a specific cause) in a particular population, scaled to the size of that population, per unit of time. ${ }^{39}$

Population health: Population health is defined as the health outcomes of a group of individuals as well as the distribution of health outcomes in this group. ${ }^{47}$

Social determinants of health: Social determinants of health are factors that are associated with the environment where people reside, study, entertain, and work that exert an effect on the health outcomes and quality of life. ${ }^{48}$ 


\section{CHAPTER 2. THE EFFECT OF DEMOCRACY ON HEALTH OUTCOMES IN COVID-19: A SYSTEMATIC REVIEW}

\section{Introduction}

COVID-19 has lasted for about two years and likely will go on spreading. The pandemic triggered by the severe acute respiratory syndrome coronavirus 2 (SARS-CoV2) has threatened humankind and healthcare systems in the global community. The viral transmission has been complicated not only by the existence of asymptomatic individuals but also by the constrained supply of testing kits, ICU beds, and healthcare workforce and more recently the transmissible Delta variant. ${ }^{49,50}$ The overloaded hospitals and tremendous loss of lives urge researchers to thoroughly capture the factors associated with morbidity and mortality of COVID-19. Most existing systematic reviews focus on the epidemiological characteristics of the novel virus, prediction models for diagnosis and prognosis of patients, and the effectiveness of mitigation measures. ${ }^{51-53}$ However, there is a lack of in-depth understanding of the fundamental factors that could explain the variations of outcomes across countries. When a re-emerging communicable disease turns into a global pandemic, synthesizing valid evidence to inform policymakers and healthcare professionals is vital for pandemic containment. In such an urgent context, the World Health Organization (WHO) suggests rapid reviews for relevant evidence to support public health policy and healthcare systems. ${ }^{54}$ Therefore, we synthesize the existing literature to review the political factors specifically, democracy, which may be correlated with the health outcomes of COVID-19.

We conducted a narrative systematic review of the existing literature to identify whether democracy had been reported in empirical studies on COVID-19 and then assessed the associations between democracy and health outcomes, including cases or deaths per capita, case fatality rate (CFR), and mortality. To overcome the lack of a reliable background about the relationship between political factors and health outcomes of COVID-19, this systematic review will not limit itself by simply investigating studies that have linked democracy level and adverse outcomes. In addition, it also appraised literature that had investigated the indirect measurements that may affect COVID-related health outcomes.

\section{Methods}

This systematic review was conducted aligned with PRISMA guidelines (Appendix A) ${ }^{55}$ We searched PubMed, EMBASE, and MEDLINE databases. The author (LY) designed the systematic review protocol and discussed it with coauthors (JCG and MHL) for modification. We used a combination of keywords, COVID-19, coronavirus, and democracy. Research articles in the English language, published from January 1, 2020, to August 16, 2021, were included. We also excluded comments, reviews, and personal perspectives. The Joanna Briggs Institute Critical Appraisal 
Checklist for studies reporting prevalence data was employed to evaluate the methodological quality of the selected articles(Appendix B). ${ }^{56}$

We comprehensively screened the title and abstract for each included article and reviewed the included studies that reported democracy and COVID-19 related outcomes. Articles that did not utilize empirical data or theoretical proposals were excluded. In the next step, we appraised the full-text papers in terms of sample size (or participants), outcomes of interests, covariates, methods, and findings to extract relevant data on whether or not democracy was addressed and its association with outcomes of COVID19.

Two independent authors (LY and JCG) reviewed the title and abstract for each article that met inclusion criteria and completed the full-text reviews. Quality assessment was carried out by LY and JCG. LY performed the database search on PubMed, EMBASE, and MEDLINE. We used an intelligent systematic review software Rayyan for article screening and collaboration between researchers. Disagreements on inclusions or exclusions were resolved through team discussions. The review team approved the final systematic review inclusions.

\section{Results}

A total of 296 articles published between January 1, 2020, to August 16, 2021, were identified from three electronic databases. In total, 126 papers were excluded since they were duplicates. Of the remaining 170 articles, 104 articles were published in 2020 and 66 articles in 2021. Seventy-seven articles were excluded because of irrelevant outcomes of the research. Meanwhile, we also excluded 74 articles due to wrong publication types, such as comments, reviews, and personal perspectives. Seven articles were excluded due to case study design and small sample size. Finally, 12 articles were selected for further review and data extraction (Figure 2-1).

We found a trend toward increasing empirical studies examining the associations between democracy and health outcomes of COVID-19. Data extractions are shown in Table 2-1. All the articles were scored as high-quality research papers (Table 2-2).

\section{Democracy as a concern}

We identified 170 articles from the database search. Nine articles were published in the journal Nature, two papers were published in JAMA, and two articles in BMJ. Of the 170 included articles, 12 surveys and four cross-sectional studies were found. Examining the included literature, we found 19 articles that reported concerns about democracy and COVID-19.Seven articles were excluded due to case study design and small sample size. Of these final 12 articles, seven investigated the relationship between democracy level and case fatality rate, mortality, and cases or deaths per capita as 


\section{Identification of studies via databases and registers}

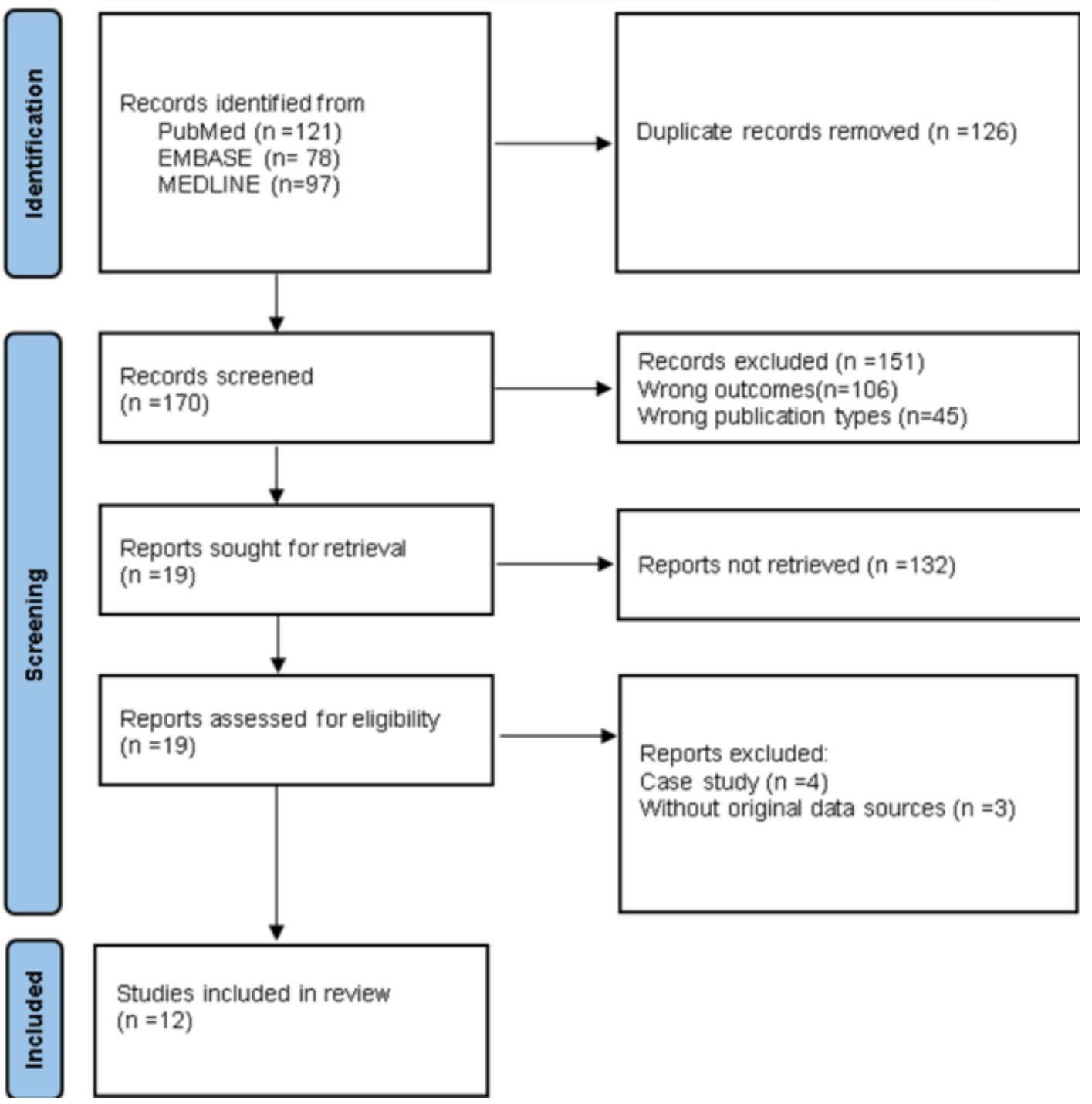

Figure 2-1. Systematic review flow chart 
Table 2-1. Data extraction for selected articles

\begin{tabular}{|c|c|c|c|c|c|}
\hline Source & Study design & Sample size & Outcomes & Predictors & Conclusions \\
\hline $\begin{array}{l}\text { Annaka } \\
\text { Susumu } \\
2021 \\
\text { Japan }\end{array}$ & $\begin{array}{l}\text { Cross- } \\
\text { sectional }\end{array}$ & 108 & $\begin{array}{l}\text { Deaths per } \\
1,000,000\end{array}$ & $\begin{array}{l}\text { Political regime; } \\
\text { Data transparency; } \\
\text { Government } \\
\text { Effectiveness; } \\
\text { Gross Domestic } \\
\text { Product(GDP) per } \\
\text { capita }\end{array}$ & $\begin{array}{l}\text { The findings of the article suggest that political regime predictors are } \\
\text { not related with the counts of deaths and cases after controlling for } \\
\text { other factors, like data transparency. However, data transparency is } \\
\text { positively associated with the deaths and cases numbers. }\end{array}$ \\
\hline $\begin{array}{l}\text { Huang et al. } \\
2020 \\
\text { Hongkong }\end{array}$ & Retrospective & 94 & $\begin{array}{l}\text { Incidence of } \\
\text { COVID-19 per } \\
100,000\end{array}$ & $\begin{array}{l}\text { COVID-19 Risk } \\
\text { Index; } \\
\text { Testing Policies; } \\
\text { Democracy Index; } \\
\text { Scientific Citation } \\
\text { Index; } \\
\text { GDP; } \\
\text { Human } \\
\text { Development } \\
\text { Index (HDI) }\end{array}$ & $\begin{array}{l}\text { Countries did not experienced SARS or MERS epidemics were more } \\
\text { likely to have higher incidence of COVID-19.Full democracy countries } \\
\text { had higher incidence of COVID-19.Data indicated that a country' } \\
\text { performance to tackle with COVID-19 is correlated with its former } \\
\text { exposure to an epidemics and Democracy Index. }\end{array}$ \\
\hline $\begin{array}{l}\text { Jardine et al. } \\
2020 \\
\text { Muslim }\end{array}$ & Retrospective & 44 & $\begin{array}{l}\text { Cases per } \\
1,000,000\end{array}$ & $\begin{array}{l}\text { Governance } \\
\text { systems; } \\
\text { Rapidity of } \\
\text { institution of } \\
\text { mitigation }\end{array}$ & $\begin{array}{l}\text { Functional democratic regimes take much longer time of doubling cases } \\
\text { from COVID-19 than non-democratic ones among Muslim-majority } \\
\text { countries. Findings indicated that functional democracies were more } \\
\text { capable to mitigate the epidemic than non-democratic regimes. }\end{array}$ \\
\hline $\begin{array}{l}\text { Jinjarak et al. } \\
2020 \\
\text { US }\end{array}$ & Retrospective & 36 & Mortality rate & $\begin{array}{l}\text { Proportion of the } \\
\text { elderly population; } \\
\text { Proportion of } \\
\text { urban population; } \\
\text { Democratic } \\
\text { freedoms }\end{array}$ & $\begin{array}{l}\text { Democratic countries are slower to reach their peak mortalities. The } \\
\text { results suggest that public health measures can reduce the mortality } \\
\text { growth, the peak mortality, and the duration to the first peak. }\end{array}$ \\
\hline
\end{tabular}


Table 2-1. (Continued)

\begin{tabular}{|c|c|c|c|c|c|}
\hline Source & Study design & Sample size & Outcomes & $\begin{array}{r}\text { Predictors } \\
\end{array}$ & $\begin{array}{r}\text { Conclusions } \\
\end{array}$ \\
\hline $\begin{array}{l}\text { Karabulut et } \\
\text { al. } 2021 \\
\text { Turkey }\end{array}$ & Retrospective & 128 & $\begin{array}{l}\text { Infection rate; Case } \\
\text { fatality rate }\end{array}$ & $\begin{array}{l}\text { Total Democracy Score; } \\
\text { Polity's Democracy Index; } \\
\text { Electoral Democracy Index of the V- } \\
\text { Dem Institute; } \\
\text { Gini coefficient; } \\
\text { tourism revenue per capita }\end{array}$ & $\begin{array}{l}\text { Democracy level is significantly positively } \\
\text { related to infection rate. However, all } \\
\text { democracy indices are negatively associated } \\
\text { with the case fatality rate. Researchers } \\
\text { concluded that COVID-19 had less effect on } \\
\text { mortality for most democratic countries. }\end{array}$ \\
\hline $\begin{array}{l}\text { Mazzucchelli } \\
\text { et al. } \\
2020 \\
\text { Spain }\end{array}$ & Retrospective & 27 & Mortality rate & $\begin{array}{l}\text { Democracy index } \\
\text { Country's political system } \\
\text { Country's corruption index }\end{array}$ & $\begin{array}{l}\text { Democracy index, the political system, and } \\
\text { the corruption index were statistically } \\
\text { associated with mortality. From west to east } \\
\text { Europe, the mortality of Covid- } 19 \text { declined. } \\
\text { Mortality variability can be partly explained } \\
\text { by political factors. }\end{array}$ \\
\hline $\begin{array}{l}\text { Naeim et al. } \\
2021 \\
\text { US }\end{array}$ & $\begin{array}{l}\text { Cross- } \\
\text { sectional }\end{array}$ & $\begin{array}{c}125,508 \\
\text { Participants }\end{array}$ & $\begin{array}{l}\text { COVID-19-related } \\
\text { concerns; } \\
\text { precautionary } \\
\text { behaviors; willingness } \\
\text { to return to activity. }\end{array}$ & $\begin{array}{l}\text { Age; gender; race; education; } \\
\text { household income; political party } \\
\text { support; religion; news consumption; } \\
\text { number of medication prescriptions; } \\
\text { perceived COVID-19 status; timing } \\
\text { of peak COVID-19 infections by } \\
\text { state }\end{array}$ & $\begin{array}{l}\text { Republicans compares to Democrats have less } \\
\text { COVID-19-related concerns, unwilling to } \\
\text { adopt the precautionary behaviors and prefer } \\
\text { to return to activity. Therefore, participants' } \\
\text { party affiliation was strongly associated with } \\
\text { COVID-19-related perceptions, precautionary } \\
\text { behaviors and activity. }\end{array}$ \\
\hline $\begin{array}{l}\text { Pak et al. } \\
2021 \\
\text { Australia }\end{array}$ & Retrospective & $\begin{array}{c}102,627 \\
\text { Participants }\end{array}$ & $\begin{array}{l}\text { Compliance } \\
\text { with government } \\
\text { restrictions and public } \\
\text { health guidelines }\end{array}$ & $\begin{array}{l}\text { COVID-19 attitudes; behavioral } \\
\text { measures; COVID-19 government } \\
\text { response policies; measures of the } \\
\text { strictness of restrictions on people's } \\
\text { behavior }\end{array}$ & $\begin{array}{l}\text { Among political regimes, public trust is } \\
\text { positively related to the compliance of public } \\
\text { health measures. This study points out the } \\
\text { significance of public trust in government } \\
\text { during the COVID-19 pandemic. }\end{array}$ \\
\hline
\end{tabular}


Table 2-1. (Continued)

\begin{tabular}{|c|c|c|c|c|c|}
\hline Source & Study design & Sample size & Outcomes & Predictors & Conclusions \\
\hline $\begin{array}{l}\text { Rocco et al. } \\
2021 \\
\text { US }\end{array}$ & Retrospective & 15 & Subnational data quality & $\begin{array}{l}\text { State capacity ; the } \\
\text { decentralization of resources and } \\
\text { authority; the quality of } \\
\text { democratic institutions }\end{array}$ & $\begin{array}{l}\text { Data showed the variations of COVID-19 } \\
\text { mortality, testing capacity and } \\
\text { hospitalization. COVID-19 data quality } \\
\text { depends on the level of democracy. }\end{array}$ \\
\hline $\begin{array}{l}\text { Sebhatu et al. } \\
2020 \\
\text { Sweden }\end{array}$ & Retrospective & 36 & $\begin{array}{l}\text { Daily counts of the } \\
\text { infected people; number } \\
\text { of deaths; speed of } \\
\text { adoption of the different } \\
\text { COVID-19 policies }\end{array}$ & $\begin{array}{l}\text { Oxford COVID-19 Government } \\
\text { Response Tracker (OxCGRT); the } \\
\text { Varieties of Democracy (V-Dem) } \\
\text { database }\end{array}$ & $\begin{array}{l}\text { Countries with a lower democracy level } \\
\text { were relatively faster to implement } \\
\text { COVID-19 measures. Democratic } \\
\text { countries are slower to respond in the } \\
\text { pandemic. }\end{array}$ \\
\hline $\begin{array}{l}\text { Sorci et al. } \\
2020 \\
\text { France }\end{array}$ & Retrospective & 72 & Case fatality rate & $\begin{array}{l}\text { Disability-adjusted life years } \\
\text { (DALYs); share of total disease } \\
\text { burden; age-standardized death } \\
\text { rates per 100,000; share of } \\
\text { deaths; Polity IV }\end{array}$ & $\begin{array}{l}\text { Case fatality rate was positively related } \\
\text { with the level of democracy. These } \\
\text { results highlight the role of political } \\
\text { factors as possible predictors of } \\
\text { COVID-19 case fatality rate. }\end{array}$ \\
\hline $\begin{array}{l}\text { Vadlamannati } \\
\text { et al. } \\
2021 \\
\text { Norway }\end{array}$ & $\begin{array}{l}\text { Cross- } \\
\text { sectional }\end{array}$ & 210 & Deaths per $1,000,000$ & $\begin{array}{l}\text { V-Dem democracy index } \\
\text { Infant mortality rate; } \\
\text { Global Burden of Disease; } \\
\text { health access and quality index }\end{array}$ & $\begin{array}{l}\text { Democratic governance shows the } \\
\text { opposite effect on fighting COVID-19 } \\
\text { when health equity is concerned. Disease } \\
\text { control might rely on the health system } \\
\text { capacity rather than the societal factors. }\end{array}$ \\
\hline
\end{tabular}


Table 2-2. JBI critical appraisal results

\begin{tabular}{lccccccccc}
\hline \multicolumn{1}{c}{ Citation } & Q1 & Q2 & Q3 & Q4 & Q5 & Q6 & Q7 & Q8 & Q9 \\
\hline Annaka. 2021 & Y & Y & Y & Y & Y & Y & Y & Y & Y \\
Huang et al. 2020 & Y & Y & Y & Y & Y & Y & U & Y & Y \\
Jardine et al. 2020 & Y & Y & Y & Y & Y & Y & Y & Y & Y \\
Jinjarak et al.2020 & Y & Y & Y & U & Y & Y & Y & Y & Y \\
Karabulut et al. 2021 & Y & Y & N & Y & Y & Y & Y & Y & Y \\
Mazzucchelli et al. 2020 & Y & N & N & Y & Y & Y & Y & Y & Y \\
Naeim et al. 2021 & Y & Y & N & N & Y & Y & N & Y & Y \\
Pak et al.2021 & Y & U & Y & Y & Y & Y & Y & Y & Y \\
Rocco et al. 2021 & Y & Y & N & Y & Y & Y & Y & Y & Y \\
Sebhatu et al. 2020 & Y & Y & Y & Y & Y & Y & Y & Y & Y \\
Sorci et al. 2020 & Y & Y & Y & Y & Y & Y & Y & Y & Y \\
Vadlamannati et al. 2021 & Y & Y & Y & Y & Y & Y & Y & Y & Y \\
Appraisal grade(\%) & 100.0 & 82.32 & 71.33 & 90.9 & 100.0 & 100.0 & 90.9 & 100.0 & 100.0 \\
\hline
\end{tabular}


dependent variables. We also found that the publications mainly originated in the US and Europe.

\section{Democracy and incidence}

One retrospective study from Hong Kong published in August 2020 reported an investigation of democracy and cases per million population in 94 countries. Their findings suggest that a higher democracy level is associated with more incidences of COVID-19. ${ }^{57}$ However, another paper argued that there is a negative association between democracy level and cases per million population in Muslim-majority countries published in October 2020. Cases in authoritarian Muslim-majority countries increased much faster than democratic counterparts, 33.9 days versus 66.5 days for cases doubling. ${ }^{58}$

Democracy was not an independent predictor of health outcomes of COVID-19. One article found that governments in democratic countries are slower to contain the pandemic. ${ }^{59}$ The other two articles had reported survey data about COVID-19 related concerns and behavior. ${ }^{60,61}$ One article published in the Journal of Health Politics found the association between subnational surveillance data quality and the quality of democracy. ${ }^{62}$

\section{Democracy and mortality}

Three articles published in SSM-Population Health, Scandinavian Journal of Public Health, and Revista Espanola de Salud Publica found the association between democracy and mortality. All three studies suggested that democratic countries are slower to respond to pandemics and experience higher deaths per capita and mortality rates compared to their authoritarian countries. ${ }^{63-65}$

\section{Democracy and case fatality rate}

One study found that there is a negative relationship between the democracy measures and case fatality rates in 128 countries. ${ }^{66}$ However, a study of 72 countries argued that case fatality rates are positively associated with democracy level. ${ }^{67}$

\section{Discussion}

We conducted a comprehensive search of the existing publications to identify whether democracy had been reported in studies of COVID-19 as well as the association between democracy and the health outcomes of COVID-19. We found that most of the empirical research articles on political factors and the pandemic have been published since 2021. This may be partially because of the gradual transmission of the virus across countries, and researchers in different countries, observing the variations of the health 
outcomes, began to consider the political factors as predictors. Most retrospective studies on democracy were based on data collected from Europe, where democracy is highly valued among the citizens. All the included studies were high-quality articles in terms of sample size, target populations, methodology, data analysis and response rate. The JBI Critical Appraisal ratings reflected the extent of our confidence that the estimates of the association were adequate to support a conclusion.

Further research is very unlikely to change the estimates of effect. In addition, European countries also experienced high morbidity and mortality of COVID-19 according to cross-country surveillance. These can explain why a majority of articles on this topic were published about European countries.

We found that peer-reviewed studies suggest that democratic countries may be at higher risk of COVID-19 attack than authoritarian countries. However, we cannot find any published evidence of an association between democracy and clinical health records; this may reflect the small number of studies focusing on this problem.

Understanding the role of democracy in a pandemic has important implications for public health policy. Even though existing literature suggests an association between democracy and adverse outcomes from COVID-19, other risk factors may also contribute to the higher risk of COVID-19 related infections and deaths in democratic countries. ${ }^{68}$

Early reports from the UK and Canada identified mobility as an important factor for outcomes from COVID-19. Researchers examining big data collected from over 3 million mobile phone users between February 1, 2020, to May 16, 2020, revealed that regional shutdowns during the COVID-19 epidemic reduced the total morbidity and mortality. ${ }^{69}$ Similarly, an international comparative study used mobility tracing data retrieved from ten countries to examine the linkage between mobility patterns, COVID19 transmission, and mortality rates across countries where different policies were deployed. ${ }^{70}$ Other studies found that slow responding countries suffered more deaths per 100,000 population and had to execute more stringent measures when compared to early responding countries. The results of these publications provide extremely meaningful evidence in helping countries better manage a predictable wave of COVID-19 or any other transmissible diseases. $^{71}$

An explanation for the relationship between mobility and outcomes of COVID-19 is the transmission patterns. ${ }^{72}$ Researchers found a positive association between mobility flow and the infected population during the COVID-19 onset in US counties from March 1 to June 9, 2020. ${ }^{73}$ Citizens' mobility may not be limited in some democratic countries, resulting in a higher risk of viral transmission and consequently increasing confirmed cases. ${ }^{74}$ The stringent lockdown and quarantine measures are common for authoritarian countries in Asia but implemented less in the European and the American continents. ${ }^{75}$ Individuals living in authoritarian countries might be likely to comply the public health strategies, protecting themselves from fatal disease. ${ }^{76}$ However, the interactions between democracy, individual behavior, and outcomes of COVID-19 remain unclear. 
A handful of fatal infectious diseases claim millions of lives worldwide each year. ${ }^{77}$ People in different countries become ill and die from a variety of infectious diseases, resulting from different responses among these populations. ${ }^{78}$ Citizens from democratic or authoritarian countries have specific behavior, interpersonal trust, and social profiles, which affect their responses to the pandemic. ${ }^{79}$ Therefore, individuals from different levels of democracy may have varying concerns and attitudes on COVID$19{ }^{80}$ For instance, a cross-national Facebook survey indicates significant heterogeneity in threat perceptions. ${ }^{81}$ Historically, countries with more serious legitimate regulations were more likely to mitigate the transmission of the Human Immunodeficiency Virus (HIV). Authoritarian countries can execute effective approaches with fewer requirements. Democratic political systems will be progressively accessible to the necessities of the population and can be fundamentally proficient in controlling the spread of HIV. ${ }^{10}$

Currently, COVID-19 vaccination coverage among adults varies among countries with different levels of democracy. According to a 33-country study, data showed that populations in China (91.3\%), Indonesia (93.3\%), Malaysia (94.3\%), and Ecuador $(97.0 \%)$ would like to accept COVID-19 vaccines. However, the COVID-19 vaccine acceptance rates in Kuwait (23.6\%), Jordan (28.4\%), Italy (53.7\%), Russia (54.9\%), Poland (56.3\%), US (56.9\%), and France (58.9\%) are found to be the lowest. ${ }^{82}$ Differences in vaccine acceptance rates may be attributed to health insurance, incentives, social-economic factors, and level of democracy. ${ }^{83,84}$ In the context of re-emerging and more transmissible variants of COVID-19, obstacles to reach herd immunity will be a public health challenge for democratic countries.

Behavioral, social, and cultural diversities may intervene in disease transmission. Housing units, education, employment, socioeconomic status, and health literacy are different in democratic and authoritarian countries. These factors may lead to a higher prevalence of COVID-19 in authoritarian countries. ${ }^{85}$ Citizens' responses to government measures have been observed in the different cultures between Asian, European, and North American countries. ${ }^{86}$ As the pandemic continues to spread with less availability of healthcare services within more underserved populations, for example, Africa, it should become necessary to strategically manage healthcare systems and public health dissemination. ${ }^{87}$

Our narrative review has several limitations. Since the rapidly changing situation, we limited our online database search to retrieve articles published in the English language from January 1, 2020, to August 16, 2021. We mainly focused on the association between democracy and outcomes of COVID-19 and did not identify papers regarding the role of democracy in other coronavirus outbreaks such as SARS. However, the synthesized results emphasize the need for evidence concerning democracy and the risk of these viral infectious diseases. To the best of our knowledge, this is the first review on this topic. We believe our review strategies approach to be reliable for an evolving pandemic. 


\section{Conclusion}

This systematic review revealed that democracy might be a risk factor for the health outcomes of COVID-19. Future work is still needed. The ideal way to compare the outcomes of COVID-19 across countries would match the countries in terms of the covariates other than democracy level. Data in the existing literature have limitations, such as the unavailability of data from developing countries. Extensive surveillance should refine these data to strengthen public health policy and inform international aid programs. Our systematic review provided policymakers and healthcare professionals with relevant evidence to make effective decisions about public health policy to respond to the pandemic. 


\section{CHAPTER 3. DEMOCRACY AND CASE FATALITY RATE OF COVID-19 AT EARLY STAGE OF PANDEMIC: A MULTICOUNTRY STUDY ${ }^{1}$}

\section{Introduction}

COVID-19 poses a major global threat to humankind, inflicting devastating consequences on the public health, politics, and economy of many countries. ${ }^{88}$ The World Health Organization (WHO) announced that the novel coronavirus disease 2019 (COVID-19) outbreak was a public health emergency of international concern on January 30, 2020. ${ }^{19}$ On March 11, 2020, the COVID-19 outbreak officially became a pandemic, ${ }^{19}$ subsequently causing 191,686,787 confirmed cases and 4,112,533 deaths worldwide as of July 20, 2021. ${ }^{21}$ The number of infections (as of July 20, 2021) are 23,677 times more than the infections that occurred during the previous outbreak of severe acute respiratory syndrome (SARS) from 2002 to $2003 .{ }^{11}$ In addition, according to the COVID-19 Dashboard managed by the Center for Systems Science and Engineering (CSSE) at Johns Hopkins University, the number of confirmed cases and deaths related to COVID-19 varies dramatically across countries, which reflects findings that cannot be explained by superficial analyses because the pandemic started earlier in some states and regions than in others. In general, countries that score higher on the Democracy Index have healthier populations, ${ }^{6,89}$ longer life expectancy, ${ }^{5,90}$ lower maternal and infant mortality, ${ }^{91}$ and higher expenditures for healthcare services. ${ }^{92}$ The rationale that democracy could improve health status is easy to understand. Firstly, when enforced through regular, free, and fair elections, democratic countries have a greater incentive than autocratic countries to provide welfare, health-related resources, and services to most of the citizens. ${ }^{6}$ In addition, democratic countries are more communicative with a broader set of interest groups, enjoy more freedom of media and press, and might be more active in utilizing the feedback from interest groups to enhance national public health programs. On the contrary, autocratic countries reduce political competition and access to information, which might deter constituent feedback and responsive governance. ${ }^{5-8}$ However, it has not been clear whether assessments of democracy in life expectancy and maternal and infant health are generalizable to infectious diseases, particularly a pandemic, at the early stage, which needs massive healthcare delivery, medical resources, healthcare professionals, and the ability to enforce public health measures such as quarantine, maskwearing, pool testing, and other potential measures of preventing disease transmission. ${ }^{93}$

Many studies have explored population health, quarantine, medical, and economic measures related to COVID-19, but few publications report on whether democracy is related to COVID-19 mortality worldwide, especially for the disease outbreak at an early stage. ${ }^{23-25}$ Karabulut and colleagues found that democracy is positively related to infections. ${ }^{94}$ In 27 European countries, the Democracy Index and the political system (full

\footnotetext{
${ }^{1}$ Modified from final submission by permission from Springer Nature. Environmental Science and Pollution Research. Democracy and case fatality rate of COVID-19 at early stage of pandemic: a multicountry study. Yao L, Li M, Wan JY, Howard SC, Bailey JE, Graff JC. 2021 Sep 7:1-11.99
} 
democracy vs. authoritarian) were statistically correlated with mortality, where higher scores on the Democracy Index were associated with higher mortality rates $(\mathrm{p}=0.003) .{ }^{95}$

Two theories suggest relevant domains to explore the relationship between political systems and health. Political epidemiology theory developed by Arthur Brownlea suggests that the role of politics in solving health issues rivals that of medical interventions and epidemiological measures. ${ }^{29}$ Social epidemiology proposes that the distribution of strengths and weaknesses in society echoes the distribution of disease and health. The theory aims to identify societal features that influence the natural history of diseases and their mechanisms. ${ }^{30}$

This study explores the association between democracy and the case fatality rate of COVID-19 at the early stage of a pandemic based on global databases that allow controlling for the effect of other risk factors. These risk factors include the percentage of the population ages 65 and above, hospital beds per capita, health expenditure as a percentage of GDP, the proportion of non-communicable diseases (NCD) caused deaths of total deaths, healthcare workforce per capita, and population density. Notably, this study evaluates a new predictor seldom used in health outcomes research. The Democracy Index may correlate with the ability of governments to enforce mandated public health measures during a pandemic. ${ }^{42}$ Further, the Democracy Index approximates the extent to which a government can mandate the behavior of its citizens and how the citizens react to the government. ${ }^{96}$ Mitigation of infectious disease transmission profoundly depends on citizens' attitude, behavior, response, and mobility. ${ }^{96-98}$ The study team hypothesized that the Democracy Index score is negatively associated with the case fatality rate of the COVID-19. ${ }^{99}$ The Approved Consent Form from Institutional Review Board appears in Appendix C.

\section{Methods}

\section{Data collection}

\section{COVID-19-confirmed cases, deaths, and tests performed}

The study team collected data of cumulative confirmed COVID-19 cases and deaths from the WHO open data repository accessed on October 25, 2020, a date chosen to reflect the early period of the pandemic, when therapeutics were limited and no vaccines had been approved. ${ }^{100}$ In addition, the team collected the total number of tests and tests per 1,000,000 population from the COVID-19 Data Repository managed by the Center for Systems Science and Engineering (CSSE) at Johns Hopkins University on October 25, 2020. ${ }^{101}$ The case fatality rate (CFR) is defined as the number of individuals who died of COVID-19 divided by the number of confirmed cases over a certain period of time. ${ }^{102}$ 


\section{Democracy index}

The dataset of the Economist Intelligence Unit's Democracy Index 2019 provided a snapshot of democracy worldwide and nearly covered the global population. ${ }^{42}$ The Democracy Index uses Economist Intelligence Unit (EIU) data to evaluate the quality of democracy as a composite score ranging from zero to ten. The Democracy Index comprises 60 different aspects of society and includes all aspects of political and civic life such as universal suffrage for adults, voter participation, perception of human rights protection, and freedom to establish organizations and parties. The Democracy Index 2019 has five subscales that address the following: political culture, the functioning of government, civil liberties, political participation, and electoral process and pluralism. Data is obtained by experts' assessment and scores are based on a range of indicators within these five categories and the composite score is calculated as the mean of the five categories. The Democracy Index is scored from zero to ten and grouped into four clusters labeled full democracy (scored 8.0-10.0), flawed democracy (scored 6.0-7.9), hybrid regime (scored 4.0-5.9), and authoritarian regime (scored 0.0-3.9). In addition, the study team stratified countries as low-income, lower-middle-income, higher-middleincome, and high-income based on world bank definitions in 2020. ${ }^{103}$ Democracy Index data were collected from the Economist Intelligence Unit database 2019. ${ }^{104}$

\section{Covariates}

Older age and presence of comorbidities are major risk factors for COVID-19 severity and mortality. ${ }^{105,106}$ The percentage of deaths caused by non-communicable disease of the total deaths is an indicator for population who is more likely to be infected by COVID-19. ${ }^{107}$ Healthcare workforce may also impact COVID-19 outcomes and was modeled as the number of medical doctors, nurses, and midwives per 10,000 population. ${ }^{108}$ Population density (population per square kilometer), ${ }^{109}$ hospital beds per 1,000 population, ${ }^{110}$ health expenditure as a percentage of gross domestic product (GDP) in US dollars, ${ }^{111}$ and the percentage of population ages 65 and above ${ }^{112}$ were taken into

account as covariates and collected from the World Bank and WHO databases. ${ }^{113,114}$

\section{Data selection and preparation}

The study team excluded countries that reported less than 2,000 confirmed cases of COVID-19 and any country that had missing data in terms of any variable. The sample size for main analyses was 148 countries while data from the 47 high-income countries were analyzed separately.

\section{Statistical analysis}

Descriptive statistics, mean, median, standard deviation, and interquartile range (IQR) were provided for all predictors. The study team implemented multiple linear regression and negative binomial regression analyses. Both are widely applied to examine 
the association between potential explanatory factors and the cases, deaths, and case fatality rate of COVID-19. ${ }^{111}$ The outcome variable was chosen as the case fatality rate, which was calculated as the rate of cumulative deaths divided by cumulative confirmed cases of COVID-19. ${ }^{115}$ Due to the highly skewed data across countries, log transformation was performed prior to multiple linear regression analysis. The main predictor variable was the Democracy Index score, and the outcome variable was the case fatality rate. A series of variables were included as potential confounders and controlled for in the regression model, including the percentage of the population ages 65 and above, hospital beds per 10,000 population, population density, healthcare workforce per capita, health expenditure as a percentage of GDP, and the percentage of deaths caused by non-communicable disease of total deaths. Multiple linear regression was conducted on two levels. The first set of analyses including the whole dataset of 148 countries and a second set of analyses of the 47 high-income countries was stratified by the four country income levels specified by the World Bank. ${ }^{113,114}$ The team employed statistical software SAS (version 9.4) and the level of significance was set at $\alpha=0.05$.

\section{Results}

\section{Variables summary}

The initial analysis showed that the means of cumulative confirmed cases, cumulative deaths, the case fatality rate, population density, the percentage of population ages 65 and above, health expenditure as a percentage of GDP, the percentage of deaths caused by non-communicable diseases of total deaths, healthcare workforce per 10,000 population, hospital beds per 1,000 population, and Democracy Index were 135,996.00, $4,325.00,2.31 \%, 146.75,9.35 \%, 6.54 \%, 68.88 \%, 63.02,2.89$, and 5.53, respectively (Table 3-1).

\section{Whole group analysis}

\section{Multiple linear regression}

For the first level, Model 1 included the whole dataset of 148 countries. The $\mathrm{R}^{2}$ for Model 1 was 0.1479 . The model is formulated as: $0.0004 X 7$

$$
\mathrm{Y}=0.00282+0.0039 \mathrm{X} 1+0.0006 \mathrm{X} 2+0.0039 \mathrm{X} 3+0.0008 \mathrm{X} 4-0.001 \mathrm{X} 5-0.0028 \mathrm{X} 6-
$$

$\mathrm{Y}$ is dependent variable, log transformation of case fatality rate. $\mathrm{X} 1$ is population ages 65 and above (\% of total population). X2 is the population density. X3 is the health expenditure of GDP. X4 is non-communicable diseases caused deaths (\% of total deaths). $\mathrm{X} 5$ is healthcare workforce per capita. X6 is hospital beds per capita. X7 is the 
Table 3-1. Descriptive statistics of variables $(\mathrm{N}=148)$

\begin{tabular}{lcccc}
\hline \multicolumn{1}{c}{ Variables } & Mean & Median & $\begin{array}{c}\text { Standard } \\
\text { deviation }\end{array}$ & $\begin{array}{c}\text { Interquartile } \\
\text { range }\end{array}$ \\
\hline Population ages 65 and above $^{\mathrm{a}}$ & 9.35 & 6.81 & 6.76 & 11.86 \\
Population density $^{\mathrm{b}}$ & 146.75 & 80.28 & 248.65 & 111.00 \\
Health expenditure of GDP $^{\mathrm{c}}$ & 6.54 & 6.43 & 2.41 & 3.59 \\
NCD-caused deaths $^{\mathrm{d}}$ & 68.88 & 76.60 & 22.78 & 44.25 \\
Healthcare workforce $^{\mathrm{e}}$ & 63.02 & 44.39 & 56.34 & 82.01 \\
Hospital beds $^{\mathrm{f}}$ & 2.89 & 2.10 & 2.44 & 3.15 \\
Democracy Index $^{\mathrm{g}}$ & 5.53 & 5.78 & 2.24 & 3.84 \\
Cumulative cases $^{\mathrm{h}}$ & $135,996.00$ & $34,470.00$ & $252,530.00$ & $115,870.00$ \\
Cumulative deaths $^{\mathrm{i}}$ & $4,325.00$ & 491.50 & $10,806.00$ & 2150.00 \\
Tests per 1,000,000 people $_{\text {Case fatality rate }}^{\mathrm{j}}$ & $148,137.90$ & $71,763.50$ & $226,368.00$ & $180,103.00$ \\
& 2.31 & 1.94 & 1.72 & 1.85 \\
\hline
\end{tabular}

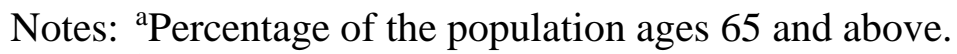

bopulation per $\mathrm{km}^{2}$ of the country's surface area.

${ }^{c}$ Health expenditure as a percentage of the gross domestic product.

${ }^{d}$ Percentage of deaths caused by non-communicable diseases of total deaths.

${ }^{\text {e}}$ Total number of medical doctors, nurses, and midwives per 10,000 population.

${ }_{\mathrm{f}}$ Number of hospital beds per 1,000 population.

'Democracy Index score $(0-10)$.

h,iThe starting points for cumulative cases and deaths were the confirmed days on which the 50th case and 50th death occurred in each country.

${ }^{\mathrm{j}}$ Ratio of cumulative deaths from COVID-19 to cumulative cases of COVID-19

(expressed as a percentage). 
Index. $\beta 0$ is 0.00282 which is the $y$-intercept when all other parameters are set to zero.

Hospital beds per 1,000 population were negatively correlated with the case fatality rate of COVID-19 $(\beta=-0.00282 ; p<0.05)$. For this model, one could conclude that increasing one hospital bed per 1,000 population would yield a 0.00282 decrease in the case fatality rate of COVID-19 population. Conversely, the percentage of the population ages 65 and above was positively associated with the case fatality rate ( $\beta$ $=0.00391 ; \mathrm{p}<0.05)$. Also, the health expenditure of the GDP was positively related to the case fatality rate of COVID-19 $(\beta=0.00397$; $<<0.05)$ (Table 3-2).

\section{Negative binomial regression}

Negative binomial regression was used to estimate the association between predictors and counts of cases and deaths of COVID-19. The regression equations for these models are shown as:

$\log (\mathrm{Yc})=7.6639-0.0668 \mathrm{X} 1-0.0003 \mathrm{X} 2+-0.04420 \mathrm{X} 3+0.0550 \mathrm{X} 4-0.0034$ $\mathrm{X} 5+0.0698 \mathrm{X} 6+0.1915 \mathrm{X} 7$

$\log (\mathrm{Yd})=3.2351-0.0110 \mathrm{X} 1-0.0010 \mathrm{X} 2+0.0199 \mathrm{X} 3+0.0648 \mathrm{X} 4-0.0079 \mathrm{X} 5-$ $0.0649 \times 6+0.1855 \times 7$

Yc is the counts of confirmed cases of COVID-19. Yd is the counts of deaths due to COVID-19. X1 is population ages 65 and above (\% of total population). $\mathrm{X} 2$ is the population density. $\mathrm{X} 3$ is the health expenditure of GDP. X4 is non-communicable diseases (NCD)-caused deaths (\% of total deaths). X5 is healthcare workforce per capita. X6 is hospital beds per capita. $\mathrm{X} 7$ is the Democracy Index.

Using these two regression models, we estimate that the percentage of deaths caused by non-communicable diseases has a coefficient of 0.0648 with log count of deaths due to COVID-19, which is statistically significant. One unit increase of deaths caused by non-communicable diseases will change the log of counts of the COVID-19 related deaths by +0.0648 unit. In other words, one unit increase of deaths caused by noncommunicable diseases will raise the number of deaths due to COVID-19 by $\exp (0.0648)-1$ or $6.7 \%$. What's more, the regression for cases suggests that the percentage of NCD-caused deaths of total deaths has a significant coefficient of 0.0550 . We expect that one unit increase of deaths caused by NCD of total deaths will change the $\log$ of counts of the COVID- 19 cases by +0.0550 unit. In other words, one unit increase of deaths caused by NCD will raise the number of confirmed cases of COVID-19 by $\exp (0.0550)-1$ or $5.7 \%$. Also, the Democracy Index has a significant coefficient of 0.1915 which shows that one unit increase in Democracy Index will change the log of counts of the cases by +0.1915 unit. In other words, one unit increase in Democracy Index will raise the number of confirmed cases of COVID-19 by $\exp (0.1915)-1$ or $21 \%$. In negative binomial regression analyses of cases and deaths in 148 countries, health expenditure as a share of GDP and Democracy Index are risk factors of COVID-19 related cases. 
Table 3-2. Multiple linear regression results of the association between predictors and case fatality rate of COVID-19 $(\mathrm{N}=148)$

\begin{tabular}{|c|c|c|}
\hline & Model & $\left(R^{2}=0.1479\right)$ \\
\hline Variables & Parameter estimate $(\boldsymbol{\beta})$ & p-Value \\
\hline Population ages 65 and above ${ }^{a}$ & 0.0039 & 0.0193 \\
\hline Population density ${ }^{\mathrm{b}}$ & 0.0006 & 0.1168 \\
\hline Health expenditure of GDP & 0.0039 & 0.0237 \\
\hline NCD-caused deaths ${ }^{\mathrm{d}}$ & 0.0008 & 0.7720 \\
\hline Healthcare workforce ${ }^{\mathrm{e}}$ & -0.0010 & 0.2958 \\
\hline Hospital beds ${ }^{f}$ & -0.0028 & 0.0116 \\
\hline Democracy Index ${ }^{g}$ & -0.0004 & 0.1747 \\
\hline
\end{tabular}

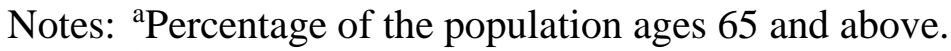

bPopulation per $\mathrm{km}^{2}$ of the country's surface area.

${ }^{c} H e a l t h$ expenditure as a percentage of the gross domestic product.

${ }^{\mathrm{d} P e r c e n t a g e}$ of deaths caused by non-communicable diseases of total deaths.

${ }^{\mathrm{e}}$ Total number of medical doctors, nurses, and midwives per 10,000 population.

${ }^{\mathrm{f}}$ Number of hospital beds per 1,000 population.

${ }^{g}$ Democracy Index score $(0-10)$. 
Meanwhile, health expenditure as a share of GDP is also a risk factor of deaths related to COVID-19 (Tables 3-3 and 3-4).

\section{Influence of democracy on the case fatality rate}

Among the 148 countries in this research, 15\% were labeled as full democracy, $31 \%$ as flawed democracy, $24 \%$ as hybrid regime, and $30 \%$ as authoritarian regime countries. Categorized by income levels, $32 \%$ of countries were classified as high-income followed by $28 \%$ higher-middle-income, $24 \%$ lower-middle-income, and $16 \%$ lowincome. Box plots demonstrated that cumulative confirmed cases, cumulative deaths, tests per 1,000,000 population, and case fatality rates differed across the four regime types. The variations between countries were significant due to the skewed data and characteristics of countries. The highest confirmed cases appeared in countries within the full democracy regime type, while countries having the least cases were attributed to authoritarian countries. The case fatality rates in full democracy countries were higher than that in most authoritarian and flawed democracy countries. Both lowest confirmed cases and case fatality rate were observed among authoritarian countries (Figure 3-1).

Figure 3-2 presents the distribution of current health expenditure of GDP compared side-by-side with four categories of regime type. Full democracy countries invested least in the health sector than the others. Similarly, the percentage of the population ages 65 and above was also the highest in full democracy countries (Figure 3-2).

As for the healthcare system, the healthcare workforce in full democracy countries were the highest for distribution of health human resources followed by flawed democracy, authoritarian regime, and hybrid regime. In addition, there were more hospital beds per 1,000 population in democratic countries than in authoritarian countries (Figure 3-3).

\section{Subgroup analysis}

\section{Multiple linear regression}

The model for the subgroup, 47 high-income countries, is calculated as:

$$
\mathrm{Y}=0.0382+0.0085 \mathrm{X} 1+0.0002 \mathrm{X} 2+0.0068 \mathrm{X} 3-0.0024 \mathrm{X} 4+0.0023 \mathrm{X} 5-0.0075 \mathrm{X} 6-
$$

\section{$0.0019 \times 7$}

$\mathrm{Y}$ is the dependent variable, log transformation of case fatality rate. $\mathrm{X} 1$ is population ages 65 and above (\% of total population). X2 is the population density. X3 is the health 
Table 3-3. Negative binomial regression estimated association between predictors and cases $(\mathrm{N}=148)$

\begin{tabular}{lcc}
\hline \multicolumn{1}{c}{ Variables } & Odds ratio & 95\% Confidence interval \\
\hline Population ages 65 and above $^{\mathrm{a}}$ & 0.9353 & $(0.8535,1.0251)$ \\
Population density $^{\mathrm{b}}$ & 0.9997 & $(0.9986,1.0007)$ \\
Health expenditure of GDP $^{\mathrm{c}}$ & 1.0565 & $(1.0360,1.0773)$ \\
NCD-caused deaths $^{\mathrm{d}}$ & 0.9568 & $(0.8388,1.0913)$ \\
Healthcare workforce $^{\mathrm{e}}$ & 0.9966 & $(0.9883,1.0051)$ \\
Hospital beds $^{\mathrm{f}}$ & 1.0723 & $(0.9112,1.2618)$ \\
Democracy Index $^{\mathrm{g}}$ & 1.2110 & $(1.0256,1.4299)$ \\
\hline
\end{tabular}

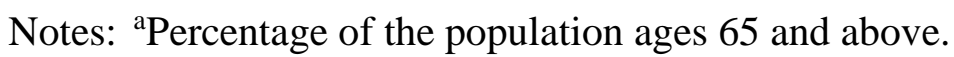

${ }^{b}$ Population per $\mathrm{km}^{2}$ of the country's surface area.

${ }^{c}$ Health expenditure as a percentage of the gross domestic product.

${ }^{\mathrm{d}}$ Percentage of deaths caused by non-communicable diseases of total deaths.

'Total number of medical doctors, nurses, and midwives per 10,000 population.

${ }^{\mathrm{f}}$ Number of hospital beds per 1,000 population.

${ }^{g}$ Democracy Index score $(0-10)$.

Table 3-4. Negative binomial regression estimated association between predictors and deaths $(\mathrm{N}=\mathbf{1 4 8})$

\begin{tabular}{lcc}
\hline \multicolumn{1}{c}{ Variables } & Odds ratio & 95\% Confidence interval \\
\hline Population ages 65 and above $^{\mathrm{a}}$ & 0.9891 & $(0.8850,1.1054)$ \\
Population density $^{\mathrm{b}}$ & 0.9990 & $(0.9978,1.0002)$ \\
Health expenditure of GDP $^{\mathrm{c}}$ & 1.0669 & $(1.0441,1.0902)$ \\
NCD-caused deaths $^{\mathrm{d}}$ & 1.0201 & $(0.8762,1.1877)$ \\
Healthcare workforce $^{\mathrm{e}}$ & 0.9921 & $(0.9826,1.0018)$ \\
Hospital beds $^{\mathrm{f}}$ & 0.9372 & $(0.7747,1.1338)$ \\
Democracy Index $^{\mathrm{g}}$ & 1.2038 & $(0.9983,1.4514)$ \\
\hline
\end{tabular}

Notes: aPercentage of the population ages 65 and above.

${ }^{b}$ Population per $\mathrm{km}^{2}$ of the country's surface area.

${ }^{c}$ Health expenditure as a percentage of the gross domestic product.

${ }^{\mathrm{d} P e r c e n t a g e}$ of deaths caused by non-communicable diseases of total deaths.

'Total number of medical doctors, nurses, and midwives per 10,000 population.

${ }^{\mathrm{f}}$ Number of hospital beds per 1,000 population.

${ }^{g}$ Democracy Index score $(0-10)$. 


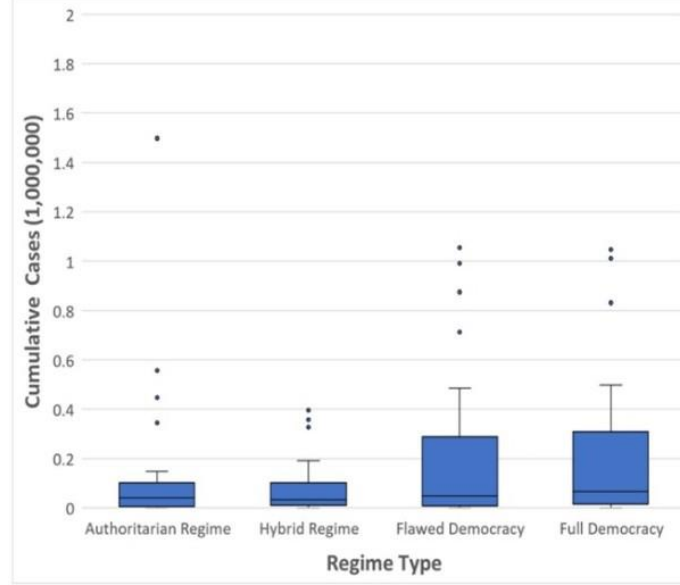

A

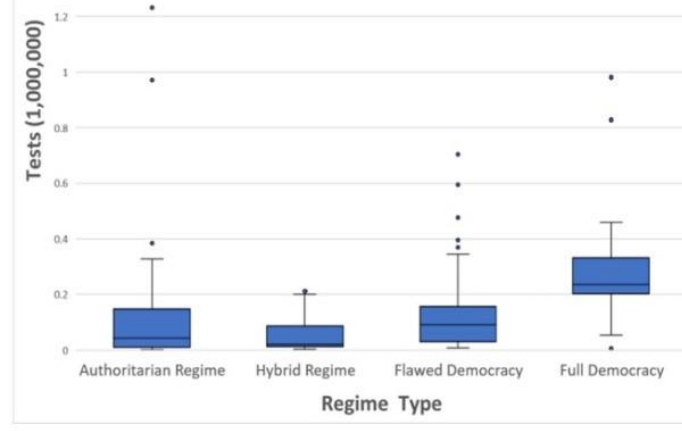

C

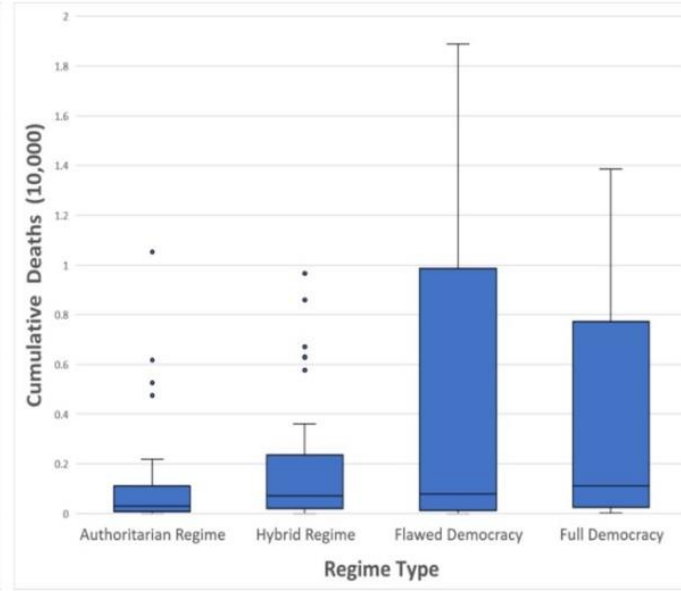

B

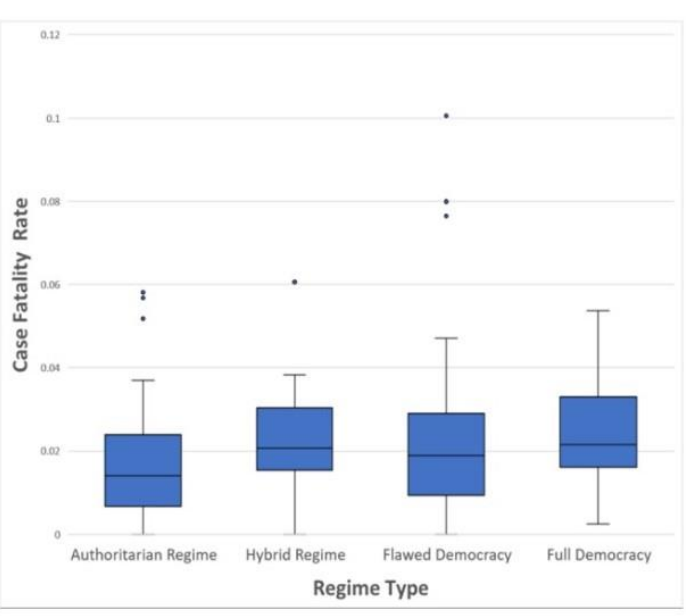

D

Figure 3-1. The cumulative confirmed cases and deaths of COVID-19, tests per $1,000,000$ population, and case fatality rate distribution by regime type

Notes: The x-axis represents the four types of regimes in the order of "Authoritarian Regime", "Hybrid Regime", "Flawed Democracy" and "Full Democracy." Y-axis units are displayed in parentheses. (A) $\mathrm{y}$-axis indicates the cumulative confirmed cases per $1,000,000$ population. (B) $y$-axis indicates the cumulative deaths per 10,000 population. (C) $\mathrm{y}$-axis indicates the tests per $1,000,000$ population. (D) $\mathrm{y}$-axis indicates the case fatality rate $(\%)$. 


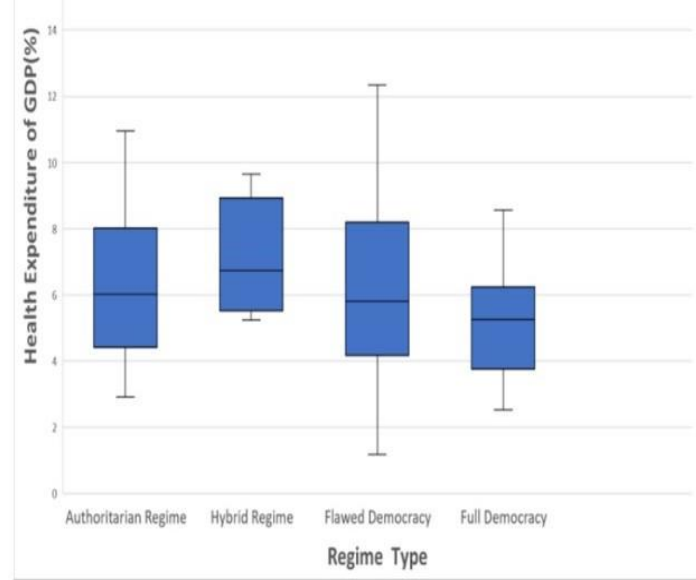

A

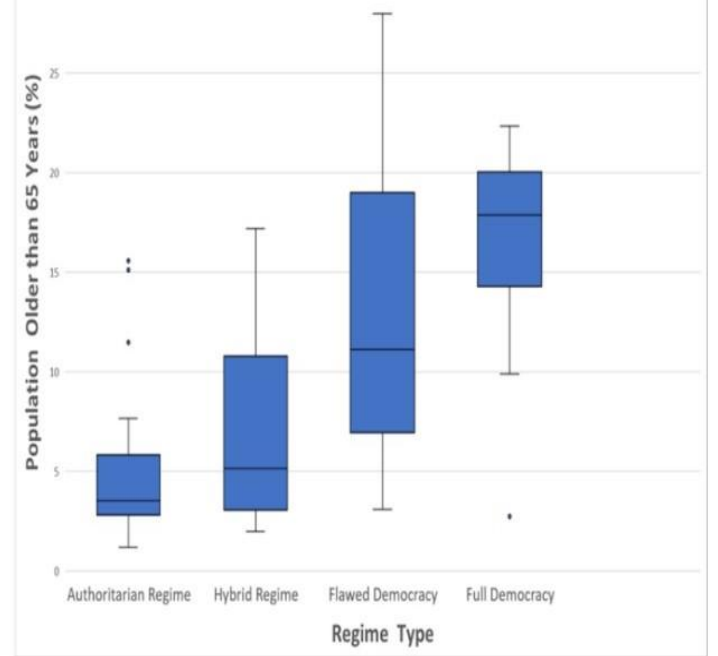

B

Figure 3-2. Health expenditure of GDP and percentage of population ages 65 and above distribution by regime type

Notes: (A) x-axis represents the four types of regimes in the order of "Authoritarian Regime", "Hybrid Regime", "Flawed Democracy" and "Full Democracy", y-axis indicates the health expenditure as a percentage of GDP (in US dollars). (B) y-axis indicates the percentage of population ages 65 and above. 


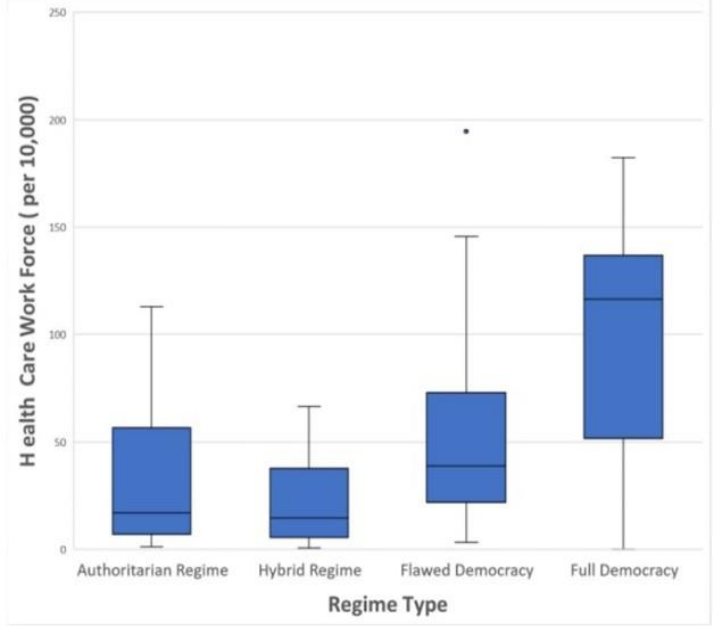

A

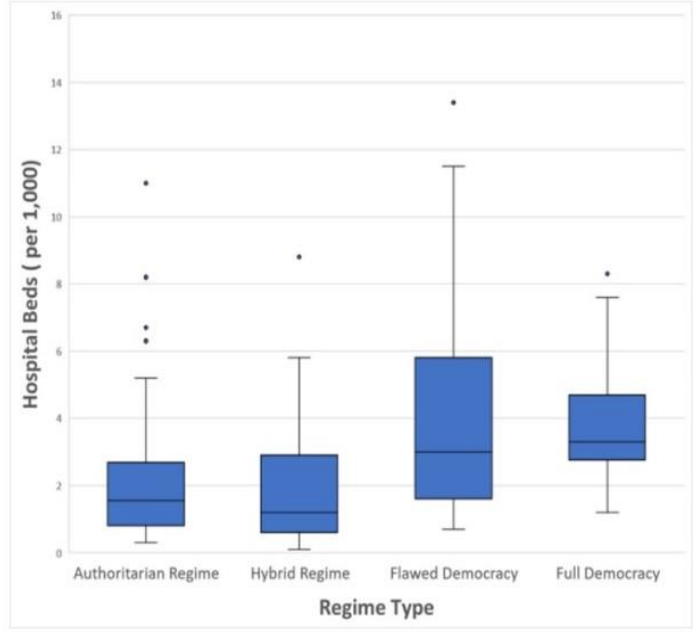

B

Figure 3-3. Healthcare workforce per 10,000 population and hospital beds per 1,000 population distribution by regime type

Notes: (A) x-axis represents the four types of regimes in the order of "Authoritarian Regime", "Hybrid Regime", "Flawed Democracy" and "Full Democracy", y-axis indicates healthcare workforce per 10,000 population. (B) y-axis indicates hospital beds per 1,000 population. 
expenditure of GDP. X4 is NCD-caused deaths (\% of total deaths). X5 is healthcare workforce per capita. X6 is hospital beds per capita. X7 is the Democracy Index. $\beta 0$ is 0.0382 which is the $y$-intercept when all other parameters are set to 0 .

Based on the calculation using the equation above, we obtained the results of association estimation (Table 3-5). Within 47 high-income countries, hospital beds per 1,000 population were negatively correlated with the case fatality rate of COVID-19 ( $\beta$ $=-0.00754 ; p<0.05)$. For the second model, increasing one hospital bed per 1,000 population yields a 0.00754 decrease in the case fatality rate of COVID-19 population. On the contrary, the percentage of population ages 65 and above was also positively associated with the case fatality rate $(\beta=0.00858 ; p<0.05)$. Finally, the Democracy Index was negatively correlated with the case fatality rate of COVID-19 ( $\beta=-0.00192 ; p$ $<0.05)$. However, the effect of health expenditure of GDP did not reach a significant level among high-income countries as shown in Model 2.

\section{Negative binomial regression}

Negative binomial regression was used to estimate the association between predictors and cases as well as deaths of COVID-19. The negative binomial regression models are formulated as following:

\section{$\log (\mathrm{Yc})=9.8196+0.0165 \mathrm{X} 1-0.0009 \mathrm{X} 2+0.0363 \mathrm{X} 3+0.5538 \mathrm{X} 4-0.0058 \mathrm{X} 5-$ 0.1072X6-0.6046X7}

$\log (\mathrm{Yd})=1.7414-0.0626 \mathrm{X} 1-0.0015 \mathrm{X} 2+0.7034 \mathrm{X} 3+0.0711 \mathrm{X} 4-0.0055 \mathrm{X} 5-$ 0.1705X6-0.6480X7

Yc and Yd represents the counts of COVID-19-related cases and deaths respectively. X1 is population ages 65 and above (\% of total population). $\mathrm{X} 2$ is the population density. $\mathrm{X} 3$ is the health expenditure of GDP. X4 is NCD-caused deaths (\% of total deaths). X5 is healthcare workforce per capita. X6 is hospital beds per capita. X7 is the Democracy Index.

In subgroup analysis, negative binomial regressions for deaths counts show that health expenditure as a percentage of GDP has a significant coefficient of 0.7034 with deaths of COVID-19. We estimate that one unit increase in health expenditure as a percentage of GDP will change the log of counts of the COVID-19-related deaths by +0.7034 unit. In other words, one unit increase in health expenditure as a percentage of GDP will raise the counts of the COVID-19-related deaths by $\exp (0.7034)-1$ or $102 \%$. In contrast, Democracy Index has a coefficient of -0.6480 which indicates that one unit increase in Democracy Index will change the log of counts of COVID-19 deaths by0.6480 unit. In other words, one unit increase in Democracy Index will lower the counts of COVID-19 deaths by $1-\exp (-0.6480)$ or $48 \%$. In addition, regression analysis for cases suggests that the health expenditure of GDP is a significant predictor with a coefficient of 0.0363 . This result means that one unit increase in health expenditure of 
Table 3-5. Multiple linear regression results of the association between predictors and case fatality rate of COVID-19 in high-income countries ( $N=47)$

\begin{tabular}{|c|c|c|}
\hline Variables & $\begin{array}{c}\text { Model } \\
\text { Parameter estimate }(\boldsymbol{\beta})\end{array}$ & $\frac{\left(\mathbf{R}^{2}=0.3857\right)}{p-\text { Value }}$ \\
\hline Population ages 65 and above ${ }^{a}$ & 0.0085 & 0.0249 \\
\hline Population density ${ }^{\mathrm{b}}$ & 0.0002 & 0.6866 \\
\hline Health expenditure of GDP ${ }^{c}$ & 0.0068 & 0.1313 \\
\hline NCD-caused deaths ${ }^{\mathrm{d}}$ & -0.0024 & 0.8982 \\
\hline Healthcare workforce ${ }^{\mathrm{e}}$ & 0.0023 & 0.2680 \\
\hline Hospital beds $^{f}$ & -0.0075 & 0.0056 \\
\hline Democracy Index ${ }^{g}$ & -0.0019 & 0.0490 \\
\hline
\end{tabular}

Notes: aPercentage of the population ages 65 and above.

bPopulation per $\mathrm{km}^{2}$ of the country's surface area.

${ }^{c} H e a l t h$ expenditure as a percentage of the gross domestic product.

${ }^{\mathrm{d} P e r c e n t a g e}$ of deaths caused by non-communicable diseases of total deaths.

${ }^{\mathrm{e}}$ Total number of medical doctors, nurses, and midwives per 10,000 population.

${ }^{\mathrm{f}}$ Number of hospital beds per 1,000 population.

${ }^{g}$ Democracy Index score $(0-10)$. 
GDP will change the log counts of the cases by +0.0363 unit. In other words, one unit increase in health expenditure of GDP will raise the counts of the cases by $\exp (0.0363)-1$ or $3.7 \%$. Furthermore, the Democracy Index has a significant negative coefficient of 0.6046 which indicates that one unit increase in Democracy Index will change the log of counts of the cases by -0.6046 unit. In other words, one unit increase in Democracy Index will lower the counts of the cases by $1-\exp (-0.6046)$ or $45 \%$. The negative binomial regression analyses showed that, in 47 high income countries, health expenditure as a share of GDP is a risk factor of cases while Democracy Index is the only protective factor for COVID-19 related cases. The analysis concerning COVID-19 related deaths suggested that health expenditure as a share of GDP is a risk factor of deaths and Democracy Index remained a protective factor in high income countries (Table 3-6 and 3-7).

\section{Discussion}

When adjusting predictors included in this analysis, the Democracy Index score was not statistically related to the case fatality of COVID-19 among the 148 countries. However, after stratifying by income levels, the Democracy Index score was negatively associated with the case fatality rate of COVID-19 patients within the 47 high-income countries. This finding highlighted an association between level of democracy according to the Democracy Index 2019 and the capacity of high-income countries to legitimate sufficient public health response to an urgent health crisis like COVID-19 in high-income countries.

Based on the multiple linear regression analysis, population density was not associated with case fatality rates in 148 countries. Scholars have argued that high population density contributed to the transmission of COVID-19. ${ }^{116}$ However, urgent lockdown and social distance policies, especially in authoritarian countries, and mandated measures to their citizens might reduce the possibility of human-to-human transmission (HHT). ${ }^{117}$ Although the Democracy Index variable was not a significant predictor in the first multiple linear regression model, those authoritarian countries are more likely to legitimate emergent and effective public health measures announced by the central governments. Like driving under the influence (DUI) is illegal because of threatening other people's lives and safety temporarily mandated measures responding to pandemics should be separated from suppression of citizens' democracy and freedom. Otherwise, the time for countries weighing the trade-off between mandates and suggestive measures would possibly lose the critical point of mitigation.

This empirical study fills the gap of current knowledge that concentrates on the extent to which the health care system and health policy can mitigate the spreading of COVID-19 across countries and regions. ${ }^{18,119}$ Although some scholars have debated the association between deaths and healthcare resource distribution, such as personal protective equipment (PPE) allocation in Italy, ${ }^{120}$ little is known about the influence of healthcare human resources. The healthcare workforce did not relate to the case fatality 
Table 3-6. Negative binomial regression estimated association between predictors and cases in high-income countries $(\mathrm{N}=47)$

\begin{tabular}{lcc}
\hline \multicolumn{1}{c}{ Variables } & Odds ratio & 95\% Confidence interval \\
\hline Population ages 65 and above $^{\mathrm{a}}$ & 1.0166 & $(0.8523,1.2126)$ \\
Population density $^{\mathrm{b}}$ & 0.9991 & $(0.9976,1.0006)$ \\
Health expenditure of GDP $^{\mathrm{c}}$ & 1.7398 & $(1.2872,2.3517)$ \\
NCD-caused deaths $^{\mathrm{d}}$ & 1.0370 & $(0.9132,1.1776)$ \\
Healthcare workforce $^{\mathrm{e}}$ & 0.9942 & $(0.9848,1.0037)$ \\
Hospital beds $^{\mathrm{f}}$ & 0.8983 & $(0.7288,1.1072)$ \\
Democracy Index $^{\mathrm{g}}$ & 0.5463 & $(0.3660,0.8155)$ \\
\hline
\end{tabular}

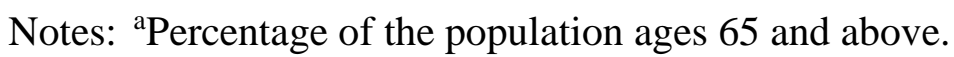

${ }^{b}$ Population per $\mathrm{km}^{2}$ of the country's surface area.

${ }^{c}$ Health expenditure as a percentage of the gross domestic product.

${ }^{\mathrm{d}}$ Percentage of deaths caused by non-communicable diseases of total deaths.

${ }^{\mathrm{e}}$ Total number of medical doctors, nurses, and midwives per 10,000 population.

${ }^{\mathrm{f}}$ Number of hospital beds per 1,000 population.

${ }^{g}$ Democracy Index score $(0-10)$.

Table 3-7. Negative binomial regression estimated association between predictors and deaths in high-income countries $(\mathrm{N}=47)$

\begin{tabular}{lcc}
\hline \multicolumn{1}{c}{ Variables } & Odds ratio & 95\% Confidence interval \\
\hline Population ages 65 and above $^{\mathrm{a}}$ & 1.0646 & $(0.8538,1.3275)$ \\
Population density $^{\mathrm{b}}$ & 0.9985 & $(0.9969,1.0002)$ \\
Health expenditure of GDP & 2.0206 & $(1.3797,2.9593)$ \\
NCD-caused deaths $^{\mathrm{d}}$ & 1.0737 & $(0.9127,1.2631)$ \\
Healthcare workforce $^{\mathrm{e}}$ & 0.9945 & $(0.9834,1.0057)$ \\
Hospital beds $^{\mathrm{f}}$ & 0.8433 & $(0.6691,1.0628)$ \\
Democracy Index $^{\mathrm{g}}$ & 0.5231 & $(0.3441,0.7952)$ \\
\hline
\end{tabular}

Notes: aPercentage of the population ages 65 and above.

${ }^{b}$ Population per $\mathrm{km}^{2}$ of the country's surface area.

${ }^{c}$ Health expenditure as a percentage of the gross domestic product.

${ }^{\mathrm{d} P e r c e n t a g e}$ of deaths caused by non-communicable diseases of total deaths.

${ }^{\mathrm{e}}$ Total number of medical doctors, nurses, and midwives per 10,000 population.

${ }^{\mathrm{f}}$ Number of hospital beds per 1,000 population.

${ }^{g}$ Democracy Index score $(0-10)$. 
rate of COVID-19. One explanation may be due to the overwhelming number of patients and the saturation of healthcare systems by the influx of patients. As the pandemic has continued to develop through 2021, health professionals have faced another unprecedented challenge: an overwhelming number of patients and more reproductive variants. Determining the healthcare system's constraints and the correlated factors to be examined in future research is critical. For instance, one case study of the United States evaluated and concluded that healthcare resource distribution equity could enhance the effectiveness of protecting citizens against the infection and deaths from COVID19. ${ }^{119,121}$ However, democratic countries neglected to implement long-term, sustainable strategies to reinforce the healthcare system to manage the abrupt shift in demand in terms of the healthcare workforce and resources caused by the COVID-19 crisis.

The result was as expected: a higher percentage of population ages 65 and above was positively correlated with higher case fatality rates among 148 countries. Therefore, this confirms that coronavirus is more fatal for the aged population regardless of race. ${ }^{122}$ Unexpectedly, the percentage of deaths caused by non-communicable disease of total deaths did not reach statistical significance. The previous research suggested that the clinical outcomes of the patients with comorbidities are worse than those without underlying health conditions. ${ }^{123}$ However, the most recent studies claim that, at the peak of the pandemic, comorbidities did not have associations with the mortality of COVID19. While diabetes, cardiovascular diseases, and hypertension are the most frequent comorbidities diagnosed among COVID-19 patients who are more likely to develop severe disease, the current study does not provide clear evidence that the prevalence of comorbidities at the country level increases overall risk of deaths from COVID-19. ${ }^{124,125}$ Although underlying health conditions often exacerbate a person's illness from the novel coronavirus, the interpretation that comorbidities relate to death rather than the viral infection is incorrect.

One surprising result was the positive relationship between the health expenditure as a percentage of GDP and the case fatality rates of COVID-19. The patients with COVID-19 related did not benefit from living in countries with higher health expenditure of GDP. This result is different from those in previous reports. ${ }^{126}$ The health expenditure of GDP contains several divisions of investment while countries differ dramatically on a budget of preventive medicine, clinical medicine, and research and development of cutting-edge equipment. ${ }^{127}$ Healthcare capacity or functionality from an infectious disease perspective may be sensitive to decisions about allocation well in advance of the pandemic. For high-income countries, chronic diseases are classified as a top priority instead of infectious diseases. ${ }^{128}$ Countries spending more on health expenditure are those with a higher proportion of senior citizens. On the other hand, countries with higher healthcare costs are more likely to test their citizens and report the confirmed cases and deaths.

Findings from the analysis of high income countries support our hypothesis and indicate a negative association between democracy and health outcomes of COVID-19, which coincides with previous studies on the relationship between democracy, maternal and infant mortality rates, and HIV/AIDS prevalence. ${ }^{5,7,10}$ Increasing empirical analyses 
show that pandemic-related factors cannot solely explain the considerable variation of outcomes across countries. Engler and colleagues suggested that the established democratic principles before the pandemic makes democratic governments reluctant to implement mandatory health policies. ${ }^{129}$ Thus, we believe that the Democracy Index explains the variation of countries' responses to COVID-19; that is, the higher the democracy level, the less the restriction of citizens' freedoms and the national public health policy. As a result, democratic governments more likely respond with self-control public health measures without stringent interventions. ${ }^{129,130}$ These may lead to increased transmission, infections, and deaths.

The results suggest that democracy might be a risk factor in high-income countries. The hospital beds, healthcare workforce, health expenditure of GDP may be protective factors. Because of the variations across countries, we suspect that some potential factors and mechanisms are likely mediating the predictors and health outcomes. Future research in this field is needed to evaluate the effect of democracy in two-way directions. The pandemic may also affect the level of democracy across countries.

The main findings of this study are subject to several limitations. First, due to the self-reported confirmed cases and deaths collected from different countries, the open-use datasets provided by international institutions and organizations may have variations of measurements across countries. Second, the confirmed cases of COVID-19 likely are underestimated because of the capacity of testing for each country and scarcity of medical resources, particularly within some low-income countries; for example, the PCR testing kits will limit the numerator of the morbidity rate. ${ }^{128}$ Conversely, the mortality of COVID-19 is likely to be overestimated because of excess deaths. The Democracy Index data may include bias with respect to the instruments and evaluations which are limited to epidemiological research. Third, data collected for the original goal or purpose might be difficult to utilize to respond to different research questions. Finally, because the current research employed a non-experimental cross-sectional study design, any demonstrated associations cannot be assumed to be causal. There are many alternative explanations for the demonstrated associations and also substantial heterogeneity among countries with both democratic and authoritarian governments. Thus, it is entirely likely that factors other than democracy may explain the observed variability in COVID-19 mortality. The stratified data within low-income, lower-middle-income, and higher-middle-income countries did not show any patterns or relations, possibly due to the relevance of predictors and variations among different levels of incomes. However, future research could leverage a retrospective research design to elucidate unanswered questions in this study.

\section{Conclusion}

This multicountry study suggests that health expenditure of GDP, hospital beds per capita, and population ages 65 and above were associated with the case fatality rates of COVID-19. However, none of these can be quickly modified in the setting of a 
pandemic, so prior preparation with excess capacity may be warranted. To our surprise, a lower Democracy Index score (more authoritarian government) was strongly and independently associated with decreased numbers of cases and decreased case fatality rate from COVID-19, suggesting that the ability to enforce health mandates on the population may be the most important element in response to a pandemic. Countries with a high Democracy Index score should consider policies that allow the healthcare equivalent of martial law so that any future pandemic can be controlled more effectively. 


\section{CHAPTER 4. GRAPHICAL TRAJECTORY COMPARISON TO IDENTIFY ERRORS IN DATA OF COVID-19: A CROSS-COUNTRY ANALYSIS ${ }^{2}$}

\section{Introduction}

Despite advances in microbiology and molecular diagnostics, timely identification of a new infectious disease such as COVID-19, its transmission pattern, hazard to humans, and case fatality rate, remains challenging. ${ }^{93,131-133}$ Investigators and clinicians in Wuhan quickly identified the novel coronavirus SARS-CoV-2 and disseminated their findings to the global community but determining the exact date of onset in Wuhan and the dates of initial arrival to other cities has been problematic. ${ }^{134}$ Moreover, before mass testing programs were initiated, researchers could determine the exact counts of COVID19 cases in Wuhan during the first quarter of the pandemic. ${ }^{134}$ However, accurate estimation of the date of virus onset in each locale and anticipation of future cases and deaths are necessary to prevent, predict, and mitigate the impact of new potentially lethal communicable diseases.

Since COVID-19 attacked the world, the term "turning point" appears frequently in the news, reports, and publications. From the perspective of epidemiology, the "turning point" means when an infectious disease reaches a point beyond any local ability to control it from spreading more widely. ${ }^{134}$ In general, the cases and deaths from the COVID-19 pandemic are expected to decrease after their turning points in a country or region. Unfortunately, new waves of COVID-19 have been observed in many countries and regions. To date, the meaning of the turning point for the development of the pandemic has received scant attention in the research literature. In this study, the turning point indicates the peak of cases or deaths in a single wave of COVID-19.

The turning points of cases and deaths caused by COVID-19 across regions and countries provide a useful tool to reexamine the data in the early stage of the Wuhan outbreak. ${ }^{133,135}$ By reviewing and comparing the turning point dates of the COVID-19 pandemic in sampled countries, the disease pattern and trajectory are evident. Despite the multiple waves of disease, some regions and countries, such as China, Hong Kong, South Korea, Switzerland, and Israel, effectively mitigated the epidemic of COVID-19 at the early stages of transmission. ${ }^{131}$ From the retrospective investigations of cases, deaths, and calendar days, we found similar patterns in these countries.

We analyzed patterns of turning points of several regions and countries for which robust data on the incidence and timing of COVID-19 cases and deaths were available. We then developed a predictive model to estimate the dates of onset and turning point and applied the model to the early Wuhan pandemic to estimate the date of onset in this

\footnotetext{
${ }^{2}$ Reprinted from final submission with MDPI open access permission. Yao L, Dong W, Wan JY, Howard SC, Li M, Graff JC. Graphical Trajectory Comparison to Identify Errors in Data of COVID-19: A CrossCountry Analysis. Journal of Personalized Medicine. 2021;11(10):955. DOI: 10.3390/jpm11100955. ${ }^{136}$
} 
and other areas for which early data were less robust due to their timing early in the pandemic. ${ }^{136}$

\section{Methods}

\section{Data collection in the early stage of the pandemic}

We collected data on COVID-19 cases in China and other countries from official and publicly accessible websites. ${ }^{132,134}$ We collected the daily new cases and deaths from the first day of the official reports within regions and countries. The cases and deaths addressed in this study referred to new cases and new deaths. Because COVID-19 was largely under control in China and a few other countries, early data were collected on or before the end of June 2020. When a country did not report the data for new cases or deaths in a single day, the cumulative cases and deaths reported before and after the missing data day were used to estimate the cases and deaths for that specific day. The pandemic period is the interval from the day of the first case to the day in which there were less than 10 cases.

\section{Peak day of cases and deaths}

For the peak day of a country, we used the weighted number method. ${ }^{132}$ Thus, the peak day of cases is defined as the day with the largest number of average cases of every three, five, and seven days. Similarly, the peak day of deaths is also calculated by the largest number of average deaths of every three, five, and seven days. There will be a maximum of three days of peaks if the peak days from three, five, or seven days are different from each other. For example, if the average deaths of every seven days are the largest number among average numbers of every three, five, and seven days, then the average number of deaths of every seven days will be the deaths peak day. The number of days between the peak days of cases and deaths is defined as the time lag. The peak period is defined as the first day with cases or deaths equal to or more than $40 \%$ of the numbers in the cases or deaths peak day to the last day with numbers equal to or more than $40 \%$ of the case or death numbers in the cases or deaths peak day, which is 13 days based on previous research. ${ }^{132}$

\section{Data analyses before and after the peak day}

The number of days of the pandemic before and after the cases peak day and deaths peak day was calculated and compared to rates of SARS-CoV-2 infection and mortality. For cases, the days before and after the cases peak day were calculated respectively and compared to the total days of the study period in different regions/countries. Similarly, the days before and after the deaths peak day were compared to the total number of total days of the study period. The cases peak day and the deaths peak 
day were not counted in the number of days either before or after the peak days. ${ }^{132}$ The term, disease peak, has also been used in the study of characteristics of COVID-19 by other researchers. ${ }^{132,133,135}$ Here we use the term disease peak to define the days of the highest number of cases and deaths as cases peak day and deaths peak day, respectively.

\section{The time lag between peaks of cases and deaths}

The time lag is defined as the number of days between the cases peak day and the deaths peak day, as calculated based on the paired comparison between three, five, and seven days of the peak day of cases and deaths. The time lags of different countries were calculated. The features of the time lag among countries included the number of days, the proportion of time lag over the total days of the pandemic period, and the proportion of deaths during the time lag over the total deaths. Mathematical calculations in time lag included the numbers in the cases peak day and deaths peak day. The features of the peak period included the duration of time lag, the ratio of time lag to the pandemic period, and the ratio of the cases and deaths to the total cases and total deaths. These features were analyzed among the countries with different pandemic duration and infectious disease outbreak scales.

\section{Results}

\section{Basic information}

Table 4-1 summarizes the numeric indicators of cases and deaths of COVID-19 in sampled regions and countries. There was considerable difference in time lag and numbers of cases and deaths among different countries/regions. The time lag ranged from 0 to 23 days. The case number at peak day ranged from 244 (Huanggang) to 42,941 (Brazil) and the number of deaths at peak day varied from 6 (Huanggang) to 2,332 (United States). There was less difference among the days in the peak period of cases and deaths, extending from 7 to 53 and from 22 to 53, respectively.

\section{Case and death patterns in Hubei province}

We compared the cases and deaths in Xiaogan, Huanggang, and Wuhan in China's Hubei province. As shown in Figure 4-1, we identified peak periods in cases and deaths in each graph and highlighted the time lags in the overlap of cases and deaths.

In Xiaogan, the peak period of cases was between January 30 to February 9, 2020. The turning point or peak day was February 5, 2020. The peak period of deaths was from February 4 to February 25; the peak day or turning point of deaths was February 18. The length of the time lag was 13 days (Figure 4-1A). 
Table 4-1. Summary of indicators of cases and deaths of sampled regions and countries using data of an average of 7-day

\begin{tabular}{lccccccccc}
\hline \multicolumn{1}{c}{ Indicators } & Xiaogan & Huanggang & Wuhan & Switzerland & Japan & Austria & United States & Brazil & Russia \\
\hline Time lag & 13 & 12 & 0 & 15 & 22 & 16 & 7 & -23 & 16 \\
Cases in peak day & 424 & 244 & 3,910 & 1,100 & 615 & 796 & 32,901 & 42,941 & 11,028 \\
Deaths in peak day & 7 & 6 & 88 & 57 & 24 & 25 & 2,332 & 1,165 & 140 \\
Cases in peak period & 1,846 & 2,578 & 25,393 & 22,890 & 11,065 & 10,449 & $1,461,040$ & 903,395 & 330,374 \\
Deaths in peak period & 64 & 110 & 1,880 & 1,594 & 617 & 491 & 86,251 & 48,766 & 3,252 \\
Cases in time lag & 1,846 & 1,815 & 0 & 14,794 & 8,330 & 7,659 & 241,640 & 723,396 & 154,751 \\
Deaths in time lag & 64 & 54 & 0 & 643 & 428 & 245 & 17,263 & 24,831 & 1,806 \\
Cases after peak day & 1,533 & 1,638 & 32,994 & 23,098 & 10,232 & 10,613 & $1,039,256$ & 0 & 152654 \\
Total cases & 3,419 & 2,884 & 50,860 & 30,572 & 16,237 & 16,201 & $1,516,575$ & $1,280,063$ & 362,380 \\
Deaths after peak day & 58 & 56 & 1,036 & 1,114 & 238 & 356 & 55,330 & 23,562 & 174 \\
Total deaths & 128 & 125 & 2,606 & 1,879 & 725 & 629 & 90,324 & 56,109 & 3,807 \\
Cases peak period & 11 & 17 & 7 & 27 & 25 & 18 & 53 & 32 \\
Deaths peak period & 22 & 31 & 22 & 36 & 35 & 29 & 39 & 47 & 53 \\
Peak cases /total cases & 0.124 & 0.894 & 0.499 & 0.749 & 0.681 & 0.645 & 0.963 & 0.706 & 0.912 \\
Peak deaths /total deaths & 0.055 & 0.880 & 0.721 & 0.848 & 0.851 & 0.781 & 0.955 & 0.869 & 0.854 \\
Cases after peak/total cases & 0.448 & 0.568 & 0.649 & 0.756 & 0.360 & 0.655 & 0.685 & 0.000 & 0.421 \\
Deaths after peak /total deaths & 0.453 & 0.448 & 0.398 & 0.593 & 0.328 & 0.566 & 0.613 & 0.420 & 0.046 \\
Cases in time lag /total cases & 0.540 & 0.629 & 0.000 & 0.484 & 0.513 & 0.473 & 0.159 & 0.565 & 0.427 \\
Deaths in time lag /total deaths & 0.500 & 0.432 & 0.000 & 0.342 & 0.590 & 0.390 & 0.191 & 0.443 & 0.474 \\
\hline
\end{tabular}

Data sources: The data of Wuhan, Huanggang, and Xiaogan were collected from the Health Commission of Hubei Province at http://wjw.hubei.gov.cn/fbjd/dtyw/ (Accessed June 30, 2020). ${ }^{137}$ The data of Switzerland, Japan, Austria, the United States, Brazil, and Russia are available in the repository from Worldometers at https://www.worldometers.info/coronavirus/ (Accessed June 30, 2020). ${ }^{138}$ 


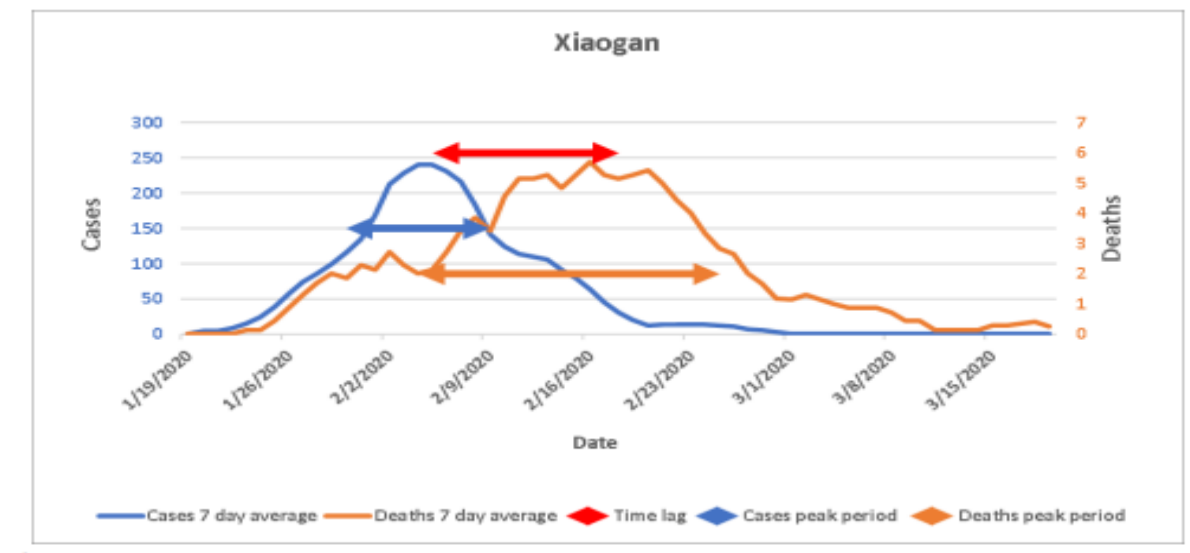

A
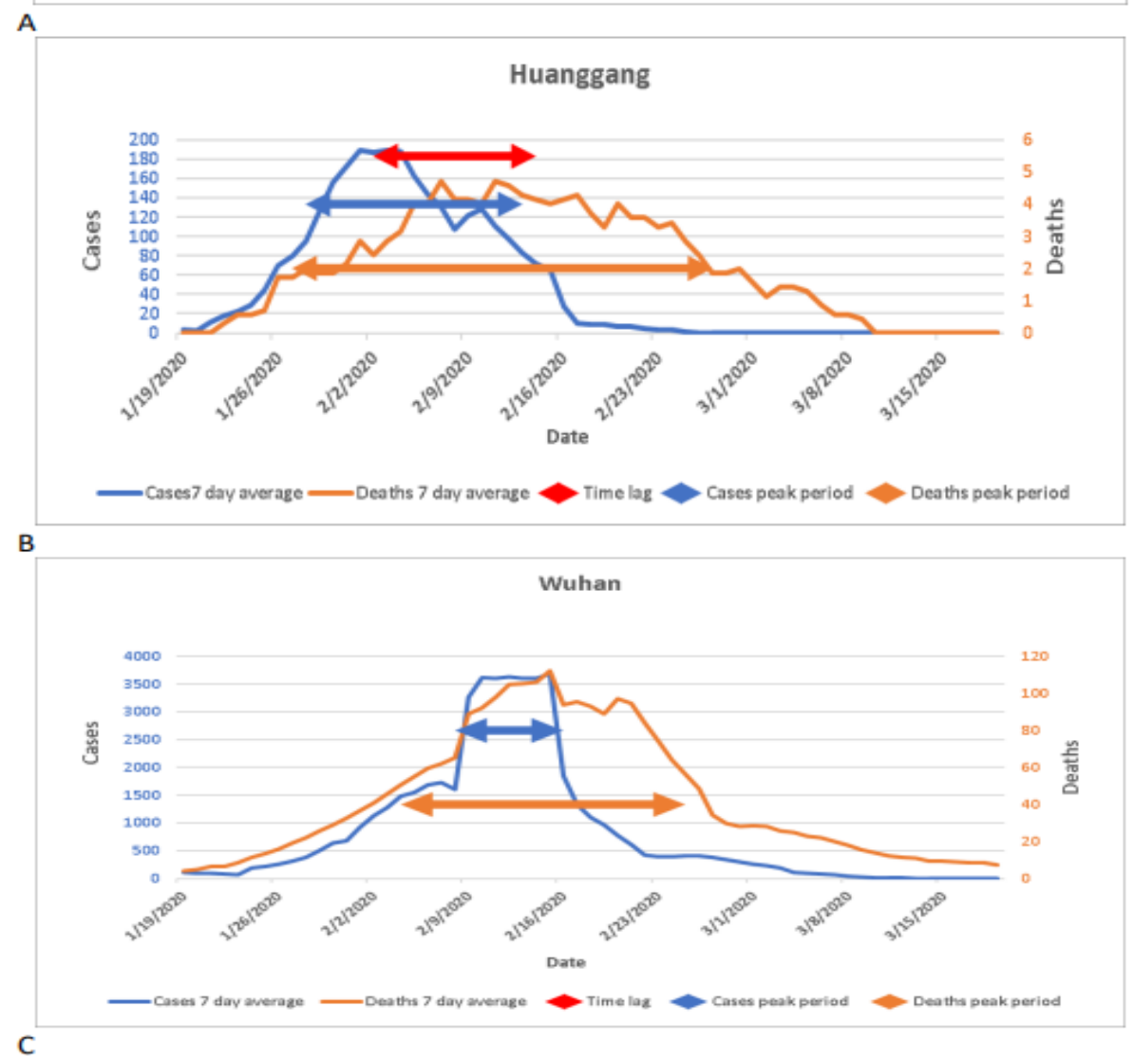

Figure 4-1. Patterns of cases and deaths from COVID-19 in three cities in China's Hubei province from January 19 to March 19, 2020

Notes: (A) New cases and deaths in Xiaogan; (B) New cases and deaths in Huanggang; (C) New cases and deaths in Wuhan.

Data source: The data of Wuhan, Huanggang, and Xiaogan were collected from the Health Commission of Hubei Province at http://wjw.hubei.gov.cn/fbjd/dtyw/ (Accessed June 30, 2020). ${ }^{137}$ 
In Huanggang, the cases peak period was from January 28 to February 13; the peak day or turning point of cases was February 2. The deaths peak period was from January 28 to February 27; the peak day or turning point of deaths was February 14. The length of the time lag was 12 days (Figure 4-1B).

The length of time lag represents the average number of days from the onset of symptoms to the deaths in the infected population. Thus, most deaths will not occur on the same day when most cases occur. However, when we examined the data reported from Wuhan, the result was not consistent with other cities. Figure 4-1C shows the cases peak period (February 9 to February 15) and deaths peak period (February 4 to February 25), but the turning point of cases and deaths were the same (February 13). Therefore, there was no time lag in Wuhan.

\section{Case and death patterns in three countries with less disease severity}

To further support the findings that the peak day of cases is before the peak day of deaths, we examined the cases and deaths in Switzerland, Austria, and Japan (Figure 4-2). Similar to data from China, cases and deaths in these three countries followed the patterns in the two cities in China. The first peak was the peak of cases, while the last peak was the peak of deaths. The length of time lag was 15 days in Switzerland, 16 days in Austria, and 22 days in Japan.

\section{Case and death patterns in three countries with large pandemics}

We chose to examine early data from the United States, Brazil, and Russia, where people are still suffering from the pandemic. COVID-19 in these countries was progressing, but their patterns were different as shown in Figure 4-3. In the United States, the peak days of cases and deaths could be distinguished, and the time lag was 11 days. In Russia, the situation was approximately the same as the trajectory of Xiaogan and Huanggang in China; the time lag was 16 days. However, in Brazil, the peak of deaths came earlier than the peak of cases; the length of time lag was 23 days (Figure 4-3).

\section{Patterns of death rate around the peak of disease onset}

To examine in detail the pandemic onset and the deaths of COVID-19 in Wuhan and to make comparisons across countries, we calculated the case fatality rate according to the 7-day period in Wuhan and sampled countries around the case peak. The case fatality rate of 13 days before and after the onset peak was calculated according to reported information. ${ }^{139}$ As shown in Figure 4-4, although the patterns of case fatality 

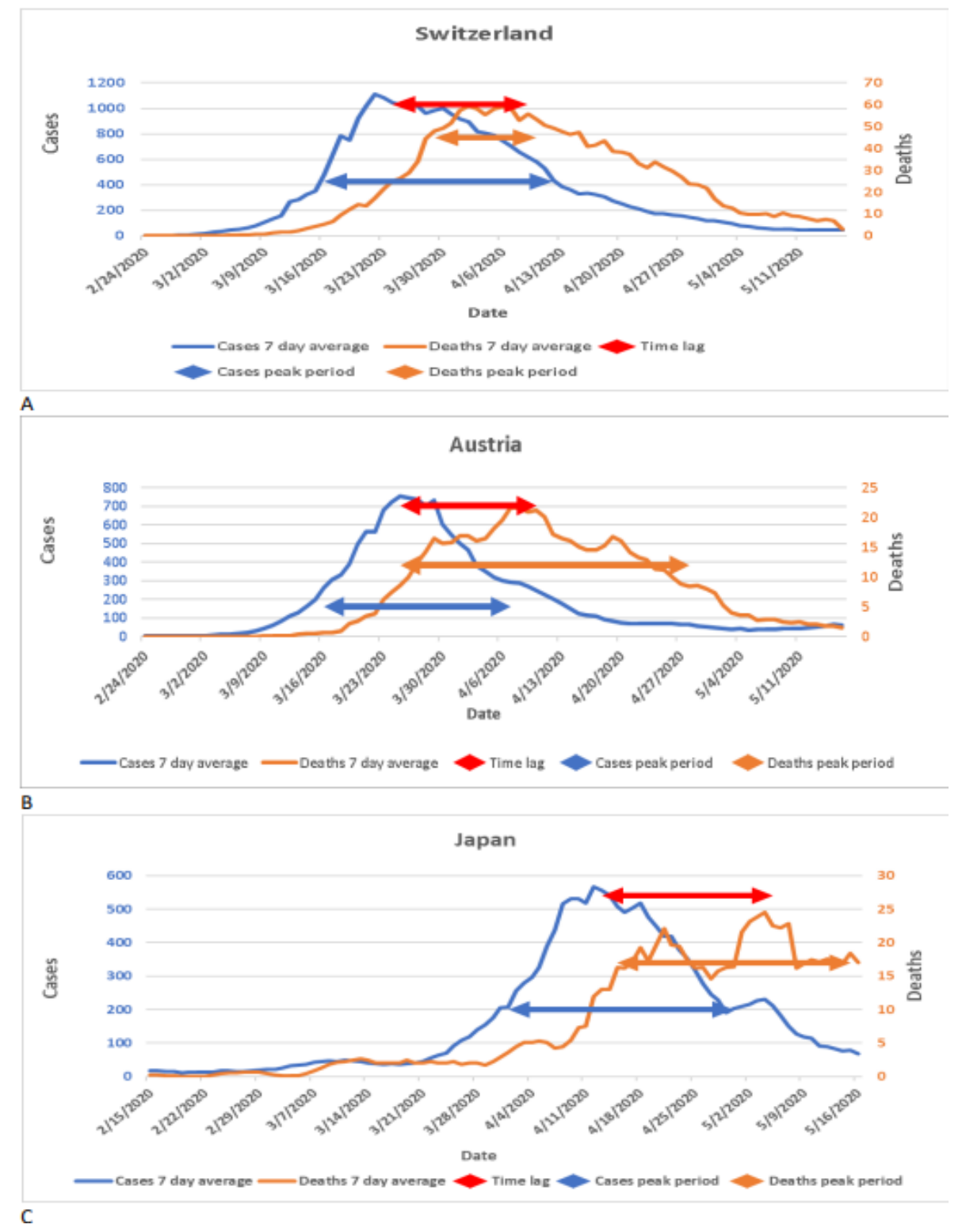

Figure 4-2. Patterns of cases and deaths from COVID-19 in three countries

Notes: (A) New cases and deaths in Switzerland; (B) New cases and deaths in Austria; (C) New cases and deaths in Japan.

Data source: The data of Switzerland, Japan, and Austria are available in the repository from Worldometers at https://www.worldometers.info/coronavirus/ (Accessed June 30, 2020). ${ }^{138}$ 

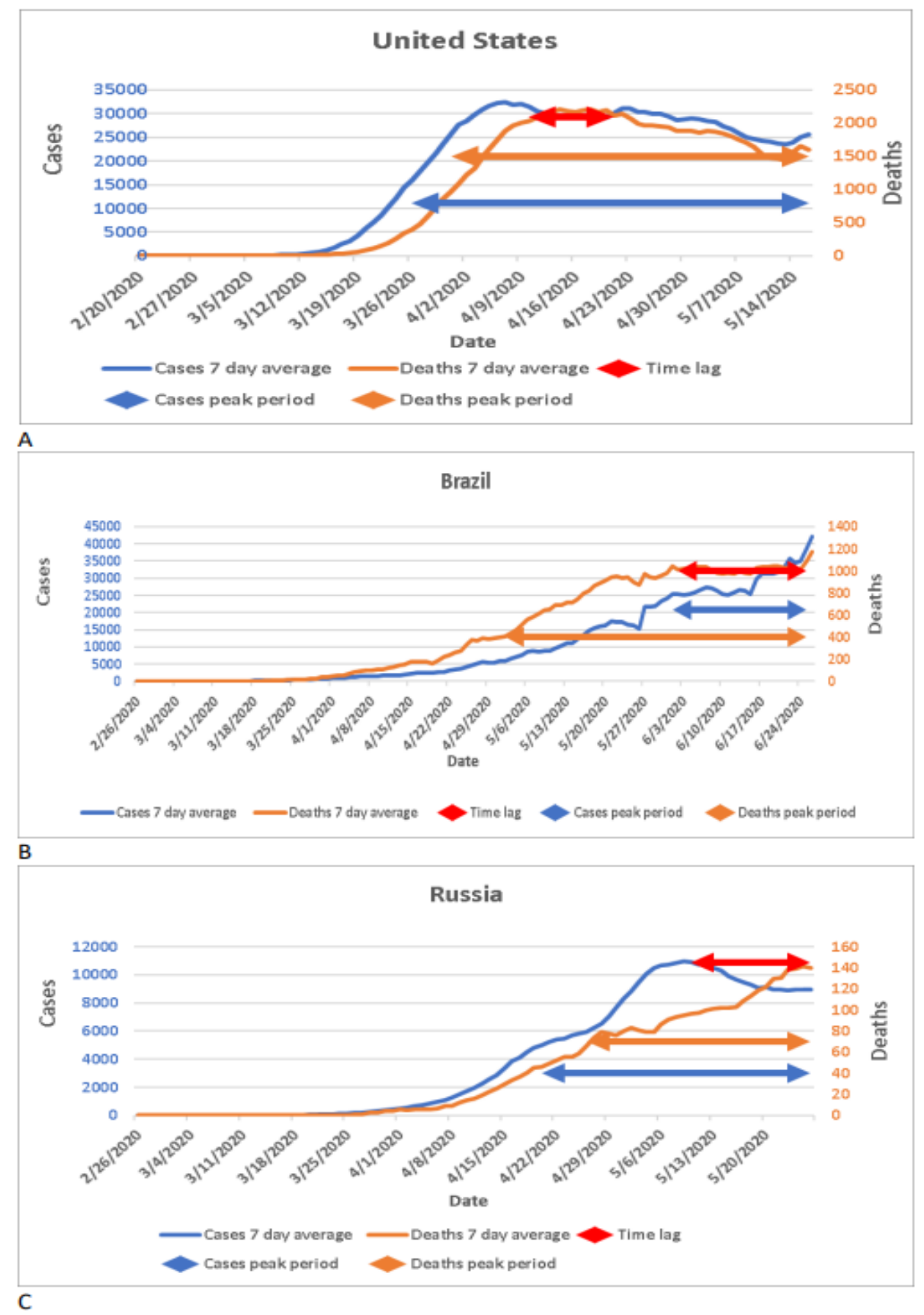

Figure 4-3. Patterns of death in three different countries with persistently high numbers of COVID-19 cases

Notes: (A) New cases and new deaths in the United States; (B) New cases and new deaths in Brazil; (C) New cases and new deaths in Russia.

Data source: The data of the United States, Brazil, and Russia are available in the repository from Worldometers at https://www.worldometers.info/coronavirus/ (Accessed June 30, 2020). ${ }^{138}$ 

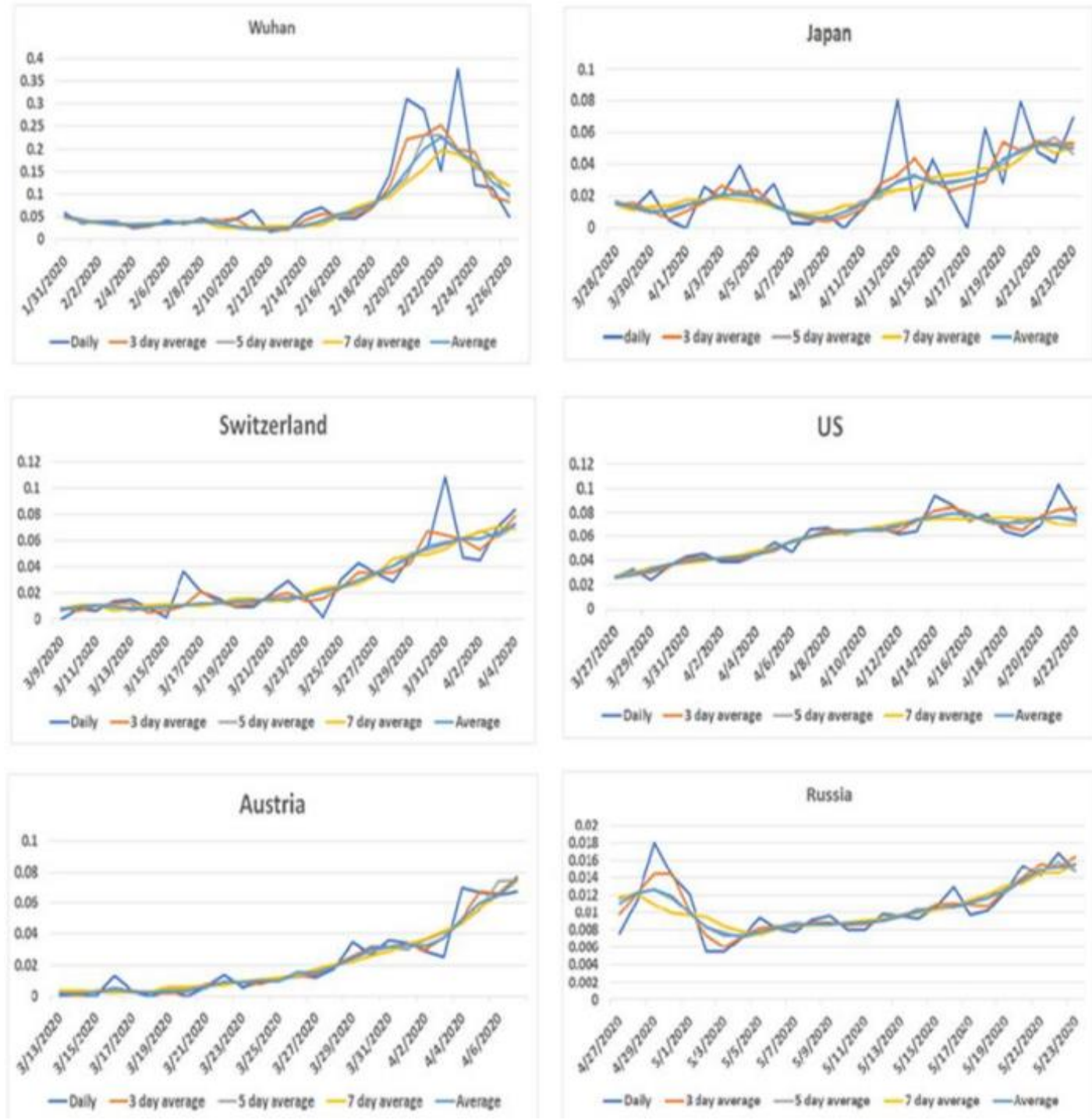

Figure 4-4. The graphic trajectory comparing COVID-19 death rates between Wuhan and five countries

Notes: X-axis represents date of observations. Y-axis indicates the death rate (\%). Daily, 3 day average, 5 day average, 7 day average are the average death rates of every day, 3 days, 5 days, and 7 days. The average means the average death rates of daily, 3 days, 5 days, and 7 days in total.

Data sources: The data of Wuhan were collected from the Health Commission of Hubei Province at http://wjw.hubei.gov.cn/fbjd/dtyw/ (Accessed June 30, 2020). ${ }^{137}$ The data of Switzerland, Japan, Austria, the United States, and Russia are available in the repository from Worldometers at https://www.worldometers.info/coronavirus/ (Accessed June 30, 2020). ${ }^{138}$ 
rate in the period around the onset peak in six countries appeared as relatively smooth slopes, the pattern in Wuhan had a drastic increase around 10 days after the disease onset peak. This unique pattern also differed from other regions and countries.

\section{Estimated peak day and cases in Wuhan}

According to the data from these countries, several circumstances could explain Wuhan's divergent results compared to other regions and countries. First, the time lag between peak days of cases and deaths was between 11 to 23 days with an average of 15.5 days. We speculate that the actual peak day of case fatality rate in Wuhan was around January 30, earlier than the reported February 13. The day of early disease onset may also be 30 days before its first reported case. ${ }^{140}$ Given that the ratio between reported deaths and cases ranged from $1 \%$ to $2 \%$, we speculate that the actual number of cases in Wuhan on the peak day was between 6,000 to 12,000 , while the reported average number of cases over a 7-day was 4,800 (Table 4-1).

\section{Potential data collection errors in Brazil}

The surprising finding is that the peak of deaths occurred earlier than the peak of cases in Brazil. The death peak day was June 2, 2020, while the case peak day occurred on June 26, 2020 (Figure 4-3B). If we assume that the reported deaths are more accurate than those of the cases and the disease pattern of the pandemic in Brazil is the same as other countries, there should be a peak day of cases observed around May 20, 2020. However, reporting bias in the counts of deaths, or the counts of both deaths and cases and improvement in clinical treatment may have led to these findings.

\section{Discussion}

Different countries may show different patterns of cases peak days, deaths peak days, and peak periods. The graphical trajectory analysis reveals significant underestimates in the early reporting of COVID-19 in Wuhan. Such an underestimation may be caused by incomplete data collection in the early stage of the disease, which generally is the case in the early stage of a novel disease. ${ }^{131}$ The data collection of COVID-19 outcomes in Wuhan are based on surveillance data with correction for reporting bias. Aggregating data from regional and national sources, we conclude that the official statistics in Wuhan are less than the actual transmission scale of the epidemic, and this finding can be generalized to some countries where the heavy burden of disease has lasted for several months. Implementing mandatory health policies that emphasize social distancing, pooled testing, and wearing masks offers a promise to fight against the pandemic until vaccinations and herd immunity become effective. ${ }^{93}$

The statistical confusion around the cases and deaths peak days in Brazil remains

a puzzle. In addition to a validation problem in data collection, there are multiple reasons 
for such a trajectory. First, an error in data collection and analysis, such as statistical analysis or technical errors, could lead to such a result. Second, if the clinical treatment was dramatically improved later, the deaths peak day could occur earlier. Third, if environmental conditions, such as temperature, lead to an early high death rate, and later the death rate decreases because of the high temperature, the deaths peak day may occur earlier than the cases peak day. ${ }^{141}$ Furthermore, because the pandemic in Brazil is still not under control, the overall pattern may change in the future.

The differences between surveillance statistics and our estimates may be due to various measurement and health policy limitations. The capacity of testing sites was a major obstacle for detecting cases in Wuhan at the early stage of the epidemic. Citizens with mild symptoms did not have access to testing and healthcare service. Most COVID19 testing was performed on hospitalized patients, and a few qualified laboratories serving a large population postponed reporting the results. Biases on the number of cases are most likely caused by the large number of asymptomatic and mild cases that did not report themselves or were not tested or diagnosed. Moreover, the overwhelmed healthcare system of Wuhan in the early stages of the outbreak could not provide sufficient services to the COVID-19 patients with mild symptoms. Last but not least, the false positive and false negative results of COVID-19 testing may have contributed to inaccurate data. ${ }^{142,143}$

The biases of underestimating the cases and deaths were not limited to Wuhan. Due to the incubation period, asymptomatic carriers, sensitivity and specificity of tests, and testing capacity, underestimating outcomes is common; however, their impact will vary across countries. Even given sufficient testing capacity, both the asymptomatic patients and false-negative results would underestimate the number of cases. ${ }^{144}$ Essentially, policymakers and healthcare professionals may encounter a substantial underestimate of the actual number of cases and thus misunderstand the development of the pandemic. We hope that this straightforward graphical trajectory approach can be used for similar conditions to eliminate bias.

In addition, these biases involve time-dependent reporting of cases and deaths and time lags in COVID-19 outcomes. In the situation of estimating COVID-19 time lag, we identify the biases and their possible relevance. Further, we provide a partially corrected estimation of these biased data from time lag and incomplete reporting of cases and deaths. This study shows that contact tracing of infected individuals despite the presence of symptoms will alleviate bias by controlling the correlation between diagnosis and deaths.

Researchers have established models to predict the progression of COVID-19, ${ }^{52}$ such as estimation of cases and deaths based on algorithms, ${ }^{132}$ deep learning models for predicting severe progression, ${ }^{145}$ and prospective validation studies of prognostic biomarkers to predict adverse outcomes. ${ }^{146}$ Our study is an evidence-based comparison and prediction, which is different from typical statistical models. 
In this article, we discuss the remaining situations that need to be considered. First, all data were derived from website data reported by each region or country. Variations in the measurement of cases and deaths in the early stage of the pandemic may exist, which is one reason there is no time lag in Wuhan. Second, countries with progressive COVID-19 require long-term attention as the existing data lead to a limited understanding of the situation. Third, studies have demonstrated that the durations from being infected with COVID-19 to death vary from 1 to 21 days, ${ }^{140,147}$ while the death peak appears about 13 days after infection. ${ }^{140}$ The causes of the same peaks of cases and deaths in Wuhan could be multifold, including the urgent shortage of medical facilities, which led to the immediate or excessive deaths, the reporting biases of cases and deaths, and the insufficient contact tracing of infected individuals. One of the errors in early Wuhan data was its high mortality rate which had been calculated as high as $20 \%$ at the early stage of the epidemic. ${ }^{132}$ If the death peak was earlier than that of the case peak, this is evidence that the data were not valid.

\section{Conclusion}

Our simulated graphical trajectory method identifies statistical biases in surveillance data. This approach incorporates all sources of available data and provides a robust method to characterize the time course of an infectious disease. Regions and countries beginning with high mortality rates from the COVID-19 epidemic will suffer a long, painful period of the disease epidemic. Where the mortality rate is relatively high, healthcare professionals should prepare for a longer period of fighting this pandemic. Data quality is key to case fatality rate estimation which is needed by policymakers to make correct and timely critical decisions. 


\section{CHAPTER 5. CONCLUSIONS}

\section{Summary of Findings}

This section summarized the main findings of our research. The primary research aim was to assess the relationship between democracy and case fatality rate of COVID19. The research aims to provide answers to this primary question by answering the following sub-questions.

Chapter 2 aimed to explore and evaluate the relevant evidence in democracy and health outcomes and better understand the associations between democracy and health outcomes of COVID-19. First, we searched PubMed and other two databases with keywords. The rapid systematic review showed that social-political factors, especially, democracy, exert an effect on life expectancy, maternal and infant mortality. Besides, the social-political factors also impact the transmission and health outcomes of infectious diseases, such as HIV/AIDS and SARS. Eventually, we synthesized the current literature about non-pharmaceutical interventions and found a set of predictors that may be associated with the severe consequences of the COVID-19 pandemic. Eventually, we focused on the predictors of health outcomes of COVID-19, meanwhile evaluated the strengths and weaknesses of the existing literature. The essential finding was a lack of multicountry studies that use comprehensive measurements of predictors to assess the relationship between democracy and health outcomes of COVID-19.

Chapter 3 intended to examine the relationships between a specific political predictor, that is, the Democracy Index, and the case fatality rate of COVID-19 across countries. In addition, it also examines the other factors, such as population density, comorbidity, and healthcare expenditures, which may be correlated with the case fatality rate of COVID-19. The exploratory data analysis reported the descriptive statistics of each predictor and outcome. Multiple linear regression was conducted on two levels. The first model included the whole dataset of 148 countries as full samples to assess the association between predictors and case fatality rates of COVID-19. As for the second level of subgroup analysis, the dataset was stratified by four income levels specified by the World Bank. Based on the preliminary data, hospital beds per 1,000 population negatively correlated to the case fatality rate of COVID-19. For this model, we conclude that a $1 \%$ increase in the hospital beds per 1,000 population would yield a $0.00282 \%$ decrease in the case fatality rate of COVID-19. Conversely, the percentage of the population older than 65 is positively associated with the case fatality rate. Also, the current health expenditure of GDP is positively related to the case fatality rate of COVID-19. Within 47 high-income countries, hospital beds per 1,000 population negatively correlated to the case fatality rate of COVID-19. For the second model, a $1 \%$ increase in the hospital beds per 1,000 population yielded a $0.00754 \%$ decrease in the case fatality rate of COVID-19. On the contrary, the percentage of the population older than 65 was also positively associated with the case fatality rate. Finally, the Democracy Index negatively correlated to the case fatality rate of COVID-19. However, the current health expenditure of GDP did not reach a significant level among high-income countries 
as shown in Model 2. The findings of high-income countries analysis demonstrated a negative association between democracy and health outcomes of COVID-19, which coincides with previous studies on the relationship between democracy, maternal and infant mortality rates, and HIV/AIDS prevalence. . $^{5,10}$

Chapter 4 investigated the information biases of cases and deaths of COVID-19 in terms of the data collection problem. Our contribution to the literature is to use a simulated graphical trajectory method to identify the biases in surveillance data. This approach incorporates all sources of available data with heterogeneity but provides a better summary of the development of an infectious disease. To sum up, regions and countries beginning with high mortality rates from the COVID-19 epidemic will suffer a long, painful period of the disease epidemic. Where the mortality rate is relatively high, healthcare professionals should prepare for a longer period of fighting this pandemic. Either ignorance or ineffective control measures may cause avoidable losses of lives. Most importantly, the quality of data is key to case fatality rate estimation. Valid data helps policymakers to make correct and timely critical decisions.

\section{Implications for Policy}

The previous literature we reviewed and the evidence we found across countries, can inform both policymakers and practitioners about effective and promising measures of containing emerging and re-emerging infectious diseases like COVID-19. From our research findings, several implications for policy concerning COVID-19 are evident:

\section{Orientation}

Improving health outcomes is the ultimate orientation of public health policy and should be a fundamental theme of policy. While the distribution of resources, welfare, human right, economy, and re-election among stakeholders are exclusively important, policymakers must keep in mind that the expected purpose of public health policy is for the well-being of individuals, communities, and populations. In essence, policies should be directed by principles that foster health.

\section{Partnership}

Policies at all levels must support partnerships within the network. Federal, state, and local health departments can empower individuals and the community through clear concepts, regulations, guidelines, and communication; support isolation and quarantine in the community; provide up-to-date information and essential resources; and disseminate effective practices at local, state and federal level. Building public health policies, establishing technological information networks, and encouraging innovation are some of the strategies that can facilitate the formation and collaboration of partnerships. 


\section{Flexibility}

Public health policies should be composed with an understanding of the contexts where they are to be executed to allow for flexibility at the local sites. While federal, state, and local policies must be written for a wide variety of contexts in which measures are implemented, policy directives should be flexible enough to accommodate diversity among the community, population, and countries. In other words, policies should not cause additional obstacles to efforts aimed toward mitigating the pandemic.

\section{Funding}

Increasing investment in health expenditure is helpful but not the key to improving health outcomes in the context of a pandemic. The health expenditure share of the GDP needs rational adjustment while the public health sector requires more financial support to activate. However, funding alone is not a powerful solution. A community should have strategic planning, professional engagement, outreach, commitment, and other non-financial resources, such as psychological resilience and self-efficacy, to be successful in fighting against the pandemic. ${ }^{148} \mathrm{~A}$ key role for policy is the provision of both financial and non-financial resources.

\section{Implications for Practice}

Our research findings have important implications for healthcare professionals and policymakers endeavoring to contain the COVID-19 pandemic and improve the health outcomes of the population. From this research and previous literature, we drew the following implications for practice.

We offer recommendations for practitioners in the following section as to how a democratic country as a whole might improve its responses to the health crisis. The first issue that needs to be reconsidered is the efficiency of the government response. Our findings show that the population density is not statistically related to the case fatality rate of COVID-19 in 148 countries. Therefore, governments in democratic countries must engage in legitimation and cannot rely on self-isolation as in authoritarian countries where citizens would follow the restrictive measures. This established constriction of democracies has triggered many challenges and disadvantages in speedily responding to an emergency. However, this disadvantage should not be treated as a good reason for slow action because, in response to a pandemic, democratic governments should have the capacity to announce a state of emergency and even require public and private resources to respond quickly. When a democratic country takes over civil rights and private resources and restricts citizens' mobility, the government should have a rational justification for the society, and it should also compensate attacked populations during or after the pandemic. Nevertheless, it is more difficult for the government to convince citizens to take action quickly during the outbreak of a communicable disease because it is often difficult to foresee the severe consequences of an epidemic. Despite statistics 
with biases, narrow-mindedness and personal interests, the slow and incorrect decisions of governments, will bring catastrophe to the whole country. The slow response of governments in Italy, India, and the United States to the pandemic has already had tremendous costs for their countries and the world. ${ }^{149,150}$

Second, this worldwide health crisis suggests the vulnerability of society in countries. We should reconsider how to protect our lives from dictatorships while achieving the goal of pandemic mitigation. In essence, democratic countries have learned a good lesson from COVID-19. The aging population and citizens with comorbidities are high-risk populations who should have the privilege of receiving healthcare services and necessary support, such as transportation, shelters, safe food supply, PPE, and social workers' assistance. We advocate for the detection of early symptoms in patients with multiple chronic diseases, health information technology for remote monitoring of quarantined or isolated patients, standardized measures in nursing homes, psychological and emotional supports for severely ill patients, and protection for a normal lifestyle and living environment of elderly patients.

Thirdly, being different from the previous international health in history, humankind faces more challenges than before: First, citizens are uncertain of the transmission of the pandemic. In democratic countries, governments are divided by partisan supporters in responding to the disease. This upsurges the trouble of executing any national public health policies. Secondly, the pandemic is also an economic crisis. Unlike before, this crisis is synchronized in both supply and demand markets. These characteristics interfere with the accountability of existing policy funding instruments and will also expand the longstanding adverse effects of the policies. Finally, the pandemic is also a showdown of the two fundamentally different political and economic systems. Ultimately, the triple crises lead to the most challenging crisis of all: The lack of world leadership among the democracies to formulate and execute concerted efforts to deal with the crises unseen. ${ }^{151}$

\section{Implications for Future Research}

The associations we investigate here are quickly evolving and it is reasonable to assume variations to these patterns in the future. For authoritarian countries, the economic recession may enhance broader business lockdowns and social distancing policies, and the healthcare capacity needed for massive testing and contact tracing may not be taken. Immediate responses by countries in such contexts, such as shutting down international airports and facilitating mobile testing sites in trucks, seem to have been useful in slowing the transmission of COVID-19, but even comparatively inexpensive measures may not be accessible for mitigating COVID-19 if the disease remains dominant. In this way, we may observe that government function, political accountability, and social interconnection in later phases of a pandemic would make differences from those of earlier phases. To examine these longer-term associations, we recommend iterating the analyses offered here, using the same variables. We suggest the primary outcomes for future work will be deaths per capita due to COVID-19 and excess deaths. 
The data on excess deaths relies to some degree on Electronic Medical Record (EMR) or Electronic Health Records (EHR) and statistics, which will vary in quality across countries with superior surveillance systems in high-income countries and inferior reporting systems in low-income countries. ${ }^{152}$ Although the Democracy Indices positively associated with case fatality rates of COVID-19 in high-income counties, the health inequity and underserved population in low-income countries need more investigations to explore the predictors of health outcomes related to epidemics and pandemics.

We look forward to future research that will implement apples-to-apples comparison. That is, simply conducting studies of $\mathrm{X}$ disease or $\mathrm{Y}$ risk factors in various countries instead of using a truly international comparative approach is problematic. Very limited research has taken place in the context of global health crises that could overcome these barriers. Current research has some limitations and difficulties, e.g., the sensitivity of the results to time and outcomes. Besides, statistical analysis results depended on the measurement of association proposed in the comparative studies.

Future work should innovate in measuring predictors and outcomes in poor resource settings because existing datasets have relied on biased death certificates and health survey data collected during the pandemic. ${ }^{153,154}$ In some cases, the statistical analysis will be limited to assessing conditional correlations and testing whether these differ from zero. We encourage researchers to conduct further analysis by integrating a broader knowledge base within this field. For example, researchers can design investigation instruments such as questionnaires and surveys that will be distributed to regions or countries where they will be able to describe and report the data and suggest supplementary tests. 


\section{LIST OF REFERENCES}

1. U.S. Department of Health and Human Services. Determinants of Health. https://www.healthypeople.gov/2020/about/foundation-healthmeasures/Determinants-of-Health. Accessed September 3, 2020.

2. Beckfield J, Krieger N. Epi + demos + cracy: Linking Political Systems and Priorities to the Magnitude of Health Inequities-Evidence, Gaps, and a Research Agenda. Epidemiol Rev. 2009;31(1):152-177.

3. Navarro V, Shi L. The political context of social inequalities and health. Int $J$ Health Serv. 2001;31(1):1-21.

4. Navarro V, Muntaner $\mathrm{C}$, Borrell $\mathrm{C}$, et al. Politics and health outcomes. The Lancet. 2006;368(9540):1033-1037.

5. Franco Á, Álvarez-Dardet C, Ruiz MT. Effect of democracy on health: ecological study. BMJ. 2004;329(7480):1421-1423.

6. Besley T, Kudamatsu M. Health and democracy. Am Econ Rev. 2006;96(2):313318.

7. Bollyky TJ, Templin T, Cohen M, Schoder D, Dieleman JL, Wigley S. The relationships between democratic experience, adult health, and cause-specific mortality in 170 countries between 1980 and 2016: an observational analysis. The Lancet. 2019;393(10181):1628-1640.

8. Lake DA, Baum MA. The Invisible Hand of Democracy: Political Control and the Provision of Public Services. Comparative Political Studies. 2001;34(6):587-621.

9. Rezwanul Hasan R, Khorshed A, Jeff G. Development of a richer measure of health outcomes incorporating the impacts of income inequality, ethnic diversity, and ICT development on health. Globalization and Health. 2018;14(1):1-12.

10. Gizelis T-I. Wealth alone does not buy health: Political capacity, democracy, and the spread of AIDS. Political Geography. 2009;28(2):121-131.

11. Fidler DP. Germs, governance, and global public health in the wake of SARS. The Journal of Clinical Investigation. 2004;113(6):799-804.

12. Badr HS, Du H, Marshall M, Dong E, Squire MM, Gardner LM. Association between mobility patterns and COVID-19 transmission in the USA: a mathematical modelling study. Lancet Infect Dis. 2020.

13. Burkle FM, Devereaux AV. 50 States or 50 Countries: What Did We Miss and What Do We Do Now? Prehosp Disaster Med. 2020:1-5.

14. Edelman EJ, Aoun-Barakat L, Villanueva M, Friedland G. Confronting Another Pandemic: Lessons from HIV can Inform Our COVID-19 Response. AIDS Behav. 2020;24(7):1977-1979.

15. Frey CB, Chen C, Presidente G. Democracy, Culture, and Contagion: Political Regimes and Countries Responsiveness to Covid-19. Covid Economics. 2020;18:1-20.

16. Greer SL, King EJ, da Fonseca EM, Peralta-Santos A. The comparative politics of COVID-19: The need to understand government responses. Glob Public Health. 2020:1-4. 
17. Kavanagh MM, Erondu NA, Tomori O, et al. Access to lifesaving medical resources for African countries: COVID-19 testing and response, ethics, and politics. The Lancet. 2020;395(10238):1735-1738.

18. Kavanagh MM, Singh R. Democracy, Capacity, and Coercion in Pandemic Response-COVID 19 in Comparative Political Perspective. J Health Polit Policy Law. 2020.

19. World Health Organization. Coronavirus disease (COVID-19). https://www.who.int/emergencies/diseases/novel-coronavirus-2019. Published 2020. Accessed July 23, 2021.

20. World Health Organization. WHO Director-General's opening remarks at the media briefing on COVID-19 - 11 March 2020. https://www.who.int/directorgeneral/speeches/detail/who-director-general-s-opening-remarks-at-the-mediabriefing-on-covid-19---11-march-2020. Published 2020. Accessed September 13, 2021.

21. Johns Hopkins Coronavirus Resource Center. COVID-19 Dashboard by the Center for Systems Science and Engineering (CSSE) at Johns Hopkins University. https://coronavirus.jhu.edu/map.html. Published 2021. Accessed July 20, 2021.

22. COVID-19 Dashboard by the Center for Systems Science and Engineering (CSSE) at Johns Hopkins University (JHU). https://coronavirus.jhu.edu/map.html. Accessed June 19, 2020.

23. Pareek M, Bangash MN, Pareek N, et al. Ethnicity and COVID-19: an urgent public health research priority. The Lancet. 2020;395(10234):1421-1422.

24. Pan A, Liu L, Wang C, et al. Association of public health interventions with the epidemiology of the COVID-19 outbreak in Wuhan, China. JAMA.

2020;323(19):1915-1923.

25. Driggin E, Madhavan MV, Bikdeli B, et al. Cardiovascular considerations for patients, health care workers, and health systems during the COVID-19 pandemic. J Am Coll Cardiol. 2020;75(18):2352-2371.

26. Robson C. Real world research: A resource for social scientists and practitionerresearchers. Wiley-Blackwell; 2002.

27. Miller K. Communication theories. USA: Macgraw-Hill. 2005.

28. Lindlof TR, Taylor BC. Qualitative communication research methods. Sage publications; 2017.

29. Brownlea A. From public health to political epidemiology. Soc Sci Med D. 1981;15(1):57-67.

30. Honjo K. Social epidemiology: Definition, history, and research examples. Environ Health Prev Med. 2004;9(5):193-199.

31. Krieger N. A glossary for social epidemiology. J Epidemiol Community Health. 2001;55(10):693-700.

32. Kazak AE. Families of chronically ill children: a systems and social-ecological model of adaptation and challenge. J Consult Clin Psychol. 1989;57(1):25.

33. Howe D. A brief introduction to social work theory. 2009.

34. Centers for Disease Control and Prevention. Health equity resource toolkit for state practitioners addressing obesity disparities 
https://www.cdc.gov/nccdphp/dnpao/state-local-programs/healthequity/pdf/toolkit.pdf. Published 2017. Accessed August 31, 2020.

35. Ellen ME, Horowitz E, Vaknin S, Lavis JN. Views of health system policymakers on the role of research in health policymaking in Israel. Israel journal of health policy research. 2016;5:24-24.

36. Marsh DS, Daniel MH. Leadership for policy change strengthening communities of color through leadership development. https://hewlett.org/wpcontent/uploads/2016/08/Leadership_for_Policy_Change.pdf. Accessed September 2, 2020.

37. Rubin GD, Ryerson CJ, Haramati LB, et al. The Role of Chest Imaging in Patient Management During the COVID-19 Pandemic: A Multinational Consensus Statement From the Fleischner Society. Chest. 2020;158(1):106-116.

38. Gundlapalli AV, Lavery AM, Boehmer TK, et al. Death Certificate-Based ICD10 Diagnosis Codes for COVID-19 Mortality Surveillance-United States, January-December 2020. Morb Mortal Weekly Rep. 2021;70(14):523.

39. Celentano DD, Szklo M, Gordis L. Gordis epidemiology. 6th ed: Philadelphia, PA : Elsevier; 2019.

40. Center for Disease Control and Prevention. Disease or Condition of the Week. https://www.cdc.gov/dotw/covid-19/index.html. Published 2021. Accessed September 14, 2021.

41. Schmitter PC, Karl TL. What democracy is... and is not. Journal of democracy. 1991;2(3):75-88.

42. Economist Intelligence Unit. Democracy Index 2019. A year of democratic setbacks and popular protest. 2020.

43. World Health Organization. Constitution of the world health organization-basic documents. https://www.who.int/governance/eb/who_constitution_en.pdf. Published 2006. Accessed September 6, 2020.

44. Adiguzel Z. Evaluating the Impact of Strategic Management and Strategic Thinking on Performance in the Public Health Sector. In: Multidimensional Perspectives and Global Analysis of Universal Health Coverage. IGI Global; 2020:231-265.

45. Hill M. McGraw Hill Concise Medical Dictionary of Modern Medicine. In: McGraw Hill Companies; 2002.

46. World Health Organization. Health policy https://www.who.int/topics/health_policy/en/\#: :text=Health\%20policy\%20Healt h\%20policy\%20refers\%20to\%20decisions \%2C\%20plans\%2C,of\%20reference\% 20for\%20the\%20short\%20and\%20medium\%20term. Accessed September 7, 2020.

47. Kindig D, Stoddart G. What is population health? Am J Public Health. 2003;93(3):380-383.

48. Center for Disease Control and Prevention. Social determinants of health: Know what affects health. https://www.cdc.gov/socialdeterminants/index.htm. Accessed September 6, 2020.

49. Gallo Marin B, Aghagoli G, Lavine K, et al. Predictors of COVID-19 severity: A literature review. Rev Med Virol. 2021;31(1):1-10. 
50. Kupferschmidt K, Wadman M. Delta variant triggers new phase in the pandemic. In: American Association for the Advancement of Science; 2021.

51. Park M, Cook AR, Lim JT, Sun Y, Dickens BL. A systematic review of COVID19 epidemiology based on current evidence. Journal of clinical medicine. 2020;9(4):967.

52. Wynants L, Van Calster B, Collins GS, et al. Prediction models for diagnosis and prognosis of covid-19: systematic review and critical appraisal. BMJ. 2020;369.

53. Ludvigsson JF. Systematic review of COVID-19 in children shows milder cases and a better prognosis than adults. Acta Paediatr. 2020;109(6):1088-1095.

54. Tricco AC, Langlois E, Straus SE, Organization WH. Rapid reviews to strengthen health policy and systems: a practical guide. World Health Organization; 2017.

55. Moher D, Liberati A, Tetzlaff J, Altman DG, Group P. Preferred reporting items for systematic reviews and meta-analyses: the PRISMA statement. PLoS Med. 2009;6(7):e1000097.

56. Munn Z, Moola S, Lisy K, Riitano D, Tufanaru C. Methodological guidance for systematic reviews of observational epidemiological studies reporting prevalence and cumulative incidence data. International journal of evidence-based healthcare. 2015;13(3):147-153.

57. Huang J, Teoh JY-C, Wong SH, Wong MC. The potential impact of previous exposure to SARS or MERS on control of the COVID-19 pandemic. Eur J Epidemiol. 2020;35(11):1099-1103.

58. Jardine R, Wright J, Samad Z, Bhutta ZA. Analysis of COVID-19 burden, epidemiology and mitigation strategies in Muslim majority countries. Eastern Mediterranean health journal $=$ La revue de sante de la Mediterranee orientale $=$ al-Majallah al-sihhiyah li-sharq al-mutawassit. 2020;26(10):1173-1183.

59. Sebhatu A, Wennberg K, Arora-Jonsson S, Lindberg SI. Explaining the homogeneous diffusion of COVID-19 nonpharmaceutical interventions across heterogeneous countries. Proc Natl Acad Sci U S A. 2020;117(35):21201-21208.

60. Naeim A, Baxter-King R, Wenger N, Stanton AL, Sepucha K, Vavreck L. Effects of Age, Gender, Health Status, and Political Party on COVID-19-Related Concerns and Prevention Behaviors: Results of a Large, Longitudinal Crosssectional Survey. JMIR public health and surveillance. 2021;7(4):e24277.

61. Pak A, McBryde E, Adegboye OA. Does high public trust amplify compliance with stringent COVID-19 government health guidelines? A multi-country analysis using data from 102,627 individuals. Risk Manage Healthc Policy. 2021;14:293302.

62. Rocco P, Rich JAJ, Klasa K, Dubin KA, Béland D. Who Counts Where? COVID19 Surveillance in Federal Countries. J Health Polit Policy Law. 2021.

63. Annaka S. Political regime, data transparency, and COVID-19 death cases. SSM population health. 2021;15(101678841):100832.

64. Jinjarak Y, Ahmed R, Nair-Desai S, Xin W, Aizenman J. Accounting for Global COVID-19 Diffusion Patterns, January-April 2020. Economics of disasters and climate change. 2020(101729939):1-45.

65. Mazzucchelli R, Agudo Dieguez A, Dieguez Costa EM, Crespi Villarias N. [Democracy and Covid-19 mortality in Europe.]. Democracia y mortalidad por Covid-19 en Europa. 2020;94. 
66. Karabulut G, Zimmermann KF, Bilgin MH, Doker AC. Democracy and COVID19 outcomes. Econ Letters. 2021;203(101084492):109840.

67. Sorci G, Faivre B, Morand S. Explaining among-country variation in COVID-19 case fatality rate. Sci Rep. 2020;10(1):18909.

68. Badman RP, Wu Y, Inukai K, Akaishi R. Blessing or Curse of Democracy?: Current Evidence from the Covid-19 Pandemic. arXiv preprint arXiv:210510865. 2021.

69. Yechezkel M, Weiss A, Rejwan I, Shahmoon E, Ben-Gal S, Yamin D. Human mobility and poverty as key drivers of COVID-19 transmission and control. BMC Public Health. 2021;21(1):1-13.

70. Gargoum SA, Gargoum AS. Limiting mobility during COVID-19, when and to what level? An international comparative study using change point analysis. Journal of Transport \& Health. 2021;20:101019.

71. Chang D, Chang XS, He Y, Tan KJK. The Determinants of COVID-19 Morbidity and Mortality across Countries. Nanyang Business School Research Paper No Forthcoming. 2021.

72. Beldomenico PM. Do superspreaders generate new superspreaders? A hypothesis to explain the propagation pattern of COVID-19. Int J Infect Dis. 2020;96:461463.

73. Xiong C, Hu S, Yang M, Luo W, Zhang L. Mobile device data reveal the dynamics in a positive relationship between human mobility and COVID-19 infections. Proceedings of the National Academy of Sciences. 2020;117(44):27087-27089.

74. Shaw R, Kim Y-k, Hua J. Governance, technology and citizen behavior in pandemic: Lessons from COVID-19 in East Asia. Progress in disaster science. 2020;6:100090.

75. Haug N, Geyrhofer L, Londei A, et al. Ranking the effectiveness of worldwide COVID-19 government interventions. Nature human behaviour. 2020;4(12):1303-1312.

76. Harper CA, Satchell LP, Fido D, Latzman RD. Functional fear predicts public health compliance in the COVID-19 pandemic. International journal of mental health and addiction. 2020:1-14.

77. Peterson S. Epidemic disease and national security. Security Studies. 2002;12(2):43-81.

78. Weiss RA, McMichael AJ. Social and environmental risk factors in the emergence of infectious diseases. Nat Med. 2004;10(12):S70-S76.

79. Van Bavel JJ, Baicker K, Boggio PS, et al. Using social and behavioural science to support COVID-19 pandemic response. Nature human behaviour. 2020;4(5):460-471.

80. Amat F, Arenas A, Falcó-Gimeno A, Muñoz J. Pandemics meet democracy. Experimental evidence from the COVID-19 crisis in Spain. 2020.

81. Perrotta D, Grow A, Rampazzo F, et al. Behaviours and attitudes in response to the COVID-19 pandemic: insights from a cross-national Facebook survey. EPJ data science. 2021;10(1):1-13.

82. Sallam M. COVID-19 vaccine hesitancy worldwide: a concise systematic review of vaccine acceptance rates. Vaccines. 2021;9(2):160. 
83. Lazarus JV, Ratzan SC, Palayew A, et al. A global survey of potential acceptance of a COVID-19 vaccine. Nat Med. 2021;27(2):225-228.

84. Milligan MA, Hoyt DL, Gold AK, Hiserodt M, Otto MW. COVID-19 vaccine acceptance: influential roles of political party and religiosity. Psychol Health Med. 2021:1-11.

85. Regmi K, Lwin CM. Factors Associated with the Implementation of NonPharmaceutical Interventions for Reducing Coronavirus Disease 2019 (COVID19): A Systematic Review. Int J Environ Res Public Health. 2021;18(8):4274.

86. Huynh TLD. Does culture matter social distancing under the COVID-19 pandemic? Saf Sci. 2020;130:104872.

87. Nkengasong JN, Ndembi N, Tshangela A, Raji T. COVID-19 vaccines: how to ensure Africa has access. In: Nature Publishing Group; 2020.

88. Greer SL, King EJ, da Fonseca EM, Peralta-Santos A. The comparative politics of COVID-19: The need to understand government responses. Global public health. 2020;15(9):1413-1416.

89. Safaei J. Is Democracy Good for Health? Int J Health Serv. 2006;36(4):767-786.

90. Mackenbach JP, Hu Y, Looman CWN. Democratization and life expectancy in Europe, 1960-2008. Soc Sci Med. 2013;93:166-175.

91. Shandra JM, Shandra CL, London B. Debt, structural adjustment, and nongovernmental organizations: a cross-national analysis of maternal mortality. Journal of World-Systems Research. 2010:217-245.

92. Blum J, Dorn F, Heuer A. Political institutions and health expenditure. Int Tax Public Finance. 2021;28(2):323-363.

93. Gu T, Yao L, Meng X, et al. A cost-effective plan for global testing-an infection rate stratified, algorithmic guided, multiple-level, continuously pooled testing strategy. Sci Total Environ. 2020:144251.

94. Karabulut G, Zimmermann KF, Bilgin MH, Doker AC. Democracy and COVID19 outcomes. Econ Letters. 2021;203:109840.

95. Mazzucchelli R, Agudo Dieguez A, Dieguez Costa EM, Crespí Villarías N. [Democracy and Covid-19 mortality in Europe.]. Rev Esp Salud Publica. 2020;94.

96. Grossman G, Kim S, Rexer JM, Thirumurthy H. Political partisanship influences behavioral responses to governors' recommendations for COVID-19 prevention in the United States. Proceedings of the National Academy of Sciences. 2020;117(39):24144-24153.

97. Kraemer MU, Yang C-H, Gutierrez B, et al. The effect of human mobility and control measures on the COVID-19 epidemic in China. Science. 2020;368(6490):493-497.

98. Yan B, Zhang X, Wu L, Zhu H, Chen B. Why do countries respond differently to COVID-19? A comparative study of Sweden, China, France, and Japan. The American Review of Public Administration. 2020;50(6-7):762-769.

99. Yao L, Li M, Wan JY, Howard SC, Bailey JE, Graff JC. Democracy and case fatality rate of COVID-19 at early stage of pandemic: a multicountry study. Environmental Science and Pollution Research. 2021:7:1-11.

100. World Health Organization. WHO Coronavirus Disease (COVID-19) Dashboard. https://covid19.who.int/. Accessed October 25, 2020. 
101. Johns Hopkins Coronavirus Resource Center. COVID-19 Dashboard by the Center for Systems Science and Engineering (CSSE) at Johns Hopkins University. https://coronavirus.jhu.edu/map.html. Published 2020. Accessed October 25, 2020.

102. Kelly H, Cowling BJ. Case Fatality: Rate, Ratio, or Risk? Epidemiology. 2013;24(4).

103. Espen Beer Prydz DW. Classifying countries by income. https://datatopics.worldbank.org/world-development-indicators/stories/theclassification-of-countries-by-income.html. Published 2019. Accessed June 19, , 2021.

104. Unit. EI. Democracy Index 2019. A year of democratic setbacks and popular protest. https://www.eiu.com/n/campaigns/democracy-index-2019/. Published 2020. Accessed October 19, 2020.

105. Sanyaolu A, Okorie C, Marinkovic A, et al. Comorbidity and its Impact on Patients with COVID-19. SN comprehensive clinical medicine. 2020:1-8.

106. Albitar O, Ballouze R, Ooi JP, Ghadzi SMS. Risk factors for mortality among COVID-19 patients. Diabetes Res Clin Pract. 2020;166:108293.

107. Kluge HHP, Wickramasinghe K, Rippin HL, et al. Prevention and control of noncommunicable diseases in the COVID-19 response. The Lancet. 2020;395(10238):1678-1680.

108. Adams JG, Walls RM. Supporting the health care workforce during the COVID19 global epidemic. JAMA. 2020;323(15):1439-1440.

109. Coşkun H, Yıldırım N, Gündüz S. The spread of COVID-19 virus through population density and wind in Turkey cities. Sci Total Environ. 2021;751:141663.

110. Sen-Crowe B, Sutherland M, McKenney M, Elkbuli A. A closer look into global hospital beds capacity and resource shortages during the COVID-19 pandemic. $J$ Surg Res. 2021;260:56-63.

111. Alhassan GN, Adedoyin FF, Bekun FV, Agabo TJ. Does life expectancy, death rate and public health expenditure matter in sustaining economic growth under COVID-19: Empirical evidence from Nigeria? Journal of Public Affairs. 2020:e2302.

112. Ho FK, Petermann-Rocha F, Gray SR, et al. Is older age associated with COVID19 mortality in the absence of other risk factors? General population cohort study of 470,034 participants. PLoS One. 2020;15(11):e0241824.

113. Bank W. World Bank Open Data. https://data.worldbank.org/. Published 2020. Accessed October 20, 2020.

114. Organization WH. The Global Health Observatory https://www.who.int/data/gho. Published 2020. Accessed October 21, 2020.

115. Kelly H, Cowling BJ. Case fatality: rate, ratio, or risk? Epidemiology. 2013;24(4):622-623.

116. Rashed EA, Kodera S, Gomez-Tames J, Hirata A. Influence of absolute humidity, temperature and population density on COVID-19 spread and decay durations: Multi-prefecture study in Japan. Int J Environ Res Public Health. 2020;17(15):5354. 
117. Tian H, Liu Y, Li Y, et al. An investigation of transmission control measures during the first 50 days of the COVID-19 epidemic in China. Science. 2020;368(6491):638-642.

118. Douglas M, Katikireddi SV, Taulbut M, McKee M, McCartney G. Mitigating the wider health effects of covid-19 pandemic response. BMJ. 2020;369.

119. Parodi SM, Liu VX. From containment to mitigation of COVID-19 in the US. JAMA. 2020;323(15):1441-1442.

120. Lapolla P, Mingoli A, Lee R. Deaths from COVID-19 in healthcare workers in Italy_-What can we learn? Infect Control Hosp Epidemiol. 2021;42(3):364-365.

121. Bartsch SM, Ferguson MC, McKinnell JA, et al. The Potential Health Care Costs And Resource Use Associated With COVID-19 In The United States: A simulation estimate of the direct medical costs and health care resource use associated with COVID-19 infections in the United States. Health Aff (Millwood). 2020;39(6):927-935.

122. Dowd JB, Andriano L, Brazel DM, et al. Demographic science aids in understanding the spread and fatality rates of COVID-19. Proceedings of the National Academy of Sciences. 2020;117(18):9696-9698.

123. Guan W-j, Liang W-h, Zhao Y, et al. Comorbidity and its impact on 1590 patients with COVID-19 in China: a nationwide analysis. Eur Respir J. 2020;55(5).

124. Bajgain KT, Badal S, Bajgain BB, Santana MJ. Prevalence of comorbidities among individuals with COVID-19: A rapid review of current literature. Am J Infect Control. 2021;49(2):238-246.

125. Novelli L, Raimondi F, Ghirardi A, et al. At the peak of Covid-19 age and disease severity but not comorbidities are predictors of mortality. Covid-19 burden in Bergamo, Italy. Panminerva Med. 2020.

126. Coccia M. High health expenditures and low exposure of population to air pollution as critical factors that can reduce fatality rate in COVID-19 pandemic crisis. Environ Res. 2021:111339.

127. Jakovljevic M, Getzen TE. Growth of global health spending share in low and middle income countries. Front Pharmacol. 2016;7:21.

128. Beaglehole R, Ebrahim S, Reddy S, Voûte J, Leeder S. Prevention of chronic diseases: a call to action. The Lancet. 2007;370(9605):2152-2157.

129. Engler S, Brunner P, Loviat R, et al. Democracy in times of the pandemic: explaining the variation of COVID-19 policies across European democracies. West European Politics. 2021:1-22.

130. Cheibub JA, Hong JYJ, Przeworski A. Rights and deaths: Government reactions to the pandemic. Available at SSRN 3645410. 2020.

131. Chen SX, Lam BC, Liu JH, Choi HS, Kashima E, Bernardo AB. Effects of containment and closure policies on controlling the COVID-19 pandemic in East Asia. Asian J Social Psych. 2021.

132. Wang L, Li J, Guo S, et al. Real-time estimation and prediction of mortality caused by COVID-19 with patient information based algorithm. Sci Total Environ. 2020;727:138394.

133. López L, Rodo X. A modified SEIR model to predict the COVID-19 outbreak in Spain and Italy: simulating control scenarios and multi-scale epidemics. Results in Physics. 2021;21:103746. 
134. Yin H, Sun T, Yao L, et al. Association between population density and infection rate suggests the importance of social distancing and travel restriction in reducing the COVID-19 pandemic. Environmental Science and Pollution Research. 2021:1-7.

135. Barry M, Althabit N, Akkielah L, et al. Clinical Characteristics and Outcomes of Hospitalized COVID-19 Patients in a MERS-CoV Referral Hospital during the Peak of the Pandemic. Int J Infect Dis. 2021.

136. Yao L, Dong W, Wan JY, Howard SC, Li M, Graff JC. Graphical Trajectory Comparison to Identify Errors in Data of COVID-19: A Cross-Country Analysis. Journal of Personalized Medicine. 2021;11(10):955.

137. Province HCoH. COVID-19 Database. http://wjw.hubei.gov.cn/fbjd/dtyw. Published 2020. Accessed June 30, 2020.

138. Worldometers. Coronavirus. https://www.worldometers.info/coronavirus/. Published 2020. Accessed June 30, 2020.

139. Lishi W, Jing L, Sumin G, Ning X, Lan Y, Yanhong C. Day Sara W., Howard Scott C., Carolyn Graff J., Gu Tianshu, Ji Jiafu, Gu Weikuan, Sun Dianjun. Realtime Estimation and Prediction of Mortality Caused by COVID-19 with Patient Information Based Algorithm. Sci Total Environ. 2020.

140. Wang C, Horby PW, Hayden FG, Gao GF. A novel coronavirus outbreak of global health concern. The lancet. 2020;395(10223):470-473.

141. Pawar S, Stanam A, Chaudhari M, Rayudu D. Effects of temperature on COVID19 transmission. Medrxiv. 2020.

142. Surkova E, Nikolayevskyy V, Drobniewski F. False-positive COVID-19 results: hidden problems and costs. The Lancet Respiratory Medicine. 2020;8(12):11671168.

143. West CP, Montori VM, Sampathkumar P. COVID-19 testing: the threat of falsenegative results. Paper presented at: Mayo Clinic Proceedings2020.

144. Carvajal G, Roser DJ, Sisson SA, Keegan A, Khan SJ. Modelling pathogen log 10 reduction values achieved by activated sludge treatment using naïve and semi naïve Bayes network models. Water Res. 2015;85:304-315.

145. Ho TT, Park J, Kim T, et al. Deep Learning Models for Predicting Severe Progression in COVID-19-Infected Patients: Retrospective Study. JMIR Medical Informatics. 2021;9(1):e24973.

146. Tang B, Shojaei M, Wang Y, et al. Prospective validation study of prognostic biomarkers to predict adverse outcomes in patients with COVID-19: a study protocol. BMJ open. 2021;11(1):e044497.

147. Huang C, Wang Y, Li X, et al. Clinical features of patients infected with 2019 novel coronavirus in Wuhan, China. The lancet. 2020;395(10223):497-506.

148. Johnston DW, Kung C, Shields M. Who is resilient in a time of crisis? The importance of financial and non-financial resources. IZA Discussion Paper No 13720. 2020.

149. Ren X. Pandemic and lockdown: a territorial approach to COVID-19 in China, Italy and the United States. Eurasian Geogr Econ. 2020;61(4-5):423-434.

150. Meghana A, Aparna Y, Chandra SM, Sanjeev S. Emergency preparedness and response (EP\&R) by pharmacy professionals in India: Lessons from the COVID- 
19 pandemic and the way forward. Research in Social and Administrative Pharmacy. 2021;17(1):2018-2022.

151. Alon I, Farrell M, Li S. Regime type and COVID-19 response. FIIB Business Review. 2020;9(3):152-160.

152. Mikkelsen L, Phillips DE, AbouZahr C, et al. A global assessment of civil registration and vital statistics systems: monitoring data quality and progress. The Lancet. 2015;386(10001):1395-1406.

153. Gill JR, DeJoseph ME. The importance of proper death certification during the COVID-19 pandemic. JAMA. 2020;324(1):27-28.

154. Weinberger DM, Chen J, Cohen T, et al. Estimation of excess deaths associated with the COVID-19 pandemic in the United States, March to May 2020. JAMA Internal Medicine. 2020;180(10):1336-1344.

155. Page MJ, McKenzie JE, Bossuyt PM, et al. The PRISMA 2020 statement: an updated guideline for reporting systematic reviews. BMJ. 2021;372:n71.

156. Porritt K, Gomersall J, Lockwood C. JBI's systematic reviews: study selection and critical appraisal. AJN The American Journal of Nursing. 2014;114(6):47-52. 
APPENDIX A. PRISMA 2020 CHECKLIST

PRISm 2020 Checklist

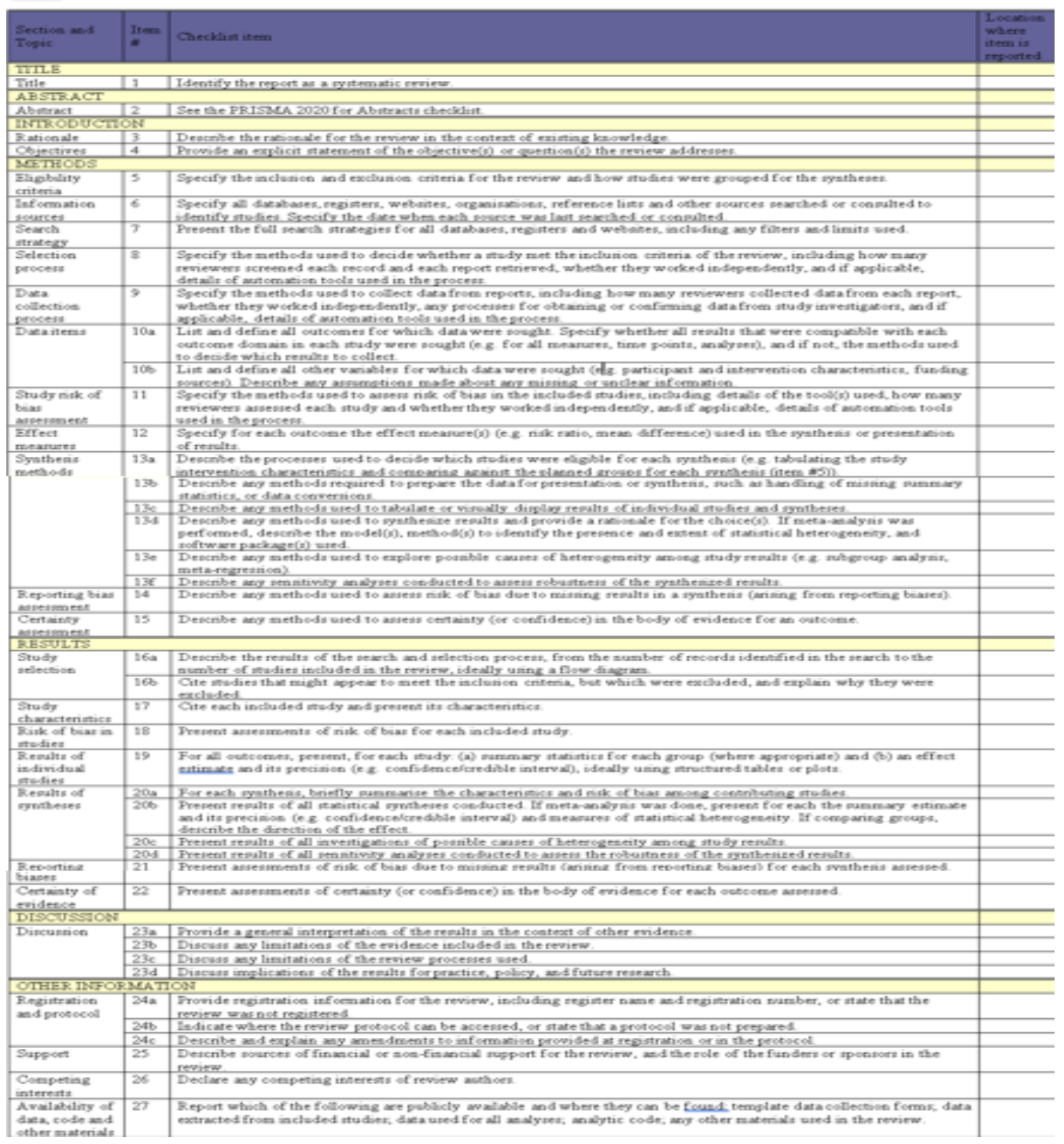

Reprinted with open access permission. Page MJ, McKenzie JE, Bossuyt PM, et al. The PRISMA 2020 statement: an updated guideline for reporting systematic reviews. BMJ. 2021;372:n71. ${ }^{155}$ 


\section{APPENDIX B. JBI CRITICAL APPRAISAL CHECKLIST FOR STUDIES REPORTING PREVALENCE DATA}

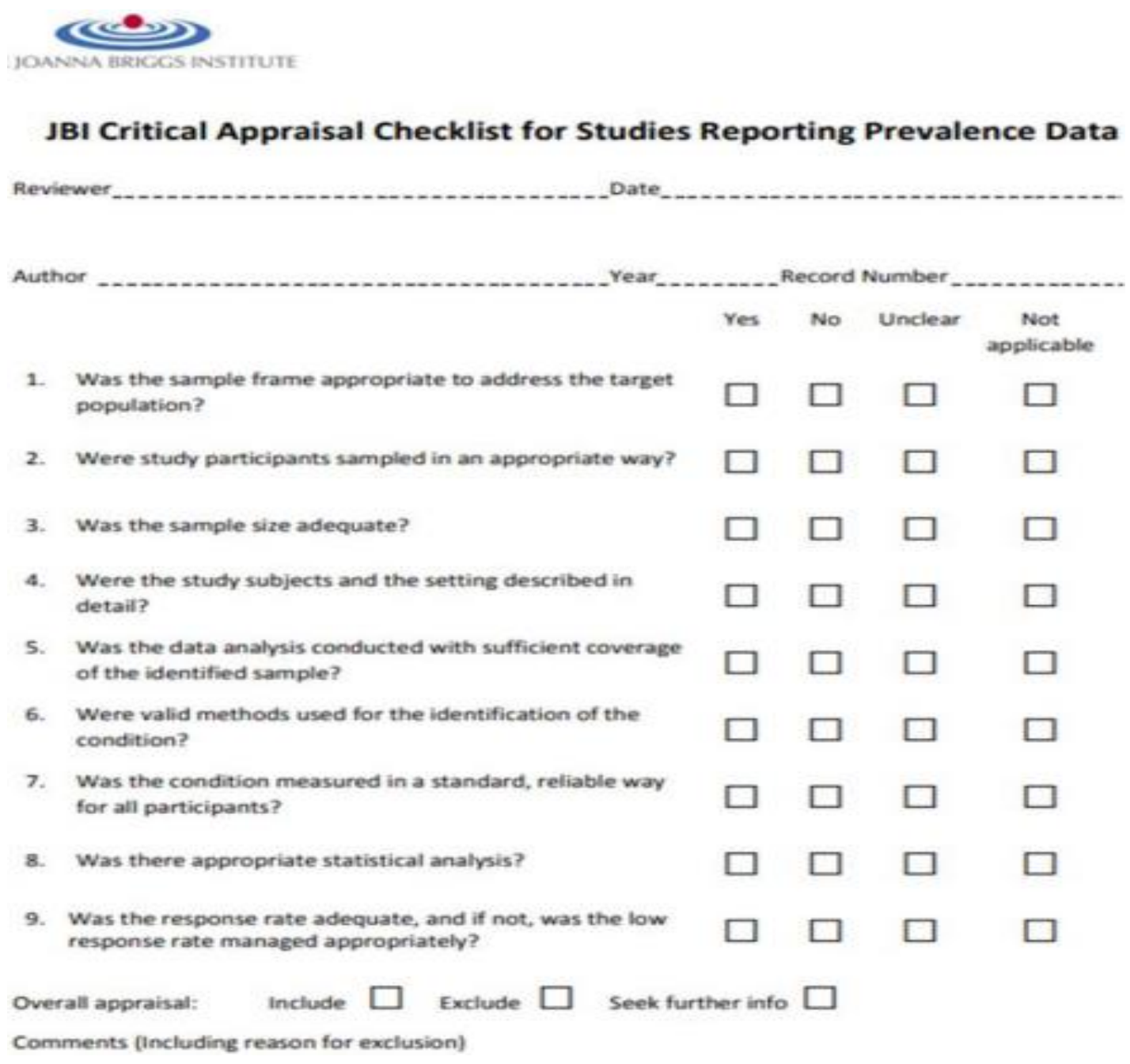

Reprinted with permission. Porritt K, Gomersall J, Lockwood C. JBI's systematic reviews: study selection and critical appraisal. AJN The American Journal of Nursing. 2014;114(6):47-52. ${ }^{156}$ 


\section{APPENDIX C. UTHSC IRB APPROVAL LETTER}

November 18,2020

Institutional Review Board

910 Madison Avenue, Suite 600

Memphis, TN 38163

Tel: (901) $448-4824$

Lan Yao

UTHSC - COGHS - Dean-Coll Grad Health Sci

Re: 20-07823-NHSR

Study Title: A Mixed-Methods Research Study of the Association Between Polities and Health

Outcomes of the COVID-19 Pandemic

Dear Ms. Yao:

The Administrative Section of the UTHSC Institutional Review Board (IRB) reviewed your application for the above referenced project.

The IRB determined that your application qualifies for NHSR (Not Human Subjeets Research) status in that it does not involve "human subjects" as defined in 45 CFR 46.102. No further interaction with the IRB is necessary if the project is conducted as currently described. However, any revision of these activities should be submitted for IRB review to determine whether the project still qualifies for NHSR status.

Sincerely.

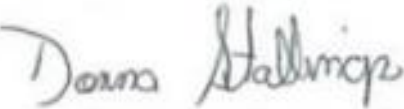

Signature applied by Donna L Stallings on 11/18/2020 10:08:25 AM CST

Donna Stallings, CIM

IRB Administrator

UTHSC IRB 


\section{VITA}

Lan Yao was born in northeast of China in 1982. She completed her undergraduate education at Harbin University of Science and Technology in 2005. She continued to pursue her master's degree in Scientific translation at Harbin University of Science and Technology, which she successfully completed in 2008. From 2008 to 2018, she had worked in Harbin Medical University. On August 2018, she joined the University of Tennessee Health Science Center (UTHSC) as a Ph.D. student in the Health Outcomes and Policy Research program, majoring in Health Policy. Lan Yao expects to complete her Ph.D. in November 2021. 